\title{
DISCLAIMER
}

PNL-10692

This report was prepared as an account of work sponsored by an agency of the United States Government. Neither the United States Government nor any agency thereof, nor any of their employees, makes any warranty, express or implied, or assumes any legal liability or responsibility for the accuracy, completeness, or usefulness of any information, apparatus, product, or process disclosed, or represents that its use would not infringe privately owned rights. Reference herein to any specific commercial product, process, or service by trade name, trademark, manufacturer, or otherwise does not necessarily constitute or imply its endorsement, recommendation, or favoring by the United States Government or any agency thereof. The views and opinions of authors expressed herein do not necessarily state or reflect those of the United States Government or any agency thereof.

\section{AREST-CT V1.0 SOFTWARE VERIFICATION}

\author{
Y. Chen \\ D. W. Engel \\ B. P. McGrail \\ K. S. Lessor
}

July 1995

Prepared for

the U.S. Department of Energy

under Contract DE-AC06-76RLO 1830

\author{
Pacific Northwest Laboratory \\ Richland, Washington 99352
}

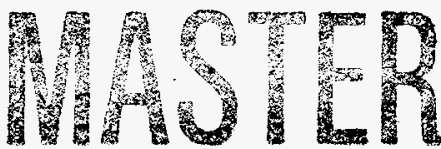




\section{DISCLAIMER}

This report was prepared as an account of work sponsored by an agency of the United States Government. Neither the United States Government nor any agency thereof, nor Battelle Memorial Institute, nor any of their employees, makes any warranty, expressed or implied, or assumes any legal liability or responsibility for the accuracy, completeness, or usefulness of any information, apparatus, product, or process disclosed, or represents that its use would not infringe privately owned rights. Reference herein to any specific commercial product, process, or service by trade name, trademark, manufacturer, or otherwise does not necessarily constitute or imply its endorsement, recommendation, or favoring by the United States Government or any agency thereof, or Battelle Memorial Institute. The views and opinions of authors expressed herein do not necessarily state or reflect those of the United States Government or any agency thereof. 


\section{DISCLAIMER}

Portions of this document may be illegible in electronic image products. Images are produced from the best available original document. 


\section{$\underline{\text { SUMMARY }}$}

The Analyzer for RadionuclidE Source-Term with Chemical Transport (AREST-CT) is a scientific computer code designed for performance assessments of engineered barrier system (EBS) concepts for the underground storage of nuclear waste, including high-level, intermediate, and low-level wastes. The AREST-CT code has features for analyzing the degradation of and release of radionuclides from the waste form, chemical reactions that depend on time and space, and transport of the waste and other products through the EBS. This document provides a description of the verification testing that has been performed on the initial version of ARESTCT (V1.0). Software verification is the process of confirming that the models and algorithms have been correctly implemented into a computer code. Software verification for V1.0 consisted of testing the individual modules (unit tests) and a test of the fully-coupled model (integration testing). The integration test was done by comparing the results from AREST-CT with the results from the reactive transport code CIRF.A. The test problem consisted of a 1-D analysis of the release, transport, and precipitation of ${ }^{99} \mathrm{Tc}$ in an idealized LLW disposal system. All verification tests showed that AREST-CT works properly and in accordance with design specifications. 


\section{CONTENTS}

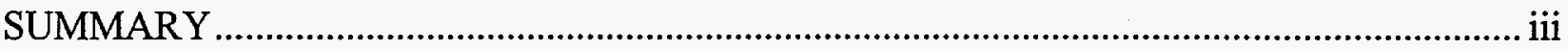

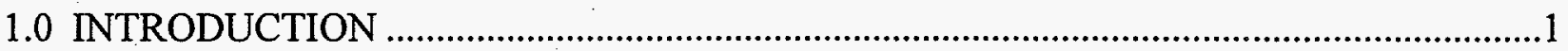

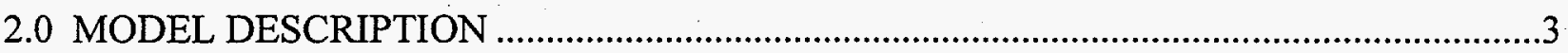

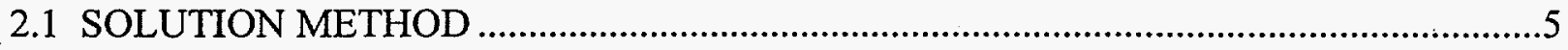

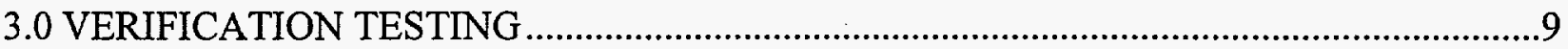

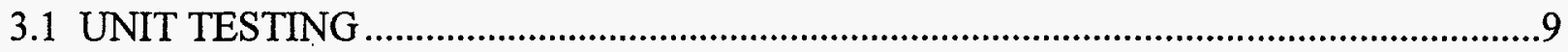

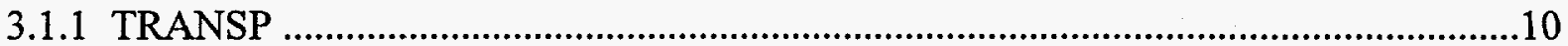

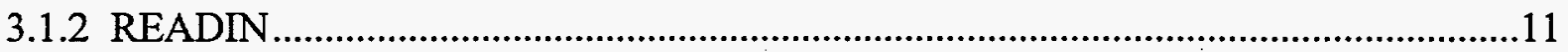

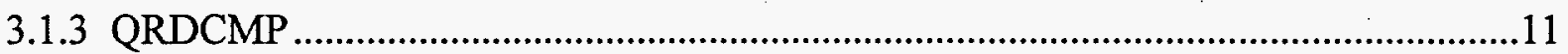

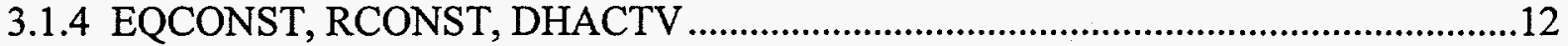

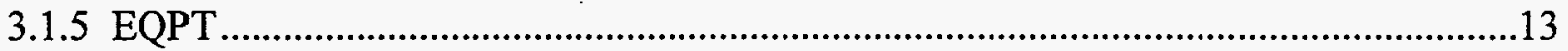

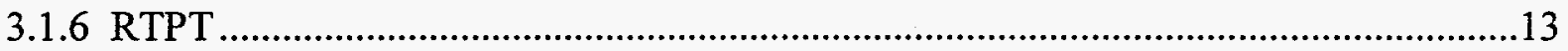

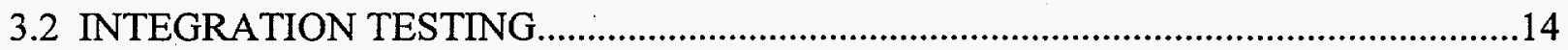

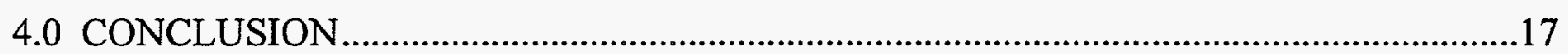

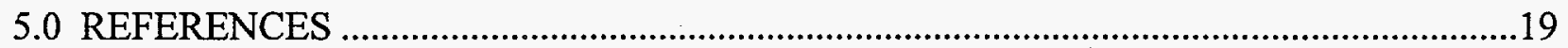

APPENDIX A - VERIFICATION OF TRANSPORT MODULE (UPWINDING) .....................1

APPENDIX B - VERIFICATION OF READIN MODULE ................................................

APPENDIX C - VERIFICATION OF QRDCMP MODULE ....................................................

APPENDIX D - VERIFICATION OF EQCONST, RCONST, AND DHACTV MODULES...D.1

APPENDIX E - VERIFICATION OF EQPT MODULE ..................................................... E.1

APPENDIX F - INTEGRATION TEST RESULTS ................................................ F.1 


\subsection{INTRODUCTION}

The Tri-Party agreement (TPA) between the State of Washington Department of Ecology, the U.S. Department of Energy (DOE), and the U.S. Environmental Protection Agency (EPA), specifies vitrification as the encapsulation technology for Hanford low-level wastes (LLW). By DOE Order 5820.2A, before any LLW can be disposed of, a performance assessment covering the disposal facility must be approved by DOE headquarters. The performance assessment is to provide "reasonable assurance" that the disposal activities will not adversely impact long-term human health and safety.

The Hanford Low-Level Waste Performance Assessment Group currently plans to publish an interim performance assessment for the disposal facility in December 1996, followed by a preliminary performance assessment due in June 1998, and a final performance assessment in July 1999. The interim performance assessment will be based on as much site-specific and materialsspecific data as possible, to demonstrate a high likelihood that the final performance assessment will be approved, and therefore, support a decision to begin construction of vitrification facilities.

Performance assessments for the disposal of Hanford LLW will require calculating radiation dose to a future population as a result of any release and transport of radionuclides to the unconfined aquifer located approximately $70 \mathrm{~m}$ below the disposal facility. The processes controlling release and transport of radionuclides to the unconfined aquifer will be simulated by computer models. A review of currently available computer codes was recently completed (McGrail and Mahoney 1995), where the codes were ranked in terms of the feature sets that match a set of physical, chemical, numerical, and functional capabilities needed to assess radionuclide release rates from a LLW engineered-system. The needed capabilities were identified from an analysis of the important physical and chemical processes expected to affect LLW glass corrosion and the mobility of radionuclides. The highest ranked computer code was found to be the Analyzer of RadionuclidE Source-Term with Chemical Transport (AREST-CT) code, developed at PNL for the U.S. Department of Energy for evaluation of arid land disposal sites. 
Computer codes selected for performance assessment calculations must undergo software verification and validation testing. Software validation, or more appropriately confirmation (Oresekes, Frechette, and Belitz 1994), is the process of demonstrating that the mathematical models or constitutive equations embodied in a computer code are consistent with observational data. Thus, validation is the process of demonstrating that a computer code reasonably represents the actual processes in a system. The validation/confirmation tests planned for the AREST-CT code primarily involve long-duration, unsaturated, flow-through tests in columns packed with low-level waste (LLW) glass, engineered barrier materials, and/or Hanford soils. Results from the confirmation testing of the AREST-CT code will be described in a future document. The subject of this document is software verification, which is the process of testing the mathematical components of a computer code to "verify" that they have been correctly implemented. This document was developed to satisfy quality assurance program requirements of the Pacific Northwest Laboratory (PNL). ${ }^{(a)}$

(a) Pacific Northwest Laboratory is a multiprogram national laboratory operated for the U.S. Department of Energy by Battelle Memorial Institute under contract DE-AC06-RLO 1830. 


\subsection{MODEL DESCRIPTION}

The AREST-CT code is a scientific computer software system developed at PNL to analyze the engineered barrier system (EBS) of a subsurface disposal site for the storage of nuclear waste. A brief overview of the model is given here. The interested reader should contact the authors to obtain more detailed documentation of the design ${ }^{(a)}$ or models ${ }^{(b)}$ used in the AREST-CT code.

Figure 1 is a schematic illustration of a multi-barrier, engineered-system concept for Hanford LLW. The engineered-system is assumed to begin with the water chemistry conditioner and end at the chemical retardation barrier. No specific materials have been selected for any of the engineered components depicted in Figure 1, and some of these components may not be included

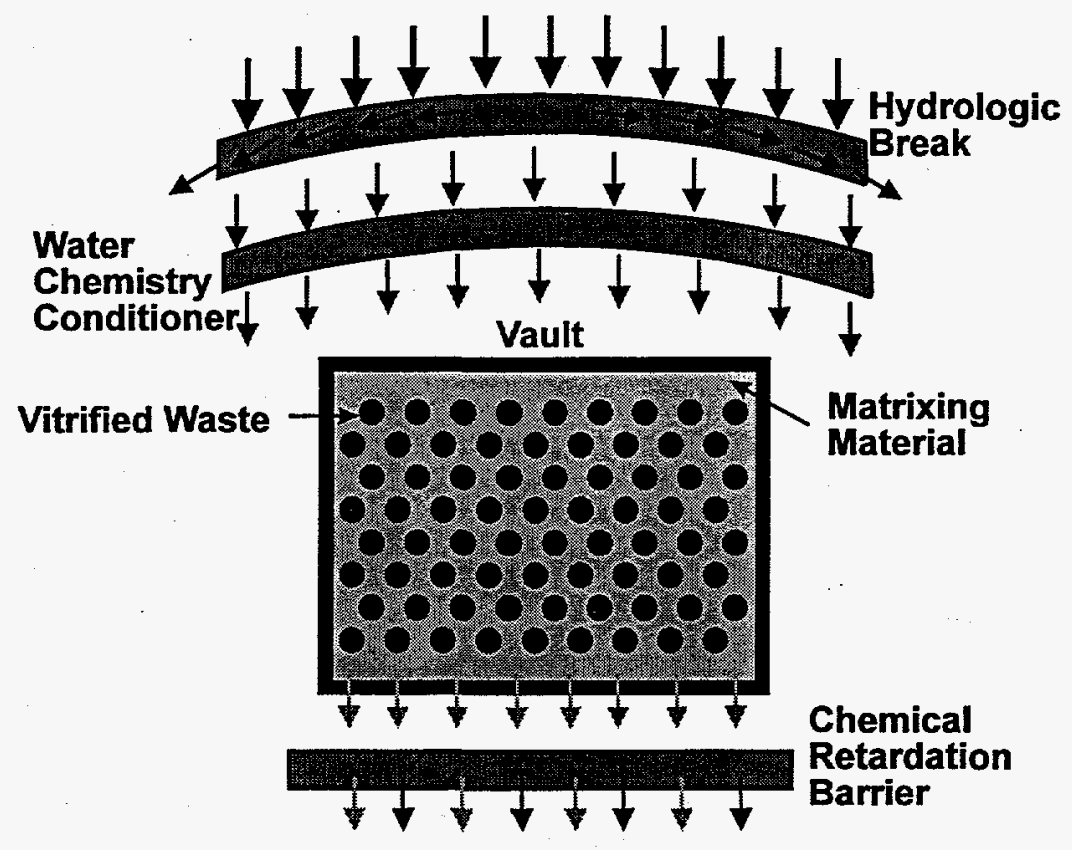

(Unsaturated Sediments)

Figure 1. Engineered-System Concept for Hanford LLW

(a) Engel, D.W., B.P. McGrail, J.A. Fort, K.S. Lessor, R.E. Williford, and M.K. Altenhofen. 1995. Software Design Description for the AREST-CT Code Development. In Press, Pacific Northwest Laboratory, Richland, Washington.

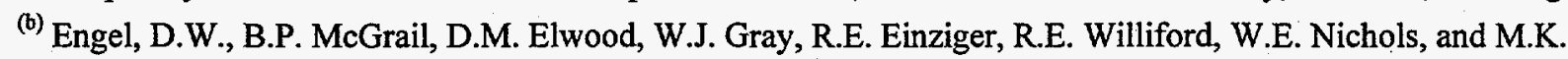
Altenhofen. 1995. Mathematical Document for the AREST-CT Code Development. In Press, Pacific Northwest Laboratory, Richland, Washington. 
in the final design of the disposal facility. However, the function of AREST-CT is to calculate the total mass flux of radionuclides exiting the vault (or retardation barrier if it exists in the final design) as a function of time. To accomplish this, a coupled set of equations is solved that describes radionuclide release from the waste form and mass transport constrained by chemical reactions. The fundamental equation system to be solved is given by

$$
\frac{\partial \phi \rho_{l} \theta_{l} c_{\alpha}}{\partial t}=-\nabla \cdot \mathbf{q}_{\alpha}+\sum_{k=1}^{N_{r}} v_{\alpha k} W_{k}, \alpha=1,2, \ldots, N_{a q} .
$$

$$
\text { where } \begin{aligned}
\phi & =\text { porosity } \\
\theta_{l} & =\text { volumetric water content } \\
\rho_{l} & =\text { fluid density, } \mathrm{kg} / \mathrm{m}^{3} \\
c_{\alpha} & =\text { concentration of species } \alpha, \text { mole } / \mathrm{kg} \\
\mathbf{q}_{\alpha} & =\text { total flux of component } \alpha, \mathrm{mole} / \mathrm{m}^{2} \cdot \mathrm{s} \\
\mathrm{t} & =\text { time, } \mathrm{s} \\
v_{\alpha k} & =\text { stoichiometric coefficient of species } \alpha \text { in reaction } k \\
W_{k} & =\text { reaction rate of } k \mathrm{th} \text { reaction }\left(\mathrm{mole} / \mathrm{m}^{3} \mathrm{sec}\right) \\
N_{r} & =\text { number of reactions, including aqueous equilibrium reactions, solid } \\
& \text { dissolution } / \text { precipitation reactions, kinetic controlled aqueous reactions and } \\
N_{a q} & \text { decay reactions }
\end{aligned}
$$

If it is assumed that the phenomenon of hydrodynamic dispersion can be represented by a Fickian type law, then the total flux due to advection, dispersion, and diffusion is given by

$$
\mathbf{q}_{\alpha}=\phi \rho_{l} \theta_{l}\left(c_{\alpha} \mathbf{V}-\mathbf{D}_{\alpha}\left(\theta_{l}\right) \cdot \nabla c_{\alpha}\right) .
$$

where $\mathbf{D}_{l} \quad=$ hydrodynamic dispersion tensor, $\mathrm{m}^{2} / \mathrm{s}$

$\mathrm{V}=$ fluid velocity vector, $\mathrm{m} / \mathrm{s}$.

Substituting Equation (2) into Equation (1), one arrives at

$$
\frac{\partial \phi \rho_{l} \theta_{l} c_{\alpha}}{\partial t}=-\nabla \cdot\left(\phi \rho_{l} \theta_{l}\left(c_{\alpha} \mathbf{V}-\mathbf{D}_{\alpha}\left(\theta_{l}\right) \cdot \nabla c_{\alpha}\right)\right)+\sum_{k=1}^{N_{r}} v_{\alpha k} W_{k}, \alpha=1,2, \ldots, N_{a q}
$$

which is commonly known as the reaction-transport equation. The solution to the system of equations (3) is the core function of the AREST-CT code. A brief overview of the solution method implemented in this version of AREST-CT is given in the next section. 


\subsection{SOLUTION METHOD}

The reactive transport equation system (3) is solved in the AREST-CT code using the method of finite-differences on an arbitrary 1-D or orthogonal 2-D grid. The solution method proceeds by solving the discretized reaction-transport equations at each grid point and each time-step. A solute concentration vector, $\vec{c}(\mathrm{~mol} / \mathrm{kg})$, is returned that contains the concentration of each aqueous species at that point and time step. This solution method will be referred to as a Type II point-solver.

Using a technique similar to that described by Friedly and Rubin (1992), a series of transformations are applied to Equation (3) to eliminate terms associated with equilibrium chemical reactions. The details of the transformation will not be discussed here but the result is that three equation sets are obtained that correspond to equilibrium reactions, non-reactive transformed species, and reactive transformed species, respectively. The transformed species, both reactive and non-reactive, are linear combinations of chemical species.

The discretized reaction-transport equations are a set of non-linear equations of the form:

$$
\vec{F}(\vec{c})=0
$$

where

$$
\vec{F}=\left\{F_{1}, F_{2}, \ldots, F_{N_{a q}}\right\}^{T}
$$

and

$$
\vec{c}=\left\{c_{1}, c_{2}, \ldots, c_{N_{a q}}\right\}^{T} .
$$

To handle the large range of $\vec{c}$ in geochemical problems, the above set of equations is usually written as functions of $\vec{x}$, instead of $\vec{c}$, where

$$
\vec{x}=\left\{x_{1}, x_{2}, \ldots, x_{N_{a q}}\right\}^{T}=\left\{\ln c_{1}, \ln c_{2}, \ldots, \ln c_{N_{a q}}\right\}^{T} .
$$

Thus, Equation (4) reads as:

$$
\vec{F}=\vec{F}(\vec{x})=0 .
$$


As mentioned above, Equation (8), which is the discretized form of Equation (3), also consists of three sets of equations. For the $N_{f}$ equilibrium reactions, applying the law of mass action yields

$$
F_{k}=\sum_{i=1}^{N_{a q}} v_{i j}\left(\ln \gamma_{i}+\ln c_{i}\right)-\ln K_{j}^{e q}=0, \quad k=j, j=1,2, \ldots, N_{f}
$$

where $v_{i j} \quad=$ stoichiometric coefficient of species $i$ in equilibrium reaction $j$

$\gamma_{i} \quad=$ activity coefficient of species $i$

$K_{j}^{e q} \quad=$ equilibrium constant of reaction $j$.

For $N_{b}$ non-reactive species, we have a set of linear equations

$$
F_{k}=\sum_{i=1}^{N_{a q}} b_{i j} c_{i}-B_{j}=0, \quad k=N_{f}+j, j=1,2, \ldots N_{b}
$$

where $b_{i j}$ is the transformation coefficient of species $i$ in the non-reactive linear transformation, and $B_{j}$ is the transformed concentration of non-reactive species $j$. For $N_{a}$ reactive species, we have the following set of non-linear equations

$$
\begin{aligned}
F_{k}= & \sum_{i=1}^{N_{a q}} a_{i j}\left[p_{1 i} c_{i}+p_{2 i}-\Delta t \sum_{l l=1}^{N_{g k}} v_{i l 1}^{f f} W_{l 1}^{f k}-\Delta t \sum_{l 2=1}^{N_{f l}} v_{i l 2}^{f d} W_{l 2}^{f d}-\Delta t \sum_{l 3=1}^{N_{s}} v_{i l 3}^{s r} W_{l 3}^{s r}-\Delta t \sum_{l 4=1}^{N_{s d}} v_{i l 4}^{s d} W_{l 4}^{s d}\right]=0, \\
& k=N_{f}+N_{b}+j, j=1,2, \ldots, N_{a}
\end{aligned}
$$

where $a_{i j} \quad=$ transformation coefficient of species $i$ for the reactive species $j$

$p_{1 i} \quad=$ coefficient describing transport properties at the previous time step for species $i$

$p_{2 i} \quad=$ coefficient describing concentration properties at the previous time step

$v_{i l 1}^{f k} \quad=$ stoichiometric coefficient of species $i$ in the kinetically-controlled reaction $l 1$

$v_{i l 2}^{f d}=$ stoichiometric coefficient of species $i$ in aqueous species decay reaction $l 2$

$v_{i l 3}^{s r} \quad=$ stoichiometric coefficient of species $i$ in dissolution/precipitation reaction $l 3$

$v_{i l 4}^{s d}=$ stoichiometric coefficient of species $i$ in solid species decay reaction $l 4$.

The terms $W_{l 1}^{f k}, W_{l 2}^{f d}, W_{l 3}^{s r}$, and $W_{l 4}^{s d}$ are the rates of the kinetically-controlled reaction $l 1$, aqueous species radioactive decay reaction $l 2$, solid dissolution/precipitation reaction $l 3$, and solid species radioactive decay reaction $l 4$, respectively. Equations (9) thru (11) are the fundamental equation sets solved by the AREST-CT code. The Newton-Raphson iteration method is used to solve this highly nonlinear equation system. 
In AREST-CT, activity coefficients $\left(\gamma_{i}\right)$ are computed using the B-dot formulation as is used in the EQ3/6 code (Wolery 1992). The four different types of aqueous species allowed are 1) charged species, 2) water, 3) neutral polar species, and 4) neutral non-polar species. The equations used to calculate the activity coefficients of the four types are:

1) For charged species:

$$
\ln \gamma_{i}=\ln (10.0) \cdot\left\{B^{*} I-\frac{Z_{i}^{2} A I^{1 / 2}}{1+a_{i} \dot{B} I^{1 /}}\right\}
$$

where the ionic strength, $I$, is given by

$$
I=\frac{1}{2} \sum_{i=1}^{N_{\text {aq }}} Z_{i}^{2} c_{i}=\frac{1}{2} \sum_{i=1}^{N_{\text {aq }}} Z_{i}^{2} e^{x_{i}}
$$

where $a_{i}$ is the closest distance (radius) of species $i ; A, B^{*}, \dot{B}$ are three parameters as functions of temperature, and $Z_{i}$ is the charge of species $i$.

2) For water:

$$
\ln \gamma_{w}=-\frac{\sum_{i \neq w} c_{i}}{\Omega}+\frac{\ln (10)}{\Omega} \cdot\left[\frac{2}{3} A I^{3 / 2} \sigma\left(a_{w} B I^{1 / 2}\right)-B I^{2}\right]-\ln \lambda_{w}
$$

where $\Omega=1000.0 / \mathrm{M}_{\text {water }}$, $\left(\mathrm{M}_{\text {water }}\right.$ is the molecular weight of water $), \lambda_{\mathrm{w}}$ is the mole fraction of water in the solution, $a_{w}=4.0(\AA)$, and

$$
\sigma(x)=\frac{3}{x^{3}}\left[1+x-\frac{1}{1+x}-2 \ln (1+x)\right]
$$

3) For non-polar neutral species:

$$
\ln \gamma_{i}=\left(C+F T+\frac{G}{T}\right) I-(E+H T)\left(\frac{I}{I+1}\right)
$$

where, $T$ is the temperature $(\mathrm{K})$, and $\mathrm{C}=-1.0312, \mathrm{~F}=0.0012806, \mathrm{G}=255.9, \mathrm{E}=0.4445$, $\mathrm{H}=-0.001606$.

4) For polar neutral species:

$$
\ln \gamma_{i}=0 \text {. }
$$

This concludes the discussion of the AREST-CT model. The verification tests that were performed on the computerized implementation of this model are discussed in the next section. 



\subsection{VERIFICATION TESTING}

This section discusses the specific confirmation tests performed to verify that the reactive transport modules in AREST-CT were correctly implemented, along with a description of the evaluation method and acceptance criteria. The actual test case results and input data are given in the appendices. This format was intentionally adopted so that revisions to this document can be easily made as new versions of the code are developed. All testing for AREST-CT V1.0 was performed on a Sun ${ }^{\mathrm{TM}}$ SparcStation 10/20, running SunOs 4.1.1.

\subsection{UNIT TESTING}

Unit testing consists of evaluating individual code modules against hand calculations, analytical solutions, or other numerical codes to verify that the algorithms implemented in the module correctly solve the governing equations. The AREST-CT code consists of the 8 modules shown in Table 1. Each module was unit tested separately before being implemented into AREST-CT. The results are described below.

Table 1. AREST-CT Modules for Unit Testing

Module Name

TRANSP

READIN

QRDCMP

EQCONST

RCONST

DHACTV

EQPT

RTPT
Function

Transport

input data structure

Q-R decomposition

equilibrium constant calculation

rate constant calculation

activity coefficient correction

point solver I (boundary condition setup)

point solver II (coupled reaction with transport) 


\subsubsection{TRANSP}

The transport module uses an upwinding scheme, with the Crank-Nicolson algorithm to achieve second-order truncation error in space and time. Five test cases have been analyzed and compared to analytical solutions. The input data are given in Appendix A, Tables A.1 thru A.8, and the results of the analyses are shown in Figures A.1 thru A.8. The results from each test case are briefly described as follows:

1) 1-D pure diffusion. The input data to analyze a one-dimensional diffusive transport case is listed in Table A.1. The resulting concentrations as a function of time and distance were plotted against an analytical solution (Haberman 1987) and are shown in Figure A.1. The numerical solution and analytical results compare to within the acceptable relative error for the plotted time steps.

2) 1-D pure convection. The input data to analyze the one-dimensional convective dominated case is shown in Table A.2. The numerical results are compared to results from an analytical solution in Figure A.2. Qualitatively, the results are similar, i.e., peaks are at the same location in space. However, the magnitude and sharpness of the moving front is not captured accurately with the numerical solution. This is a consequence of numerical dispersion inherent with any upwind finite-difference scheme used to solve a hyperbolic partial . differential equation. Resolution of the numerical solution can be increased by increasing the number of grid nodes and increasing the number of time steps, although neither of these solutions is practicable for large, 2-D problems. Higher-order transport schemes are available that provide better front-tracking. However, these schemes.typically use a flux limiter to ensure that the solution to the PDE is total variation diminishing (TVD) throughout the spatial domain. The method works very well for pure transport problems but we have not implemented these schemes in V1.0 of AREST-CT because chemical reactions tend to dominate the shape and position of any moving front, and so can increase the total variation of the solution, independent of transport. As a result, reactive chemical transport problems can become nonconvergent when using a standard TVD flux-limiter algorithm. A modified TVD scheme is under development for use in reactive transport problems.

3) 1-D diffusion + convection. The input data to analyze the one-dimensional diffusive plus convective transport case is shown in Table A.3. The results of this analysis are shown in Figure A.3. The numerical results were compared to results from an analytical solution (Sauty 1980). The numerical and analytical results compare quite well for this problem. As in the previous case, the numerical model could be refined by increasing the number of grid nodes and time steps.

4) 2-D diffusion + convection with uniform $X$-direction flow $\left(V_{x}>0\right.$ and $\left.V_{y}=0.0\right)$. The input data to analyze the two-dimensional diffusion plus convection case with uniform flow in the $\mathrm{X}$-direction is shown in Table A.4. For this case, the flow in the X-direction is in the positive direction; the flow is zero in the Y-direction. The results of this analysis, compared to an analytical solution (Fried 1975) are shown in Figure A.4. Essentially, the test case is a point source problem. Because of the singularity at the point source, it is difficult to obtain an 
accurate value of the analytical solution and numerical solution near the point source. However, qualitatively, the results are similar as the peaks are located at the same point and the peak height increases with increasing time.

5) 2-D diffusion + convection with different uniform flow directions. Four cases were analyzed to look at the transport given a flow in one direction, (a) $\mathrm{V}_{\mathrm{x}}>0$ \& $\mathrm{V}_{\mathrm{y}}=0.0$; (b) $\mathrm{V}_{\mathrm{x}}<0$ \& $\mathrm{V}_{\mathrm{y}}$ $=0.0$; (c) $\mathrm{V}_{\mathrm{x}}=0.0 \& \mathrm{~V}_{\mathrm{y}}>0$; and (d) $\mathrm{V}_{\mathrm{x}}=0.0 \& \mathrm{~V}_{\mathrm{y}}<0$. The input data for these four test cases are listed in Tables A.5 thru A.8. The results of the analyses are shown in Figures A.5 thru A.8. The results of the test cases show the same behavior for flow in all four directions. Thus, the results verify that the correct solution is obtained for all flow directions.

\subsubsection{READIN}

The input structure was tested by comparing the input file (listed in Appendix B, Table B.1) against an output file that contains most of the input information (also listed in Appendix B, Table B.2). Several simple operations are carried out by the input module and are listed below (these calculations have been compared against hand calculations):

1) eliminate zero stoichiometric coefficients of aqueous species in reactions, including fast reactions, solid reactions, fluid-species radioactive decay, and solid-species radioactive decay

2) calculate molecular weights for each aqueous and solid specie according to its formula weight

3) calculate porosity of each lithology unit according to volume fractions of each solid species

4) calculate number densities of solid species in each lithology unit. A negative radius of the solid species is an indication (flag) that the initial volume fraction of the species is actually zero, and that the input volume fraction and the absolute value of the radius should be used to calculate the number density of the species. The result is actually the number of nucleation sites.

\subsubsection{QRDCMP}

The Q-R decomposition module, which is used to determine the linear transformation performed on Equation (3), was tested by comparing the results from AREST-CT to results calculated externally. The CIRF.A reaction model (Chen et al. 1995) was used for this test.

The input file for AREST-CT is shown in Appendix C, Table C.1. The same input values were input into CIRF.A for the comparison. The general reaction matrix, qrxntot, is listed in Table C.2 and C.3. Several criteria were used to judge if the Q-R decomposition was correctly implemented into AREST-CT: 
1) The square of each $A$-vector should be 1.0

2) The dimensions of [A $x$ qrxntot] are navect by nrxnt

3) The first nfrxn (number of equilibrium reactions) columns of [A $x$ qrxntot] should be zero or very close to zero and the matrix should have the property of upper triangular.

The output file containing the general reaction matrix [qrxntot], the A-vector [avector], and [A x qrxntot] are also shown in Appendix C, Table C.2. These results compare favorably with the results from CIRF.A for qavector and [A x qrxntot] shown in Table C.3.

\subsubsection{EQCONST, RCONST, DHACTV}

This section combines the testing of the respective modules for calculation of 1 ) equilibrium constant as a function of temperature for each reaction, 2) rate constant of kinetic reactions as a function of temperature, and 3) activity coefficients using the B-DOT equation.

The input file for the analysis is shown in Appendix D, Table D.1. The results of this analysis are shown in Table D.2. In the input file, equilibrium constants are expressed as zeroth to fourth order polynomial functions of temperature. The thermodynamic data are from the EQ3/6 (Wolery 1992) database (Table D.3), which were fit as polynomial functions of temperature using Mathematica ${ }^{\mathrm{TM}}$. Calculated values (Table D.2) were compared against the original data from $\mathrm{EQ} 3 / 6$ and the results compare well to four significant digits.

Rate constants (k) are calculated internally in AREST-CT using $k=k_{o} e^{E_{a} / R T}$, where $k_{o}$ is the rate coefficient (assumed $=1.0 \mathrm{E}-2$ ) and $E_{a}$ is the activation energy (assumed $=10.0 \mathrm{~kJ} / \mathrm{mol}$ ). The calculated rate constants were compared against results calculated with Mathematica at different temperatures. These results also agree to within four significant digits.

Four types of aqueous species are considered in calculating activity coefficients. They are: charged species, water, polar neutral species, and non-polar neutral species. In the input file, all four types of aqueous species are included. The output contains their calculated activity coefficients at different temperatures. The activity coefficients were also calculated with Mathematica. The results were the same to within machine precision.

\footnotetext{
${ }^{n}$ Mathematica is a registerd trademark of Wolfram Research, Inc.
} 


\subsubsection{EOPT}

The EQPT module is a so-called point solver of type I that calculates concentrations at each grid point according to the specified total concentration and equilibrium reactions without transport. In AREST-CT, this module is used to set up the initial and boundary conditions for a problem. Five types of reactions are considered including: 1) fast aqueous, 2) kinetically controlled aqueous, 3) fluid species radioactive decay, 4) solid species dissolution/precipitation, and 5) solid species radioactive decay. Aqueous reactions are usually assumed to be fast reactions and so may be treated as in local chemical equilibrium. However, AREST-CT allows the user to specify whether aqueous reactions are kinetically-controlled or assumed to be in local equilibrium.

The initial concentration of each species must also be specified for the point solver Type I. When total concentration is specified, one can either state the concentration of one species or the total concentration of one component and let the program do speciation calculations. One has to remember that the number of reactions in local equilibrium plus the number of specified total concentrations must exactly equal the number of aqueous species. Problem input data that under-specifies or over-specifies these conditions cannot be solved, and the code will issue an error message and stop execution.

The input test file for verifying the point solver I is shown in Appendix E (Table E.1). The output from this test case is shown in Table E.2. In the output, the equilibrium constants of each equilibrium reaction, $k$, are listed along with the ion activity products $(\mathrm{Q})$ and saturation index $(\mathrm{Q} / \mathrm{K})$. If the calculation is accurate, all $\mathrm{Q} / \mathrm{K}$ values should be equal to 1.0. Also listed are the specified total concentrations and the calculated total concentrations. Mass conservation requires that they be equal.

\subsubsection{RTPT}

The RTPT module is the so-called point solver of type II discussed in section 2.1 , and is the main driver routine for calculating coupled chemical reactions with transport. Several existing routines are called by RTPT, including: 1) y_getabb; 2) y_getacoef; 3) y_getacoedx; 4) b_ludcmp and 5) b_lubksb. The first three routines have been tested in the activity coefficient 
module (shown in Appendix D), and the last two routines were taken from a standard text -"Numerical Recipes" (Press et al. 1986). Thus, no unit testing was considered necessary for these five routines.

Because no analytical solutions are available to test against the output from this module, no unit testing was possible. Consequently, several extra steps were taken to ensure accurate implementation and coding. The equation derivation given in section 2.1 has been carefully examined by the authors. Also a code "walk-through" was done, where each FORTRAN statement in the subroutines was checked. Several coding errors were discovered during this process and were corrected. Additional testing of this module will be done as part of the integration testing phase.

\subsection{INTEGRATION TESTING}

Integration testing is the process of testing a computer code as a whole object. One purpose of integration testing is to examine the logical relationships between submodules, which can be achieved by examining the qualitative behavior of simulation results, with judgment based on geochemical common sense. Another purpose is to ensure that the results are quantitatively correct. However, because there are no analytical solutions for the reaction-transport problems AREST-CT is designed to solve, at least to the authors' knowledge, such comparisons were not possible. The next best alternative is to benchmark the code against simulation results from a similar reaction-transport code. For this purpose, we have used the CIRF.A code which has some of the same functions as AREST-CT, and which has been applied to different types of problems in the past few years.

The test case we have selected is a 1-D idealization of a LLW engineering system that is illustrated schematically in Figure 2. The system consists of 7 solids and 12 aqueous species (Appendix F, Tables F.1 and F.2). Two types of reactions are considered: (1) equilibrium aqueous reactions (Table F.3) and solid dissolution/precipitation reactions (Table F.4). Water enters the system at the left side, infiltrates through the system and exits at the right side boundary. The infiltration velocity is assumed to be a constant $5.2 \mathrm{~cm} / \mathrm{year}$ and the temperature is assumed uniform and constant at $25^{\circ} \mathrm{C}$. Initial conditions are uniform concentrations 


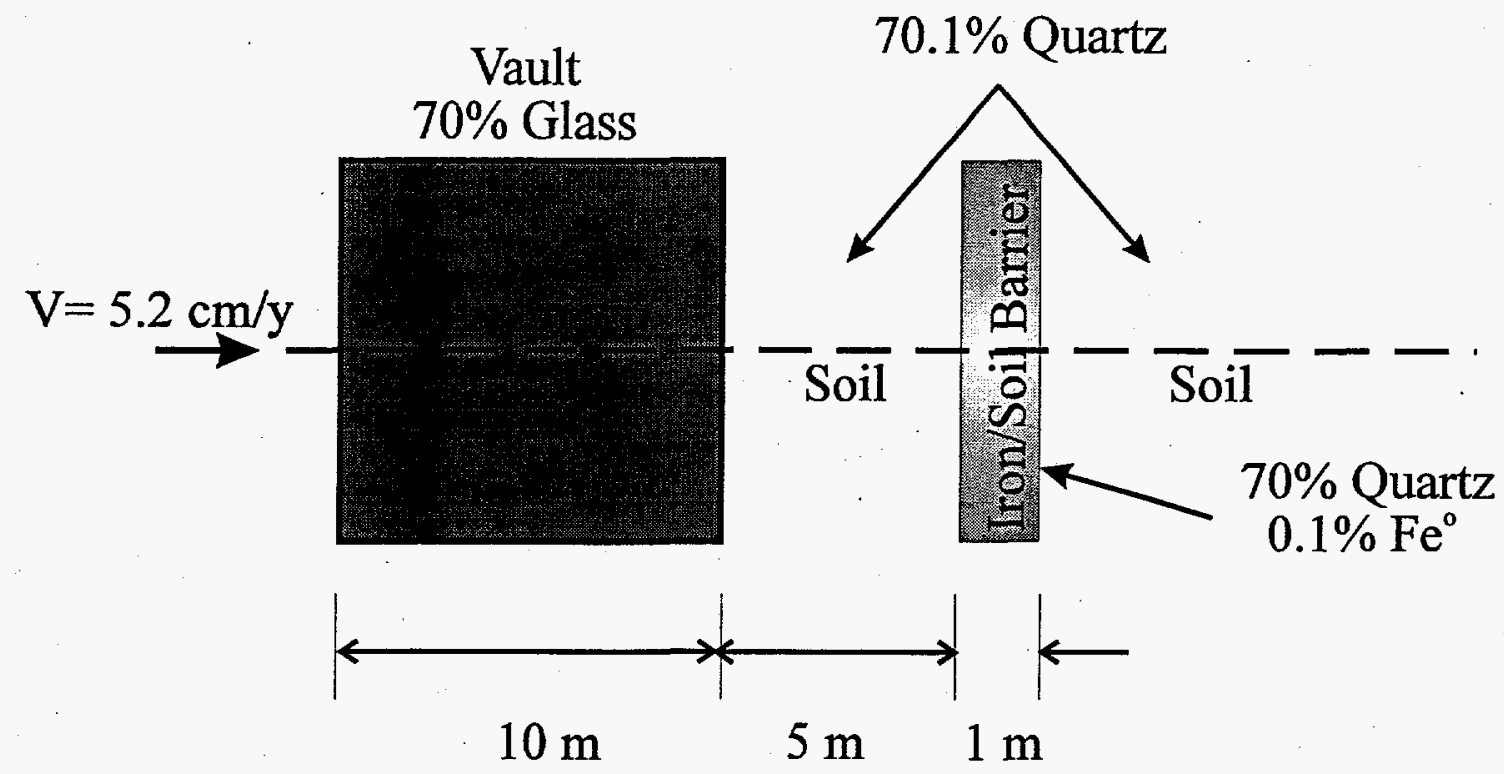

Figure 2. Schematic of One-dimensional Integration Test Problem. Mineral percentages are given in volume percent.

throughout the whole domain. At the left side boundary, concentrations are specified (Dirichlet type boundary conditions). At the right side boundary, zero diffusive flux conditions were used.

Simulations with AREST-CT and CIRF.A were carried out with exactly the same system configurations as described above, except for infiltration velocity. CIRF.A adopts a fully coupled model. In this model, the infiltration velocity changes with porosity as a result of solid dissolution/precipitation reactions. The initial design of AREST-CT required that the water velocity be computed externally and used as an input to the code. Consequently, Version 1.0 of AREST-CT cannot simulate changes in the fluid velocity field as a result of chemical reactions. ${ }^{\text {(a) }}$ Thus, AREST-CT simulations were carried out under uniform and constant infiltration velocity, but the CIRF.A simulation was carried out under non-uniform, time-varying infiltration velocity. Other input parameters, such as equilibrium constants and rate constants were exactly the same.

Simulation results at 5166 years are presented in Appendix F. (Figure F.1 - F.9). Solid lines are from AREST-CT calculation, while dashed lines are from CIRF.A calculation. Figure F.1 shows that the $\mathrm{pH}$ increases in the iron/soil barrier. This occurs because the dissolution reaction of natural iron consumes $\mathrm{H}^{+}$(reaction 1 in Table F.4). In this same region, the $\mathrm{HCO}_{3}^{-}$should

(a) An unsaturated flow solver is being implemented and will be included in the next version of AREST-CT. 
increase and $\mathrm{CO}_{2}(\mathrm{aq})$ should decrease, corresponding to the increase in $\mathrm{pH}$. This occurs because the total carbonate $\left(\mathrm{CO}_{2}(\mathrm{aq})+\mathrm{HCO}_{3}^{-}\right)$is fixed as specified in the initial and inlet boundary conditions. So, to maintain equilibrium in reaction 2 in Table F.3, the increase in $\mathrm{pH}$ results in higher concentrations of $\mathrm{HCO}_{3}^{-}$and lower concentrations of $\mathrm{CO}_{2}(\mathrm{aq})$. These expected changes are reflected in Figures F.2 and F.3.

Figure $\mathrm{F} .4$ shows that the concentration of $\mathrm{TcO}_{4}^{-}$increases with the penetration depth into the vault until it reaches a maximum and then drops to near zero. The increase in concentration with penetration depth is caused by the release of Tc from the waste glass (reaction 7 in Table F.4). The decrease is due to the reduction of $\mathrm{TcO}_{4}^{-}$to $\mathrm{Tc}^{3+}$ (reaction 1 of Table F.4) that occurs in the iron/soil barrier, as shown in Figure F.5. Reaction 4 in Table F.4 then controls the precipitation of the highly insoluble $\mathrm{Tc}_{3} \mathrm{O}_{4}(\mathrm{~s})$, as shown in Figure F.6, so that the total flux of Tc exiting the iron/soil barrier is essentially zero. Qualitatively, the simulation results are consistent with expectations from theoretical analysis.

Quantitatively, the AREST-CT simulations compare very well with the CIRF.A results, especially for the solid species (Figures F.7-F.9). There are some exceptions, e.g., in Figure F.1, the CIRF.A calculation has an extra spike that is believed to be numerical noise. There are other small differences in the profiles of aqueous species concentrations (Figures F.1-F.3 and F.5). We suspect that the time-varying velocity field in CIRF.A is the cause of these differences. This hypothesis will be tested in the near future after an unsaturated flow solver is coupled with the AREST-CT code. 


\subsection{CONCLUSION}

Verification testing of AREST-CT (version 1.0) has been completed. Testing will continue on this version, to get a good understanding of the capabilities of the code and to find possible bugs. Specifically, the resolution will be increased (more grid nodes and smaller time steps) for the one-dimensional transport test cases (diffusion, convection, and diffusion + convection), to match the analytical solutions more closely. Integration testing showed that AREST-CT works properly and no significant errors were found. However, the testing so far is for relatively simple cases. Several other functions of AREST-CT have yet to be tested, including mechanisms of radioactive decay and decay chain ingrowth, and the 2-D simulation capability. Additional integration testing is planned to test these functions. 



\subsection{REFERENCES}

Chen, Y., W. Chen, J. Mu, A. Park, W. Sibo, and P. Orotleva. 1995. "CIRF.A: A General Coupled Reaction-Transport Model and Simulator." Appl. Geochem. (In press).

Fried, J.J. 1975. Groundwater Pollution. Elsevier Scientific Publishing Co., p131-133.

Friedly, J. C. and J. C. Rubin. 1992. "Solute Transport With Multiple Equilibrium-Controlled or Kinetically-Controlled Chemical Reactions." Water Resour. Res. 28(6):1935-1953.

Haberman, R. 1987. Elementary Applied Partial Differential Equations. Prentice-Hall Inc., Engelwood Cliffs, New Jersey, 2nd edition, pp. 84-85.

McGrail, B. P. And L. A. Mahoney. 1995. Selection of a Computer Code for Hanford LowLevel Waste Engineered-System Performance Assessment. PVTD-C95-04.01E, Pacific Northwest Laboratory, Richland, Washington.

Oreskes, N., K. Shrader-Frechette, K. Belitz. 1994. "Verification, Validation, and Confirmation of Numerical Models in the Earth Sciences." Science 263:641-645.

Press, W.H., B.P. Flannery, S.A. Teukolsky, and W.T. Vetterling. 1987. Numerical Recipes: The Art of Scientific Computing. Cambridge University Press, Cambridge, MA.

Sauty, J.P. 1980. "An Analysis of Hydrodispersive Transfer in Aquifers." Water Resour. Res. 16(1):145-158.

Wolery, T.J. 1992. EQ3NR, A Computer Program for Geochemical Aqueous Speciation-Solubility Calculations: Theoretical Manual, User's Guide, and Related Documentation. UCRL-MA-1 10662-PT-III, Lawrence Livermore Laboratory, Livermore, California. 
APPENDIX A

Verification of Transport Module (Upwinding) 


\section{APPENDIX A}

\section{Verification of Transport Module (Upwinding)}

This appendix contains the input data and results of the test case runs to verify the implementation of the upwinding numerical transport model.

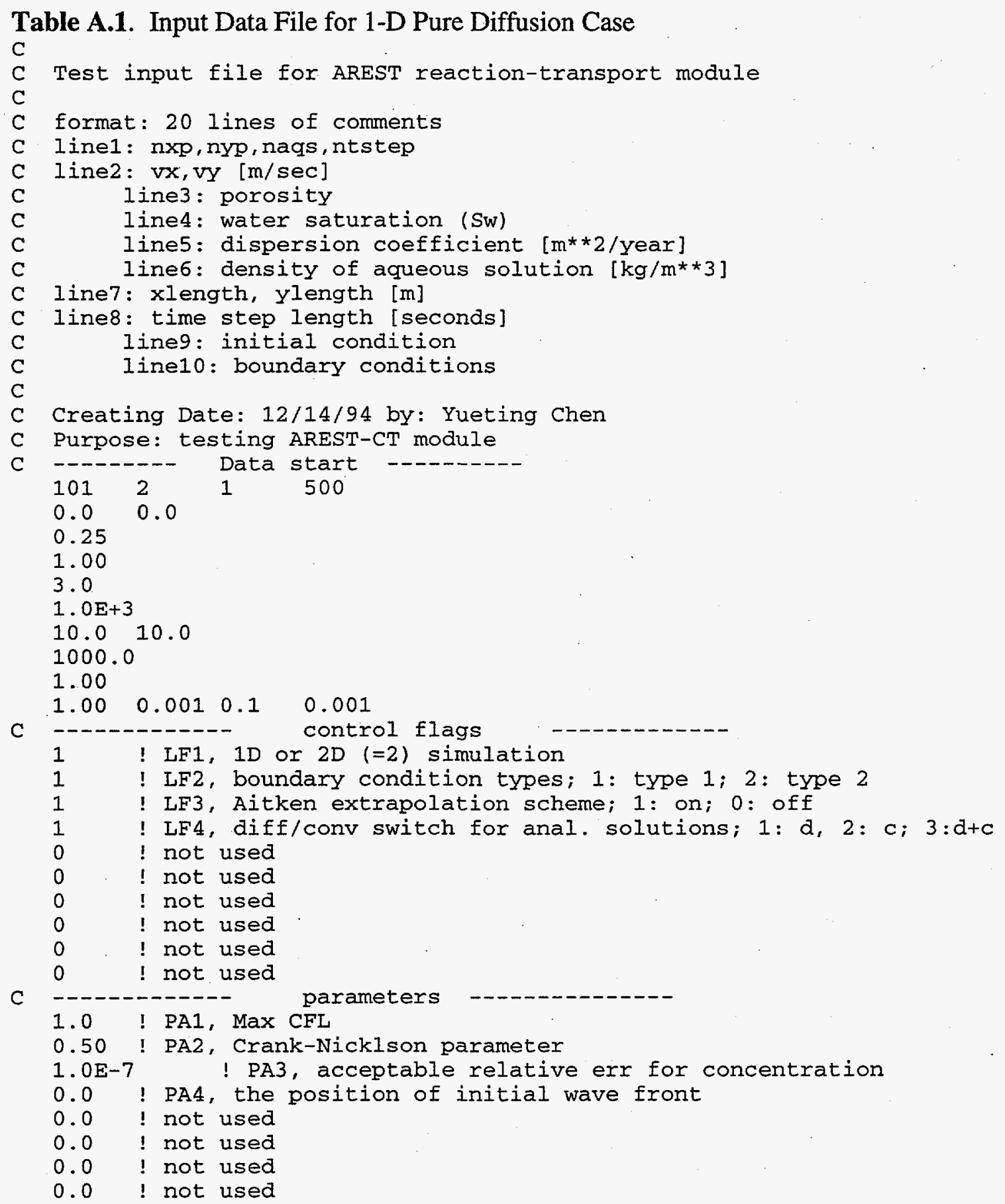


$\begin{array}{ll}0.0 & \text { ! not used } \\ 0.0 & \text { !. not used }\end{array}$

Table A.2. Input Data File for 1-D Pure Convection Case

$C$
$C$
$C$
$C$
$C$
$C$
$C$
$C$
$C$
$C$
$C$
$C$
$C$
$C$
$C$
$C$
$C$
$C$
$C$

Test input file for AREST reaction-transport module

format: 20 lines of comments

line1: nxp, nyp, naqs, ntstep

line2: vx, vy [m/sec $]$

line 3 : porosity

Iine4: water saturation (Sw)

line5: dispersion coefficient [m**2/sec]

line6: density of aqueous solution $[\mathrm{kg} / \mathrm{m} * \star 3]$

line 7: xlength, $y$ length $[\mathrm{m}]$

1ine8: time step length [seconds]

line9: initial condition

Iine10: boundary conditions

Creating Date: $12 / 14 / 94$ by: Yueting Chen

Purpose: testing AREST-CT module

-.-.-- Data start ---------

$\begin{array}{llll}101 & 2 & 1 & 100\end{array}$

0.020 .0

0.25

1.00

0.0

1. $O E+3$

$20.0 \quad 10.0$

1000.0

1.00

$\begin{array}{llll}0.100 & 0.001 & 1.0 & 0.001\end{array}$

C

1 ! LF1, 1D or 2D (=2) simulation

1 ! LF2, boundary condition types; 1: type 1; 2: type 2

1 ! LF3, Aitken extrapolation scheme; 1: on; 0 : off

2 ! LF4, diff/conv switch for anal. solutions; $1: d, 2: c ; 3: d+c$

1 ! LF5, Upwinding/TVD flag, 1: upwinding; 2: TVD

0 ! not used

0 ! not used

0 ! not used

0 ! not used

0 ! not used

C

0.50 ! PA1, Max CFL

0.50 ! PA2, Crank-Nicklson parameter

1.0E-7 ! PA3, acceptable relative err for concentration

0.1 ! PA4, the position of initial wave front

0.0 ! not used

0.0 ! not used

0.0 ! not used

0.0 ! not used

0.0 ! not used

0.0 ! not used 
Table A.3. Input Data File for 1-D Diffusion + Advection Case

C

C Test input file for AREST reaction-transport module

C format: 20 lines of comments

C line1: nxp, nyp, naqs, ntstep

C line2: vx, vy [m/sec]

C line3: porosity

C line4: water saturation (Sw)

C line5: dispersion coefficient [m**2/sec]

C line6: density of aqueous solution $[\mathrm{kg} / \mathrm{m} * * 3]$

C line7: xlength, ylength [m]

C 1ine 8: time step length [seconds]

C line9: initial condition

C line10: boundary conditions

C

C Creating Date: 12/14/94 by: Yueting Chen

C Purpose: testing AREST-CT module

$\mathrm{C}$

Data start

$\begin{array}{llll}101 & 2 & 1 & 200\end{array}$

$5.0 \quad 0.0$

0.25

1.00

0.40

1. $0 \mathrm{E}+3$

$20.0 \quad 10.0$

1000.0

1.00

$\begin{array}{llll}1.00 & 0.001 & 0.0 & 0.001\end{array}$

C - control flags

1 ! LF1, 1D or 2D (=2) simulation

1 ! LF2, boundary condition types; 1: type 1; 2: type 2

1 ! LF3, Aitken extrapolation scheme; 1: on; 0: off

3 ! LF4, diff/conv switch for anal. solutions; $1: d, 2: c ; 3: d+c$

1 ! LF5, Upwinding/TVD flag, 1: upwinding; 2: TVD

0 ! not used

$0 \quad$ inot used

0 ! not used

0 ! not used

o ! not used

C

0.25 ! PA1, Max CFL

0.50 ! PA2, Crank-Nicklson parameter

1.0E-7! PA3, acceptable relative err for concentration

0.1 ! PA4, the position of initial wave front

0.0 ! not used

0.0 ! not used

0.0 ! not used

0.0 ! not used

0.0 ! not used

0.0 ! not used

Table A.4. Input Data File for 2-D Diffusion + Convection Case with Uniform X-Direction Flow

C

C Test input file for AREST reaction-transport module

C

C format: 20 lines of comments

C line1: nxp, nyp, naqs, ntstep 
$\mathrm{C}$

$\mathrm{C}$

$\mathrm{C}$

C

C

C

C

C

$\mathrm{C}$

C

C

1ine2: vx, vy [m/sec]

line3: porosity

line4: water saturation (Sw)

line5: dispersion coefficient [m**2/sec]

line6: density of aqueous solution $[\mathrm{kg} / \mathrm{m} * \star 3]$

line 7 : xlength, ylength [m]

line8: time step length [seconds]

1ine9: initial condition

1ine10: boundary conditions

Creating Date: $12 / 14 / 94$ by: Yueting Chen

Purpose: testing AREST-CT module

$5151 \quad 1 \quad 100$

$0.0-8.0$

0.25

1.00

3.0

1. $0 \mathrm{E}+3$

20.020 .0

1000.0

1.00

$1.00 \quad 0.0010 .0 \quad 0.001$

C

2 ! LFI, 1D or $2 \mathrm{D}(=2)$ simulation

1 ! LF2, boundary condition types; 1 : type 1; 2: type 2

1 ! LF3, Aitken extrapolation scheme; 1: on; 0 : off

4 ! LF4, diff/conv switch for anal. sol.; $1: d, 2: c ; 3: d+c ; 4: 2 D$

1 ! LF5, not used

0 ! not used

o ! not used

0 ! not used

0 ! not used

0 ! not used

C

0.25 ! PA1, Max CFL

0.50 ! PA2, Crank-Nicklson parameter

1.OE-7 ! PA3, acceptable relative err for concentration

0.1 ! PA4, the position of initial wave front

0.5 ! PA5, the injection rate at point $(26,26)$, for $2-\mathrm{D}$ testing only

0.0 ! not used

0.0 ! not used

0.0 ! not used

0.0 ! not used

0.0 ! not used

Table A.5. Input Data File for 2-D Diffusion + Convection Case with Different Uniform Flow Directions $\left(\mathrm{V}_{\mathrm{x}}>0 \& \mathrm{~V}_{\mathrm{y}}=0\right)$

$\mathrm{C}$

C Test input file for AREST reaction-transport module

C format: 20 lines of comments

C line1: nxp, nyp., naqs, ntstep

C line2: vx, vy $[\mathrm{m} / \mathrm{sec}]$

C line3: porosity

C Iine4: water saturation (SW)

C Iine5: dispersion coefficient $[\mathrm{m} * * 2 / \mathrm{sec}]$

C Iine6: density of aqueous solution [kg/m**3]

C line 7: xlength, ylength [m] 


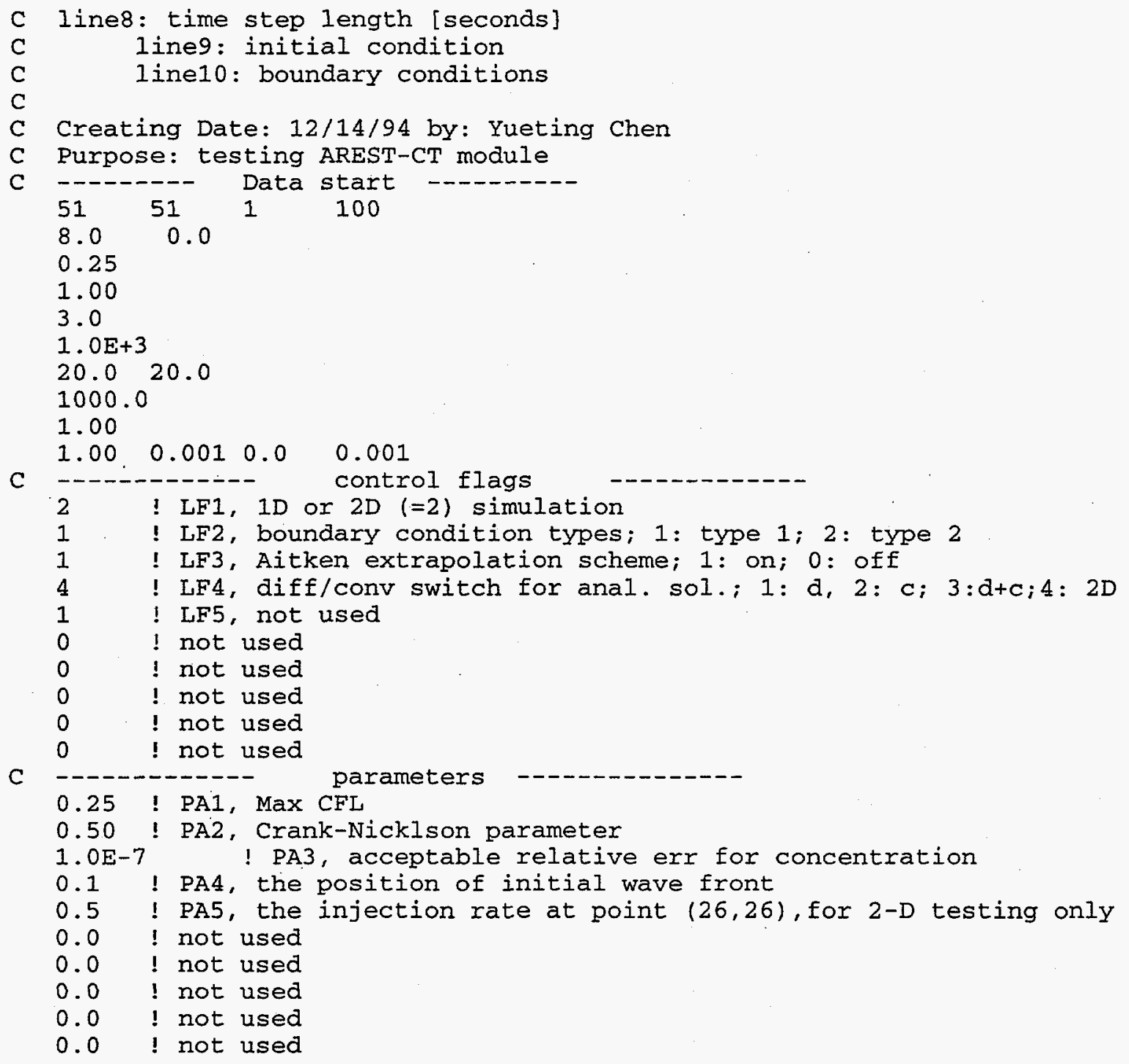

Table A.6. Input Data File for 2-D Diffusion + Convection Case with Different Uniform Flow Directions $\left(\mathrm{V}_{\mathrm{x}}<0 \& \mathrm{~V}_{\mathrm{y}}=0\right)$

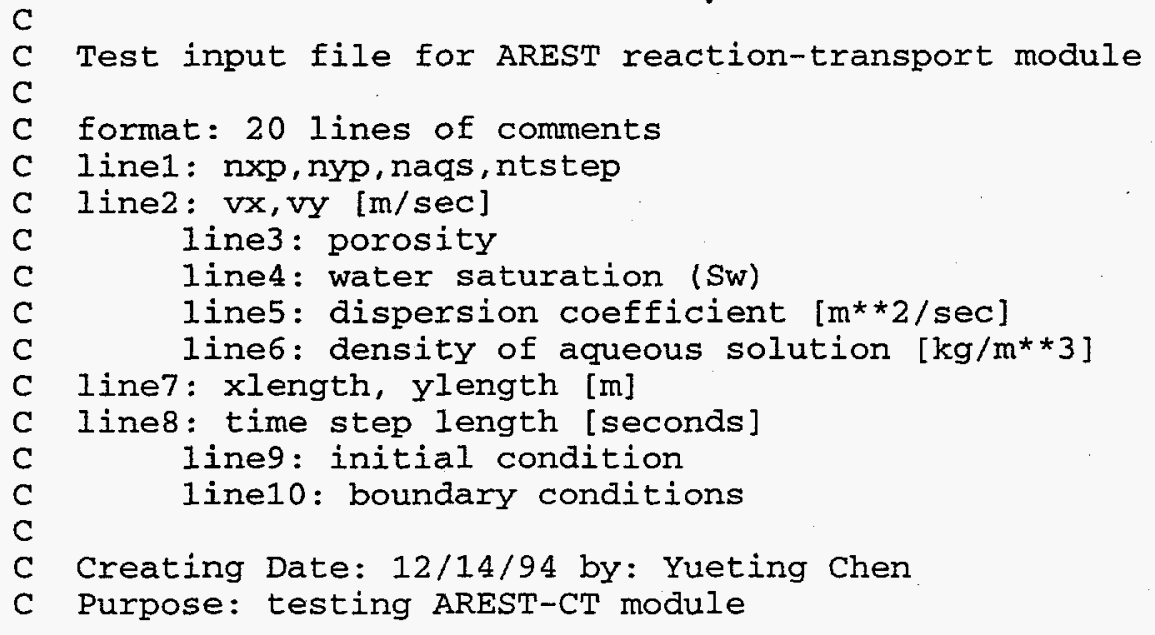




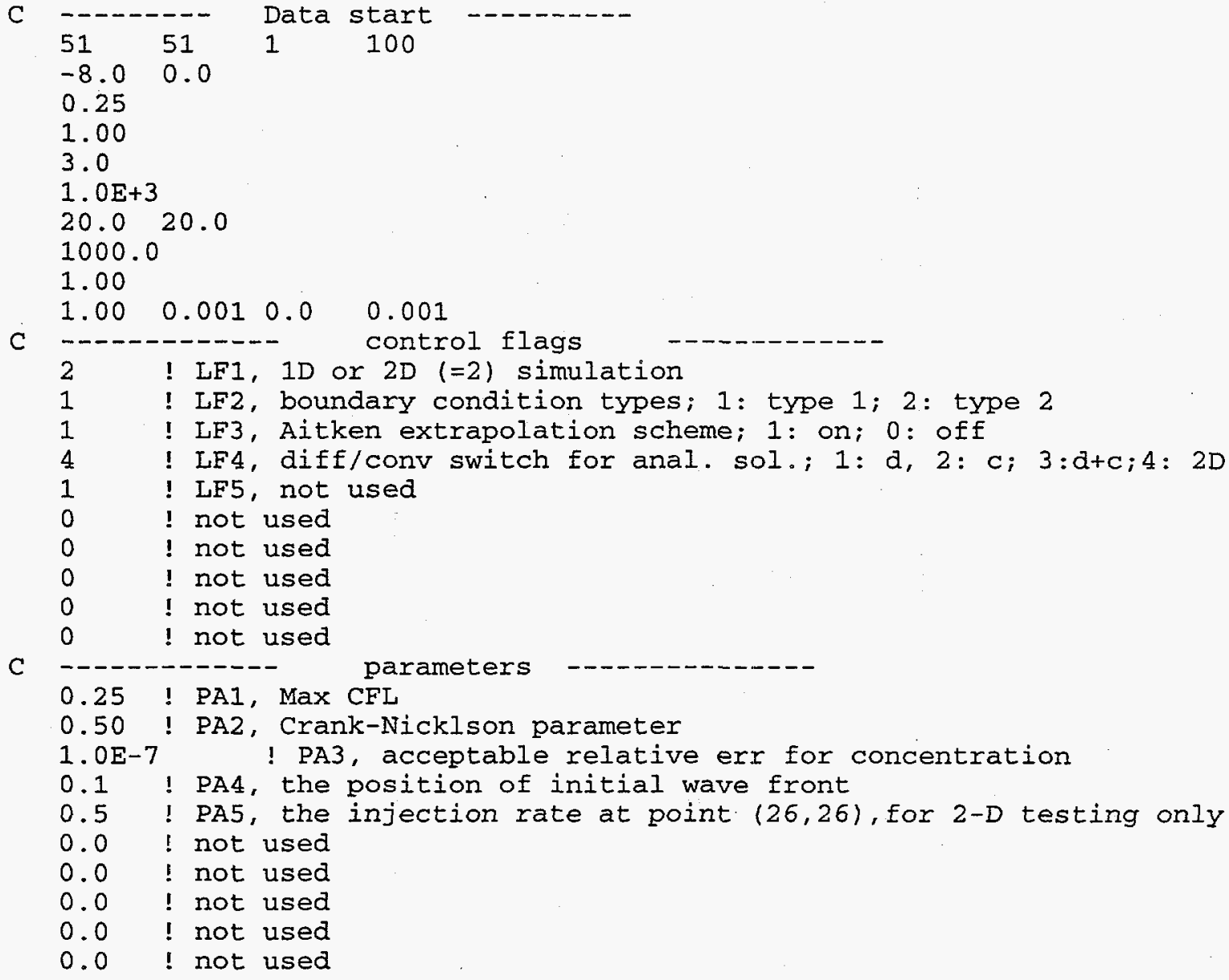

Table A.7. Input Data File for 2-D Diffusion + Convection Case with Different Uniform Flow Directions $\left(\mathrm{V}_{\mathrm{x}}=0 \& \mathrm{~V}_{\mathrm{y}}>0\right)$

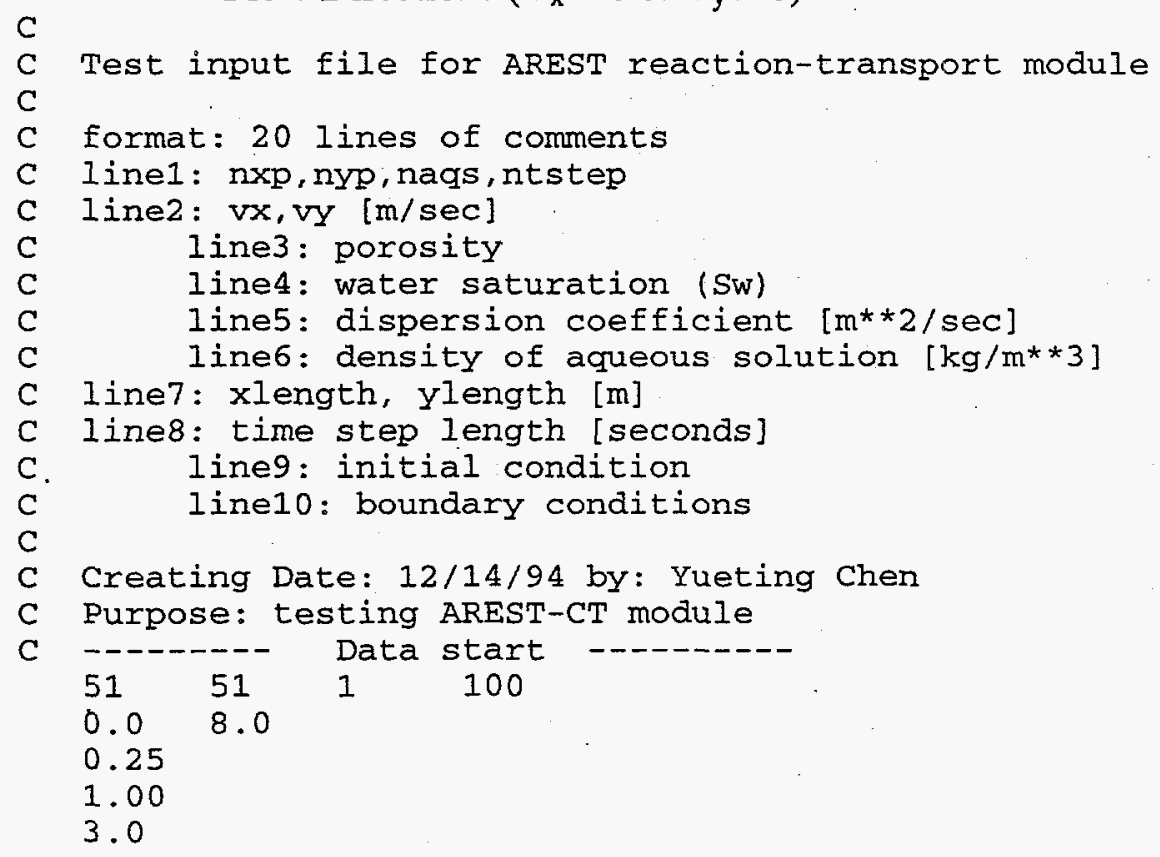




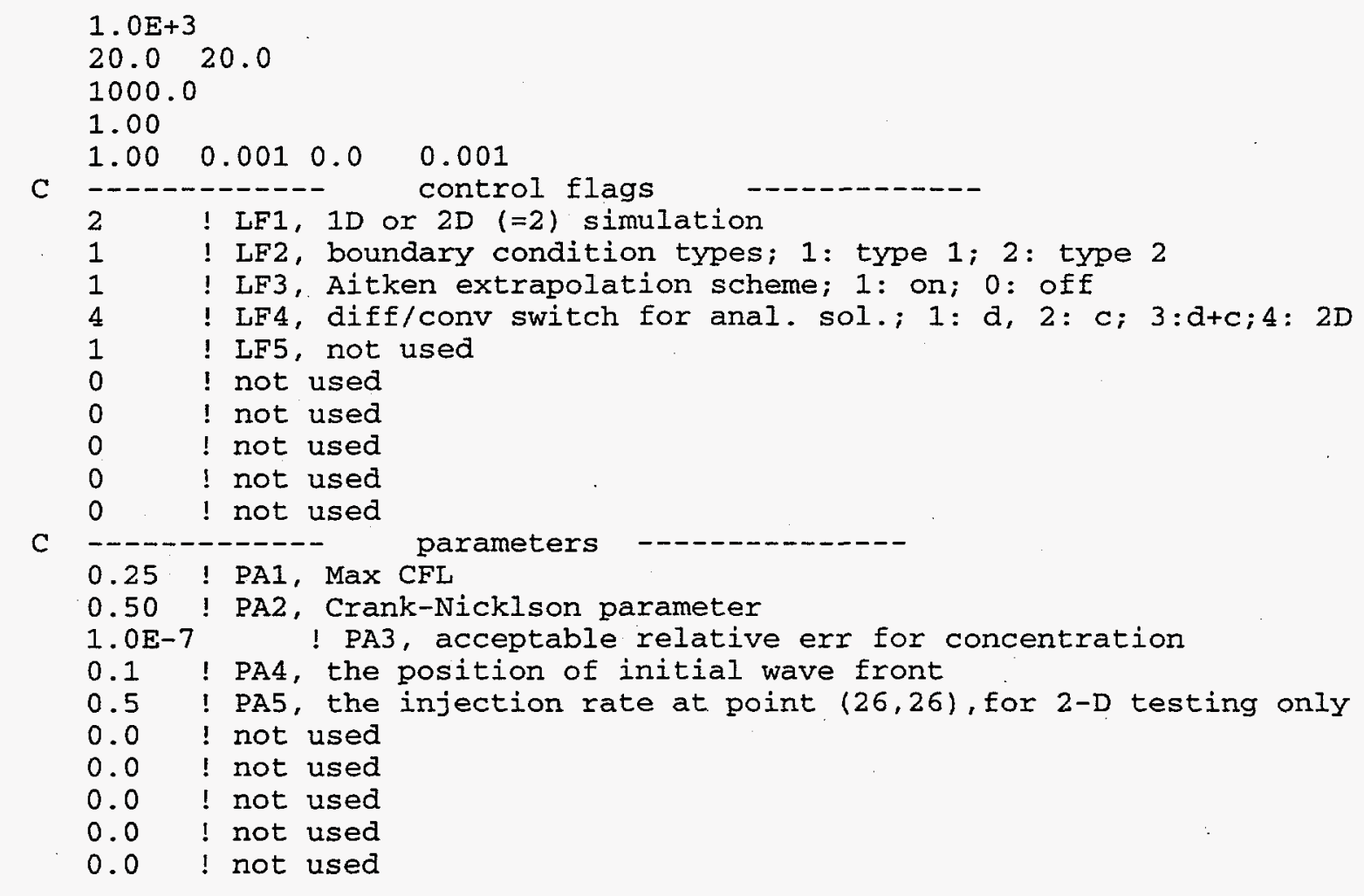

Table A.8. Input Data File for 2-D Diffusion + Convection Case with Different Uniform Flow Directions $\left(\mathrm{V}_{\mathrm{x}}=0 \& \mathrm{~V}_{\mathrm{y}}<0\right)$

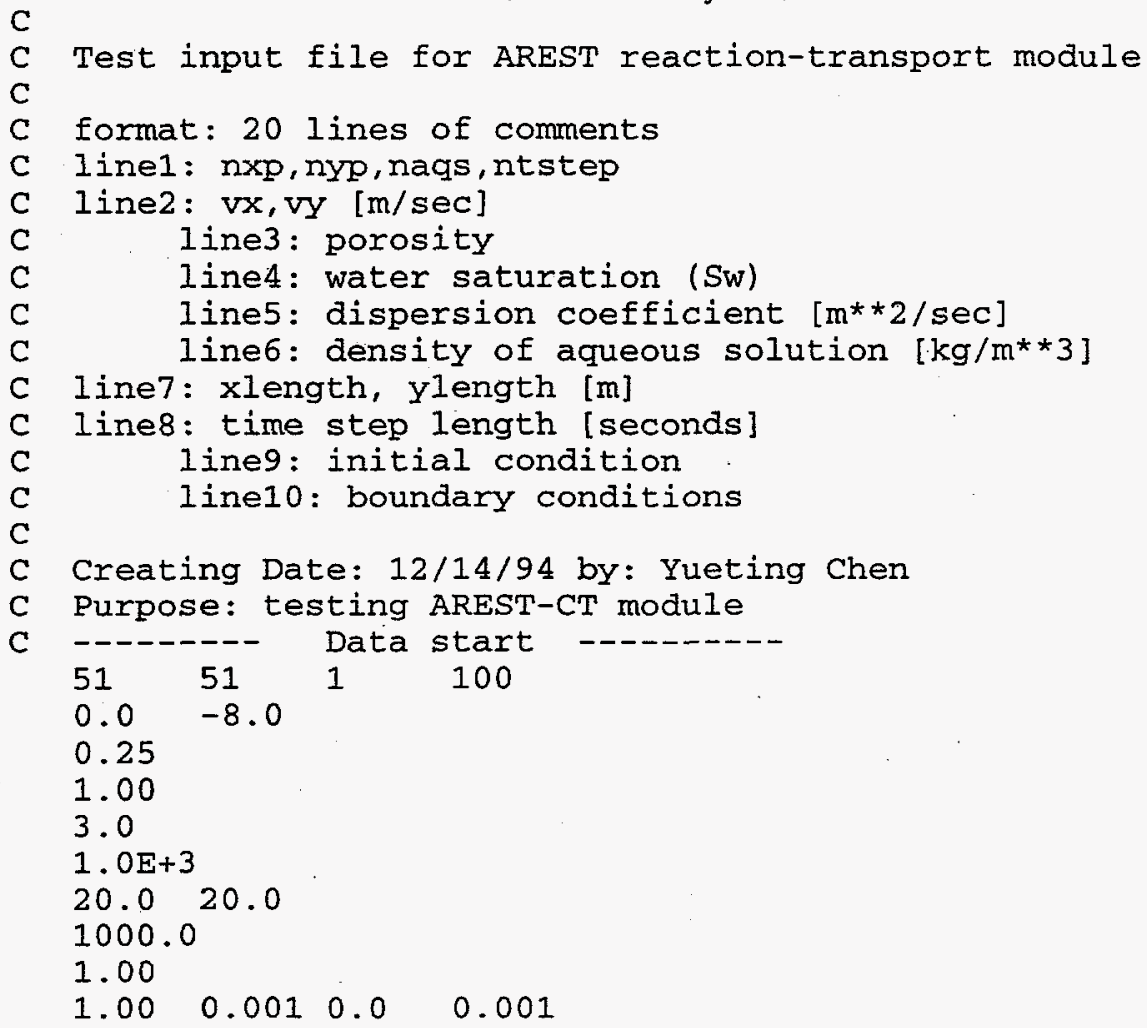




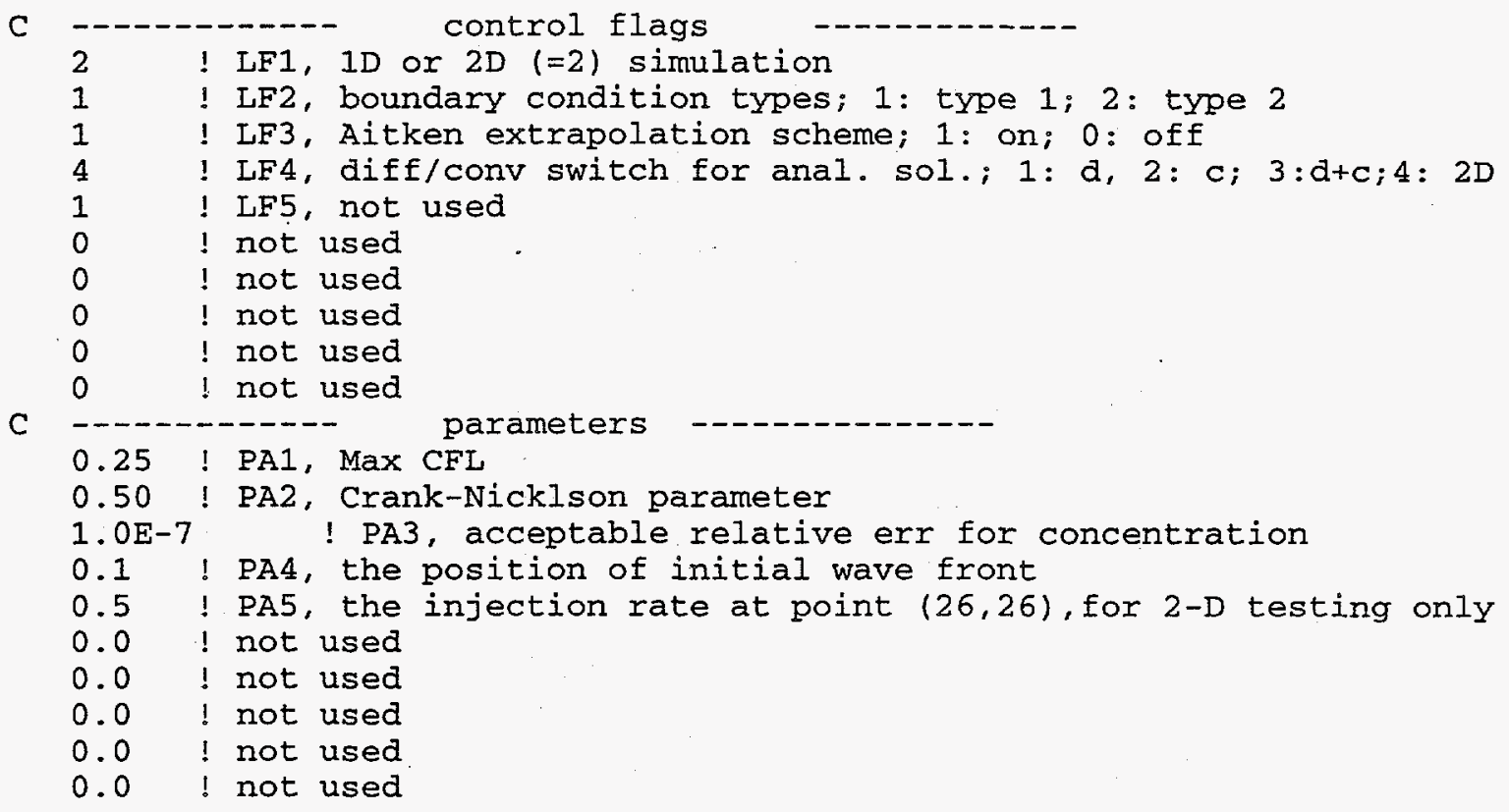


(2D) I| Print I| 6 Jan 1995 || diffcomp.ball II

No. of grids: 101 , time step: 0.01 years

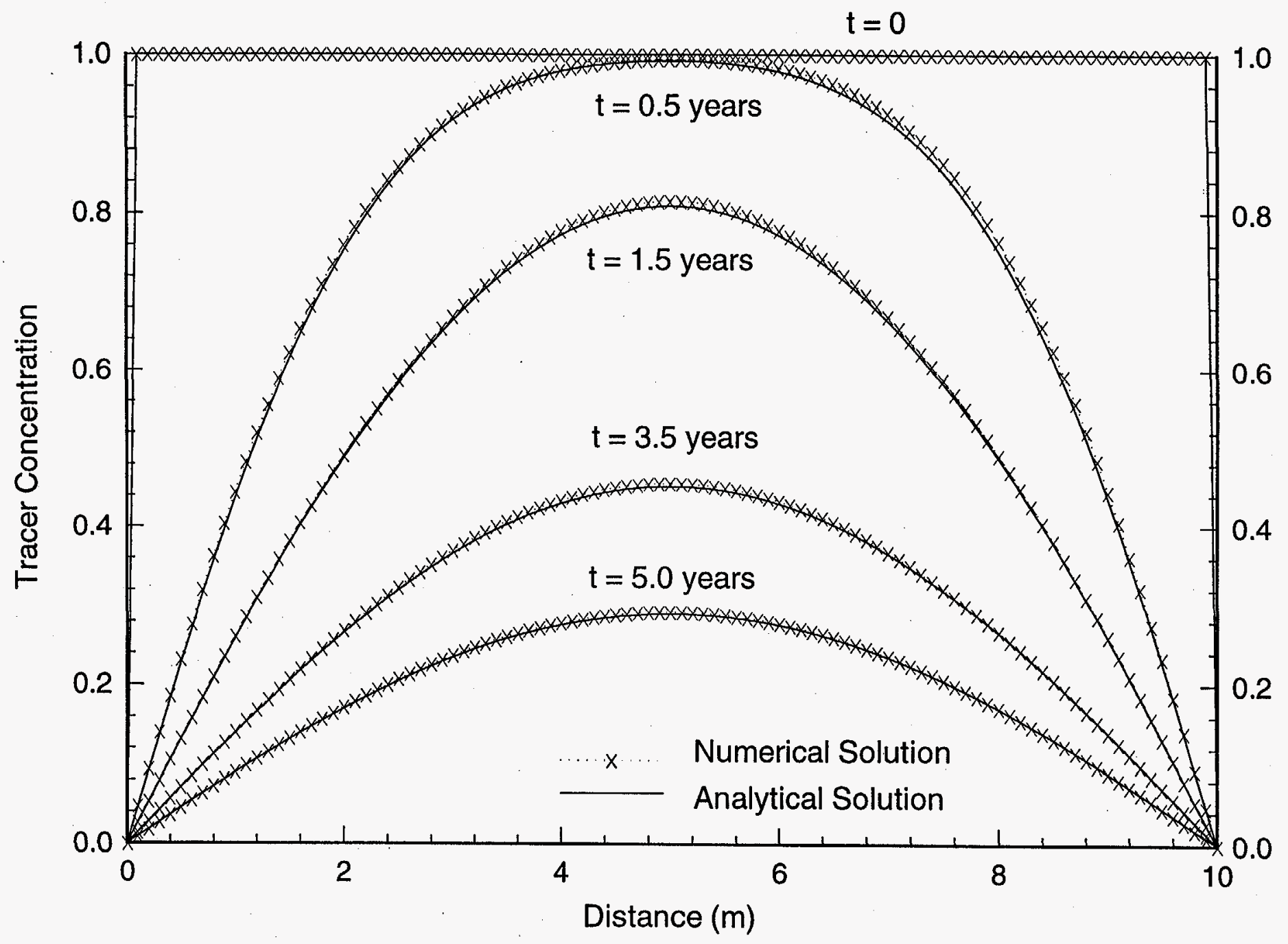

Figure A.1. Results from the 1-D Pure Diffusion Case 


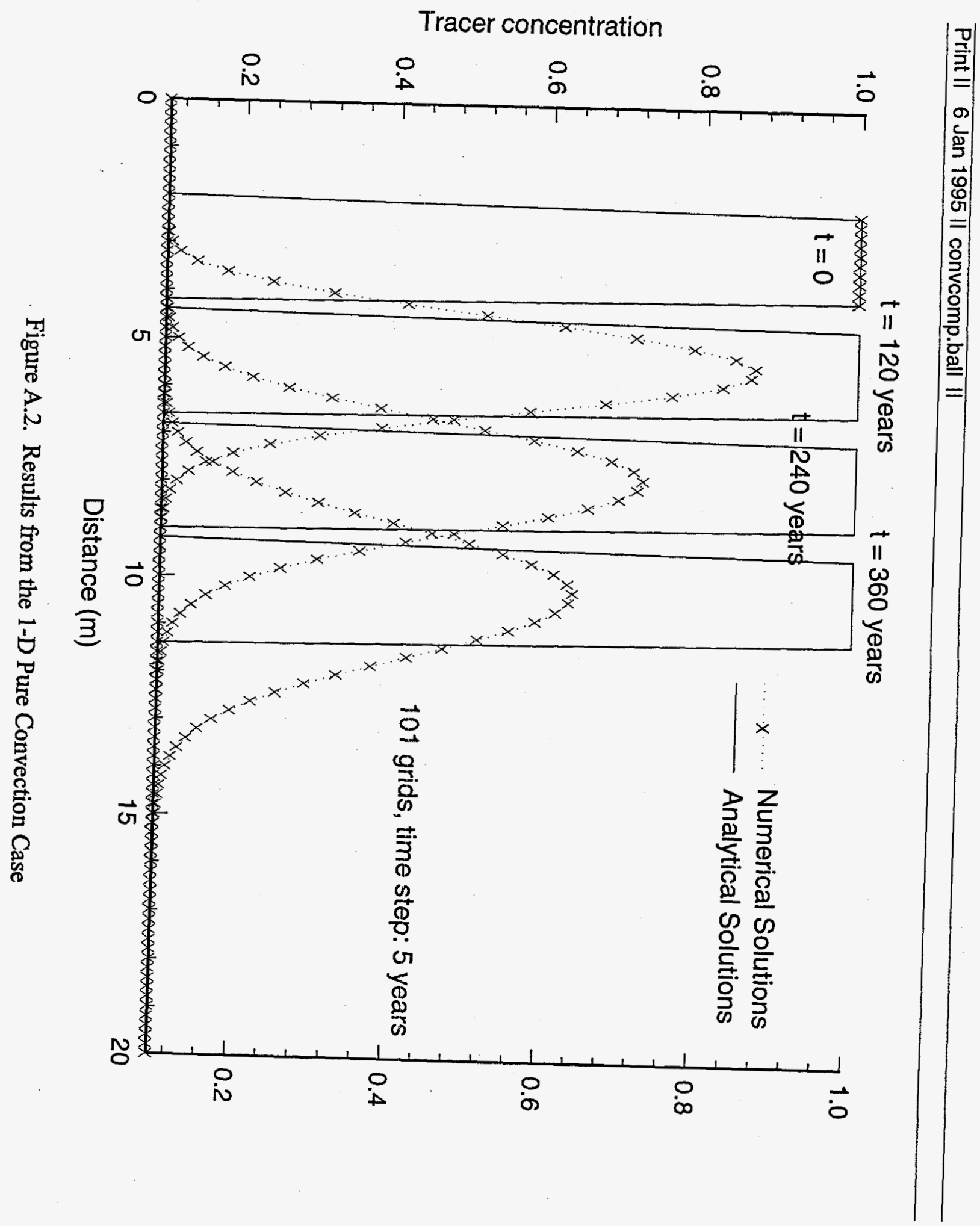




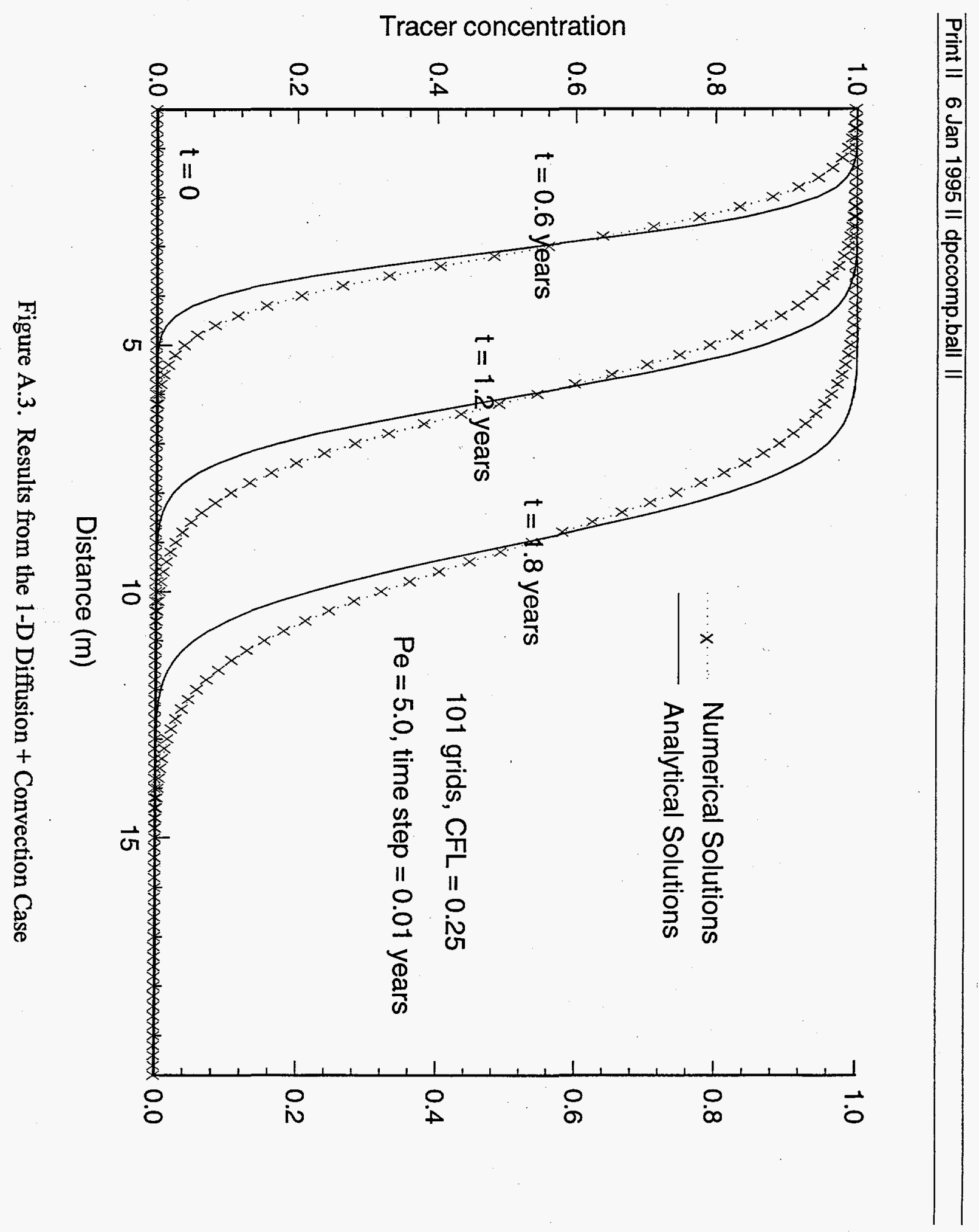




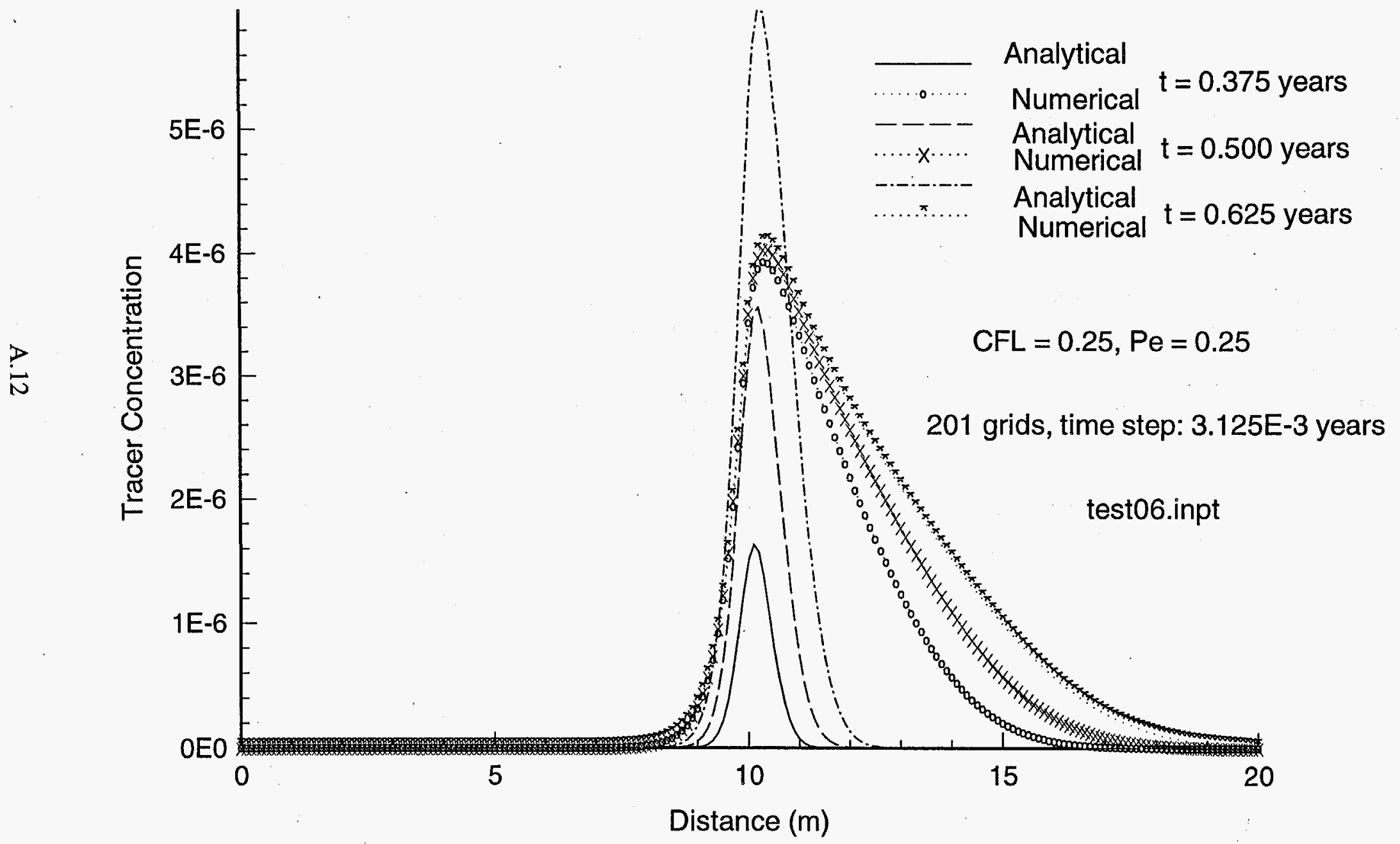

Figure A.4. Results from the 2-D Diffusion + Convection Case, Uniform Flow in the X-Direction 


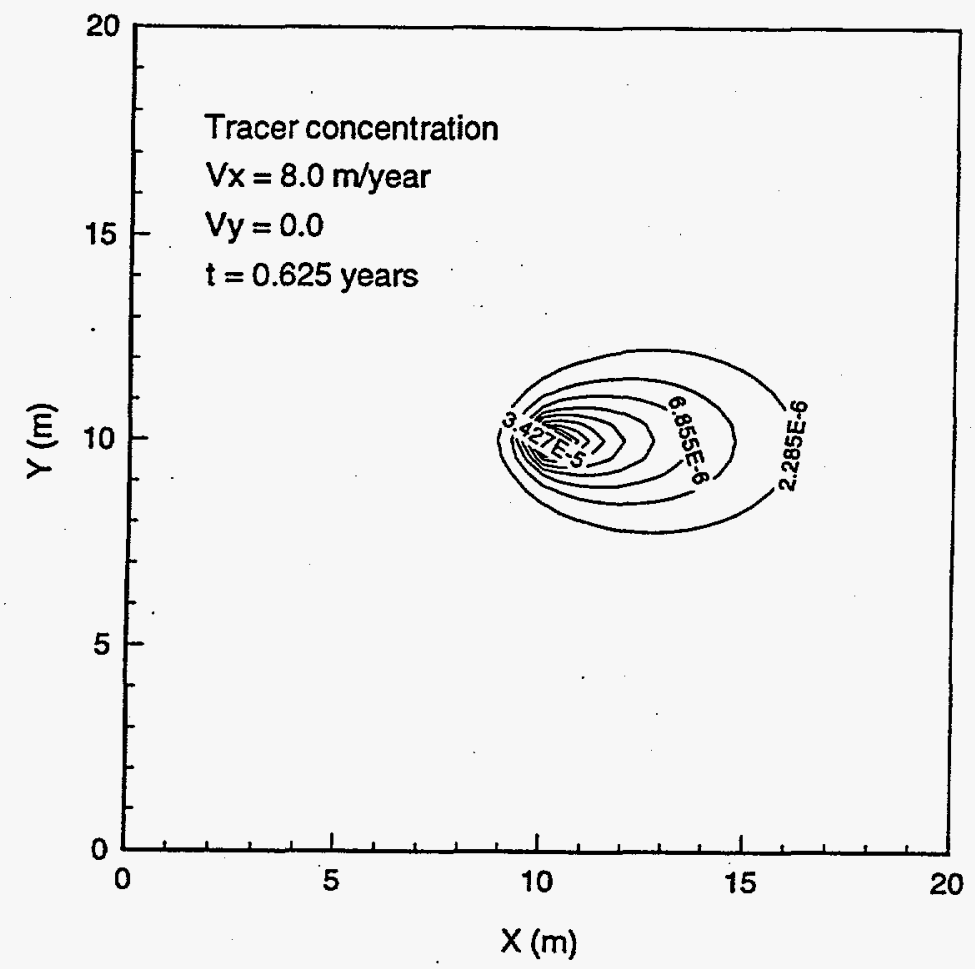

Figure A.5. Results from the 2-D Diffusion + Convection Case with Different Uniform Flow Directions $\left(V_{x}>0, V_{y}=0\right)$

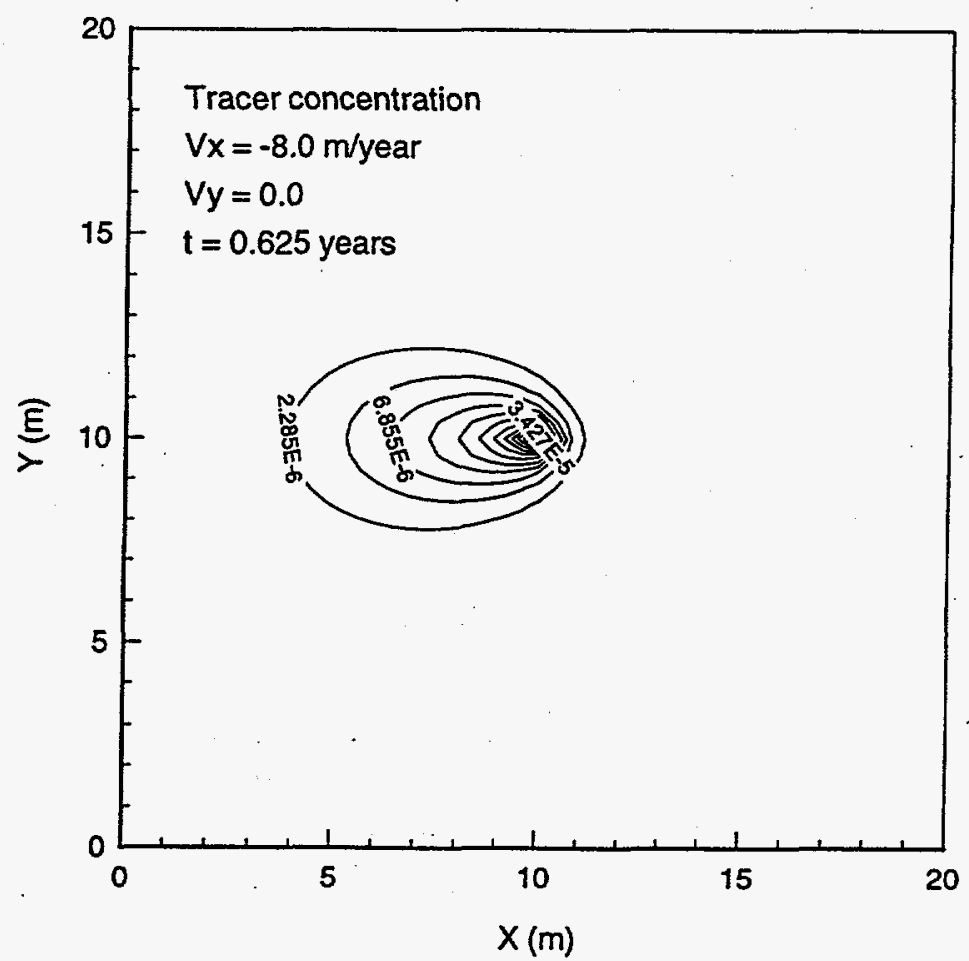

Figure A.6. Results from the 2-D Diffusion + Convection Case with Different Uniform Flow Directions $\left(V_{x}<0, V_{y}=0\right)$ 


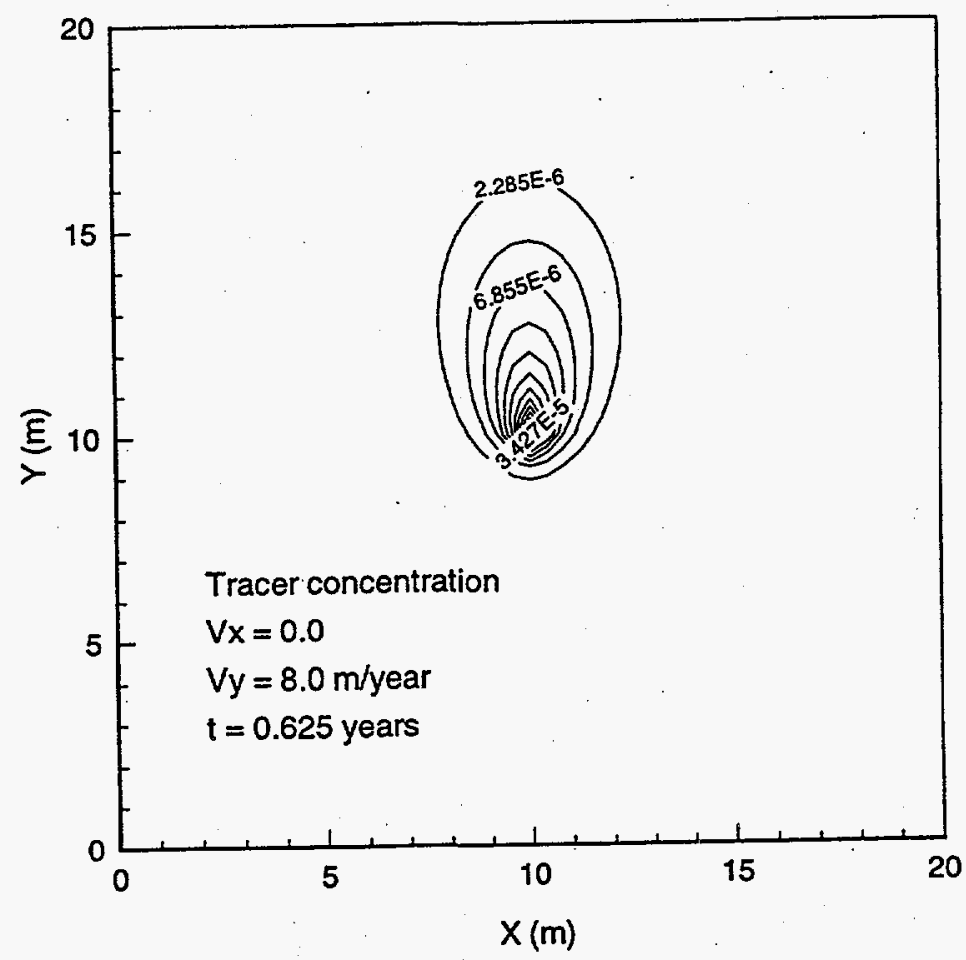

Figure A.7. Results from the 2-D Diffusion + Convection Case with Different Uniform Flow Directions $\left(V_{x}=0, V_{y}>0\right)$

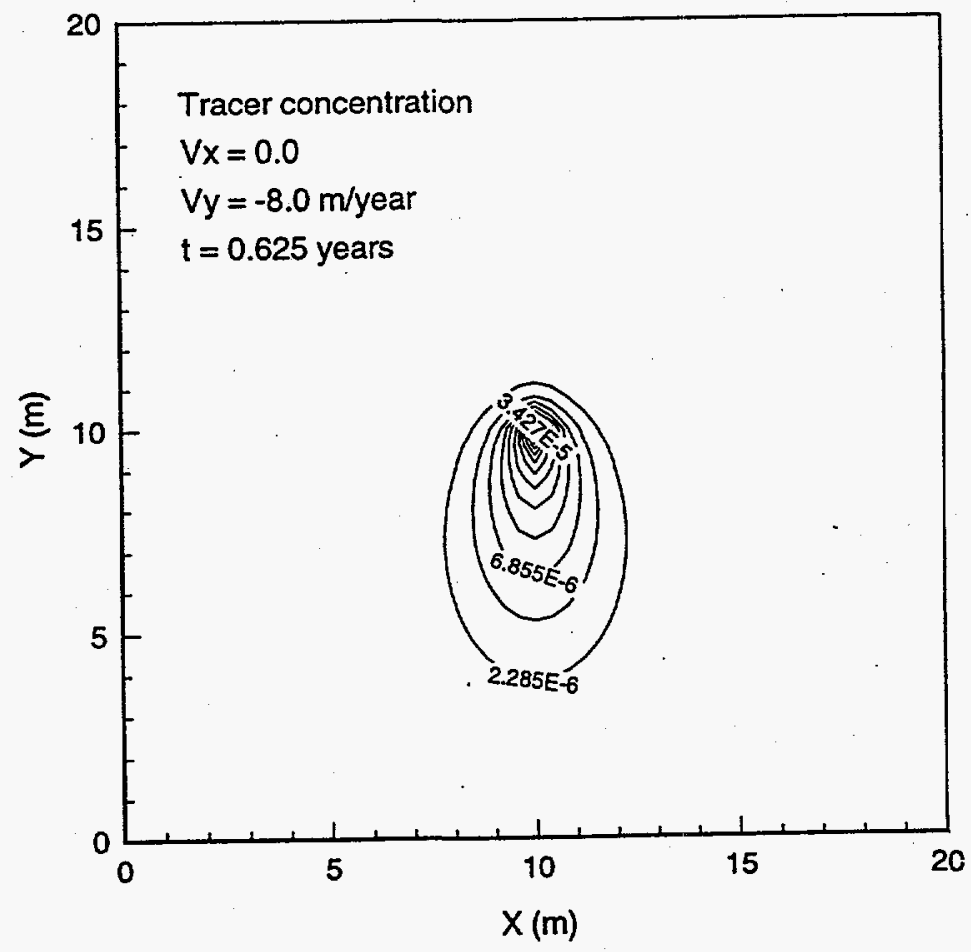

Figure A.8. Results from the 2-D Diffusion + Convection Case with Different Uniform Flow Directions $\left(\mathrm{V}_{\mathrm{x}}=0, \mathrm{~V}_{\mathrm{y}}<0\right)$ 


\section{APPENDIX B}

Verification of READIN Module 


\section{APPENDIX B}

\section{Verification of READIN Module}

This appendix contains the input data and results of the test case runs to verify the implementation of the READIN input module.

Table B.1. Input Data File for Testing Input Module

Test input file for AREST reaction-transport module

format: 20 lines of comments

line1: nxp, nyp, ntstep

line2: vx, vy [m/sec]

line3: water saturation (Sw)

line4: dispersion coefficient [m**2/sec]

line5: density of aqueous solution [ $\left.\mathrm{kg} / \mathrm{m}^{* * 3}\right]$

line6: xlength, $y$ length [m]

line 7: temperature [C]

Creating Date: 12/14/94 by: Yueting Chen

Purpose: testing AREST-CT module

Data start

$51 \quad 2 \quad 100$

0.020 .0

1.00

3.0

1. $0 \mathrm{E}+3$

20.01 .0

25.0

C

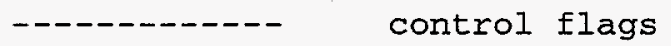

2 ! LF1, ID or $2 \mathrm{D}(=2)$ simulation

1 ! LF2, boundary condition types; 1 : type $1 ; 2$ : type 2

1 ! LF3, Aitken extrapolation scheme; 1: on; 0 : off

0 ! LF4, column scan switch, 0 : off, 1: on while LF1=2

0 ! LF5, 0: uniform lithology even more than 1 units in file.

o ! not used

o ! not used

o ! not used

i not used

C

!. not used

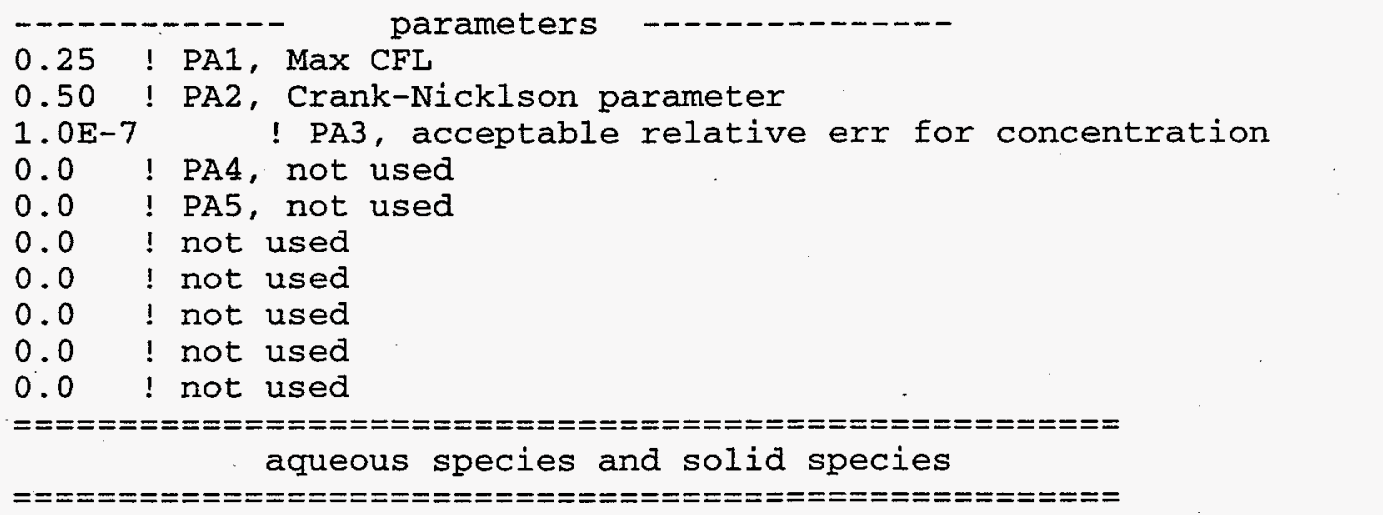

B.1 


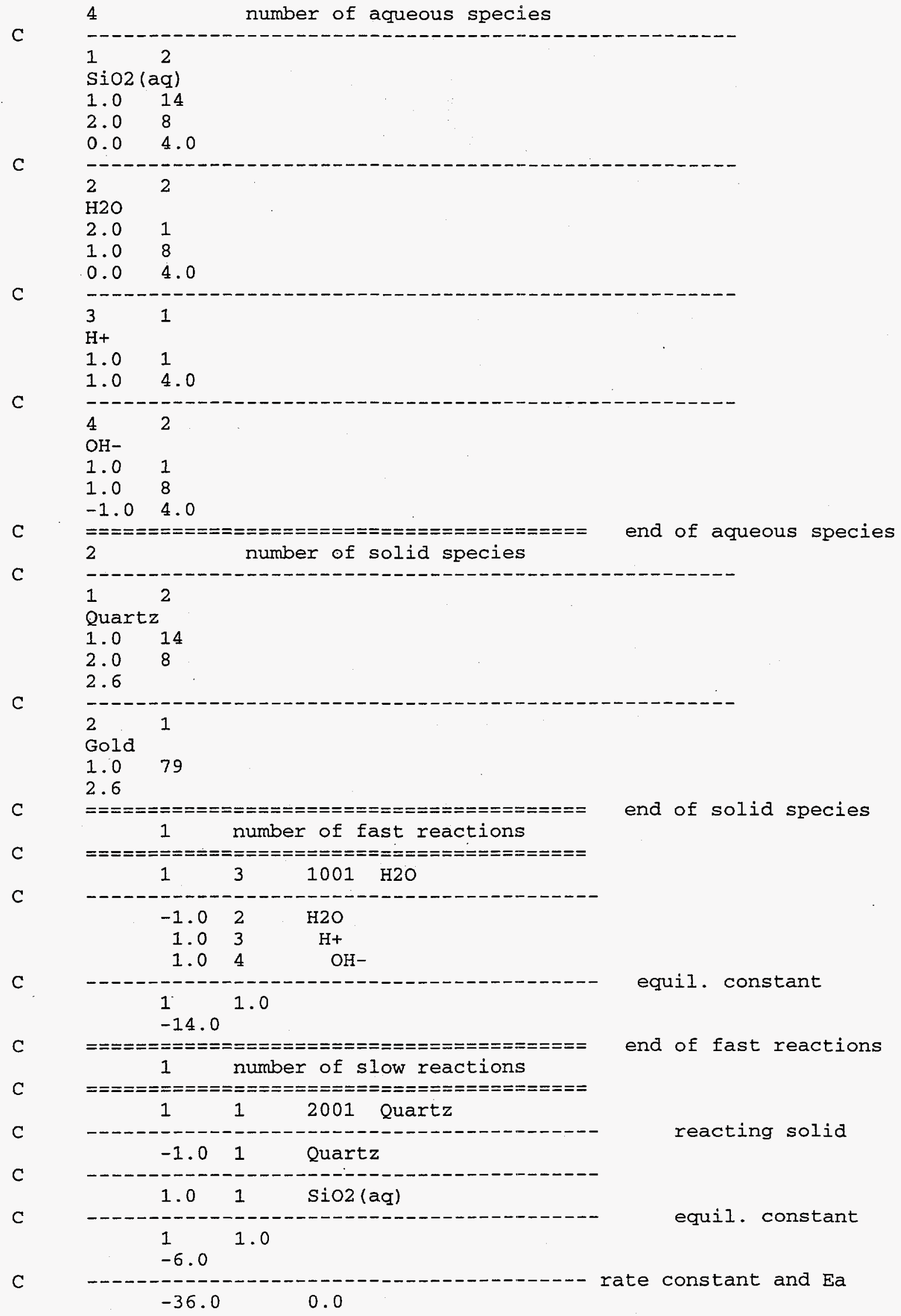

B. 2 


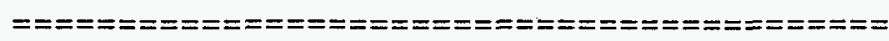
1 number of fluid decay

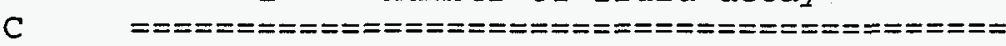

C

1 2 $1001 \mathrm{H} 2 \mathrm{O}$

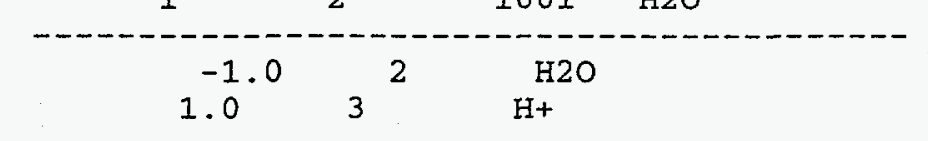

C

$1.0 E-7$

C

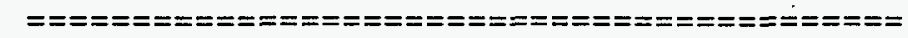
1 number of solid decay

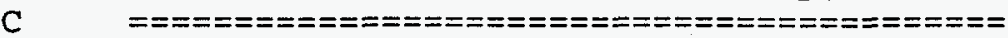

$\begin{array}{lllll}1 & 0 & 2001 & \text { Quartz } & 0\end{array}$

C

C

C

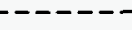
(20...........

end of slow reactions

-1.01 quartz decay reactant

1.02
0 gold decay product

$$
1.0 \mathrm{E}-5
$$

=

$$
1 \text { number of lithology units }
$$

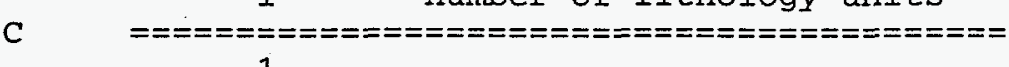
1

sandstone

C

$\begin{array}{rrrr}1 & 0.700 & 0.001 & \text { Quartz } \\ 2 & 0.001 & -0.001 & \text { Gold }\end{array}$

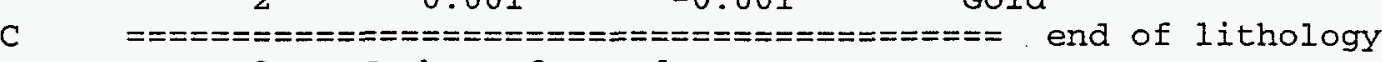

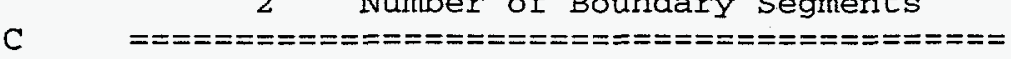

C 11 segment 1 (left) type 1

0 in equilibrium with number of solids

C $\quad$ -

11 condition 1,1 species

number
1.0
1
SiO2 (aq)
stoichio. coeff. and species
C
1. $0 \mathrm{E}-6$
total concentration

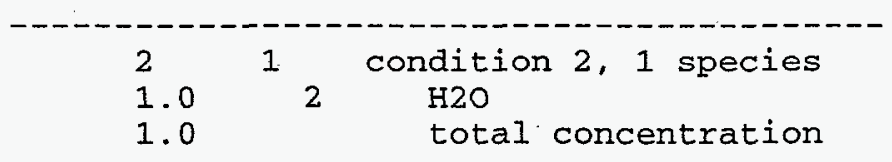
C

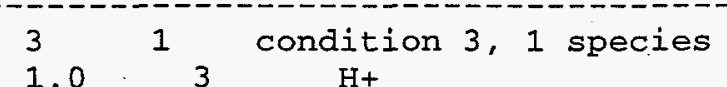
1.0E-7 total concentration

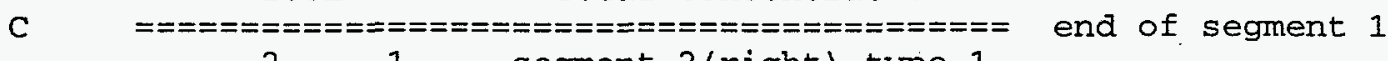
2. 1 segment 2 (right) type 1
C
0 in equilibrium with number of solids
C -
C
3 number of specified concentrations
11 condition 1,1 species
1.011 SiO2 (aq)
C
total concentration




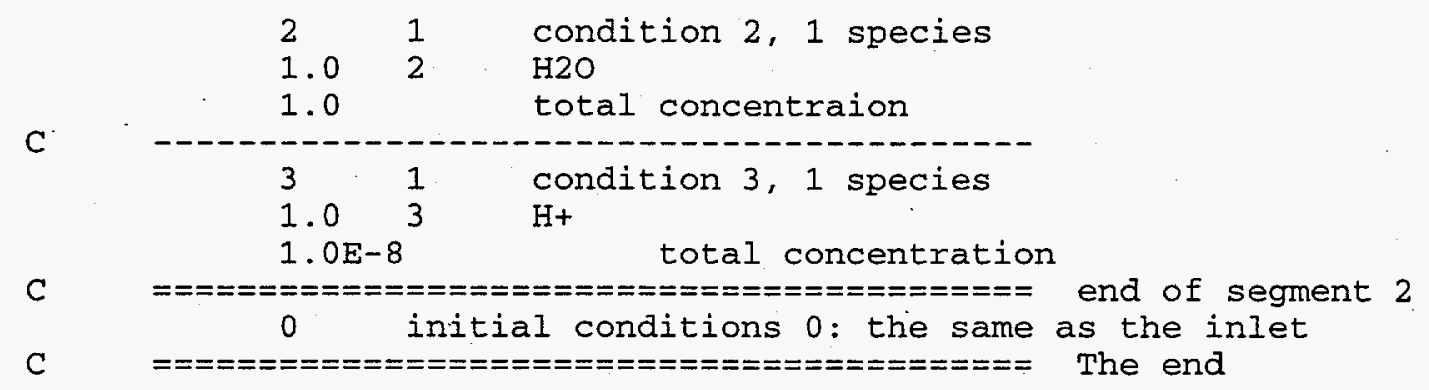

Table B.2. Output Data File for Testing Input Module

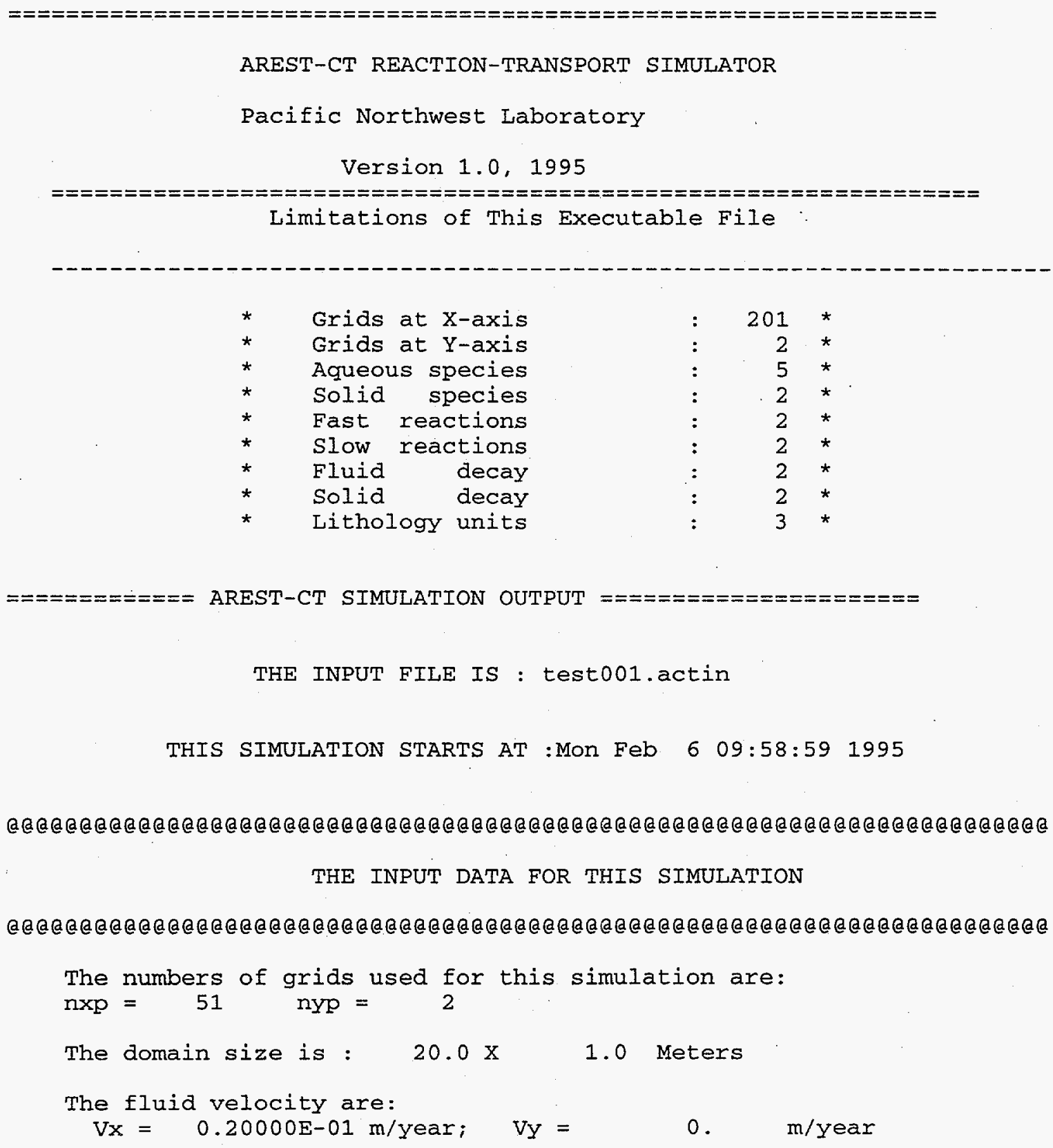

$\begin{array}{rrr}: & 201 & * \\ : & 2 & * \\ : & 5 & * \\ : & 2 & * \\ : & 2 & * \\ : & 2 & * \\ : & 3 & \end{array}$

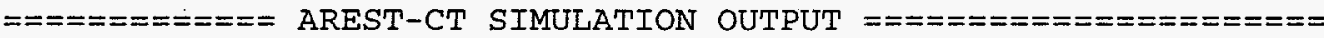

THE INPUT FILE IS : test001.actin

THIS SIMULATION STARTS AT :MON Feb 6 09:58:59 1995

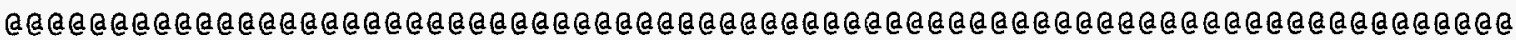

THE INPUT DATA FOR THIS SIMULATION

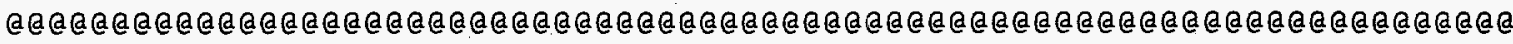

The numbers of grids used for this simulation are:

$\mathrm{nxp}=51 \quad$ nyp $=\quad 2$

The domain size is: $20.0 \mathrm{x} \quad 1.0$ Meters

The fluid velocity are:
$\mathrm{Vx}=$
$0.20000 \mathrm{E}-01 \mathrm{~m} /$ year;
$V y=$
0 .
$\mathrm{m} /$ year

\section{B.4}


The density of the fluid is: $1000.00 \quad\left[\mathrm{~kg} / \mathrm{m}^{\wedge} 3\right]$

The dispersion coefficient is: $\quad 3.00000\left[\mathrm{~m}^{\wedge} 2 / \mathrm{sec}\right]$

The initial water saturation is: 1.000

The temperature is : 25.0 [C]

Total number of aqueous species: 4

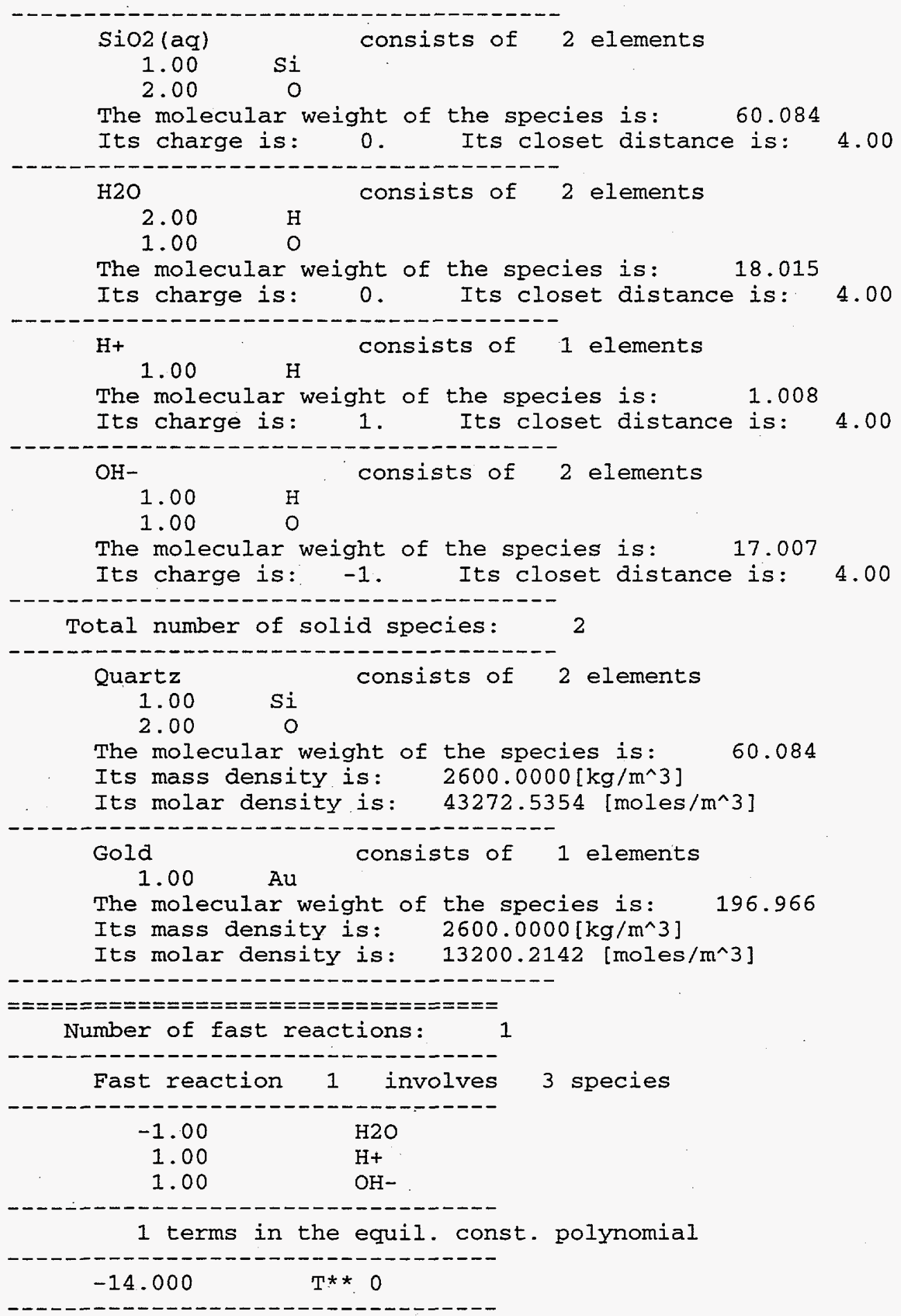


Exponential factor for this reaction is:

$===========================0$
Number of fluid decays :

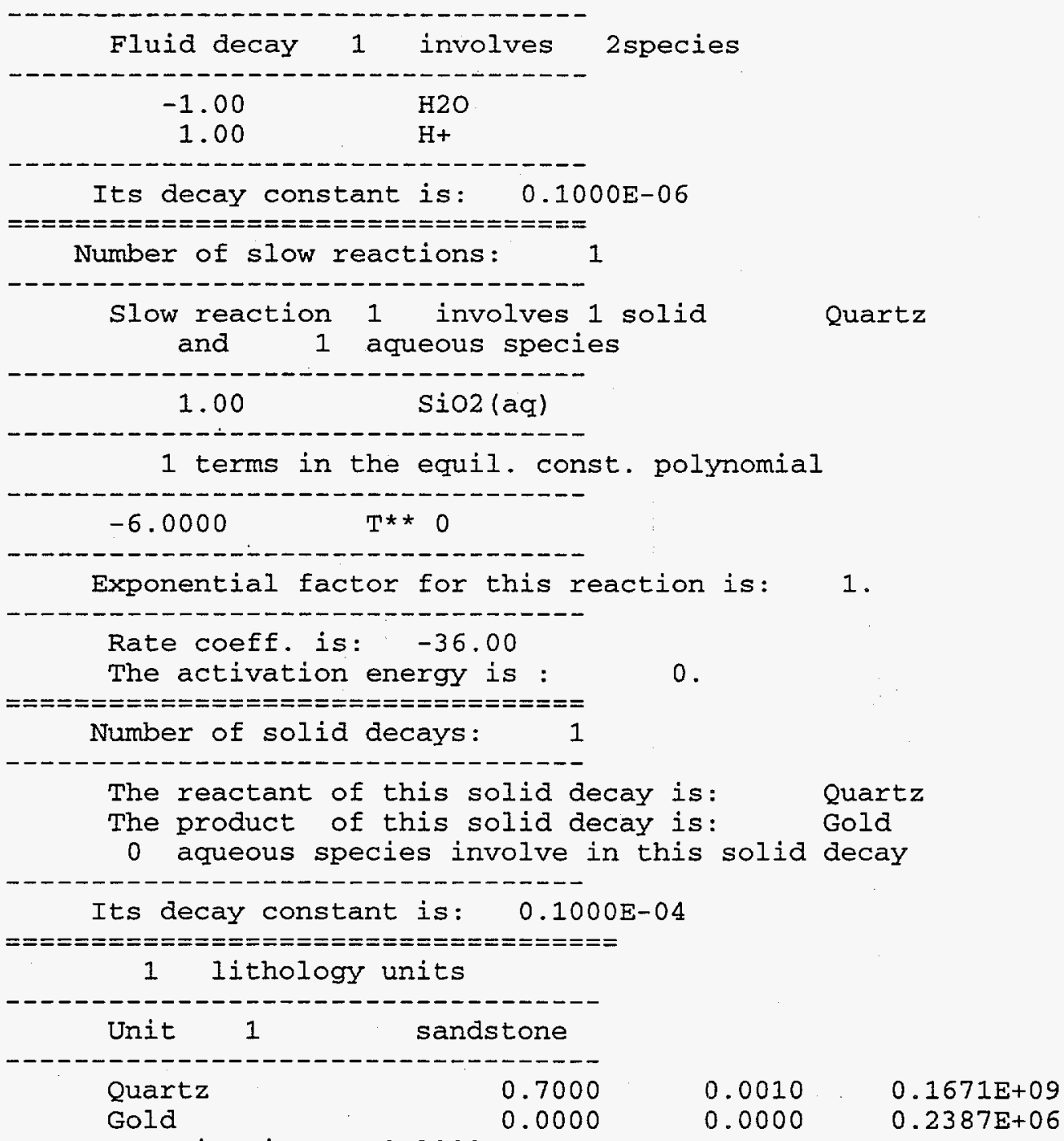

Porosity is: $\quad 0.3000$

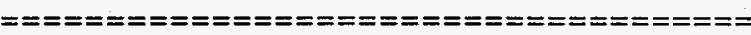
2 segments of boundary

Boundary segment 1 with type

1 conditions

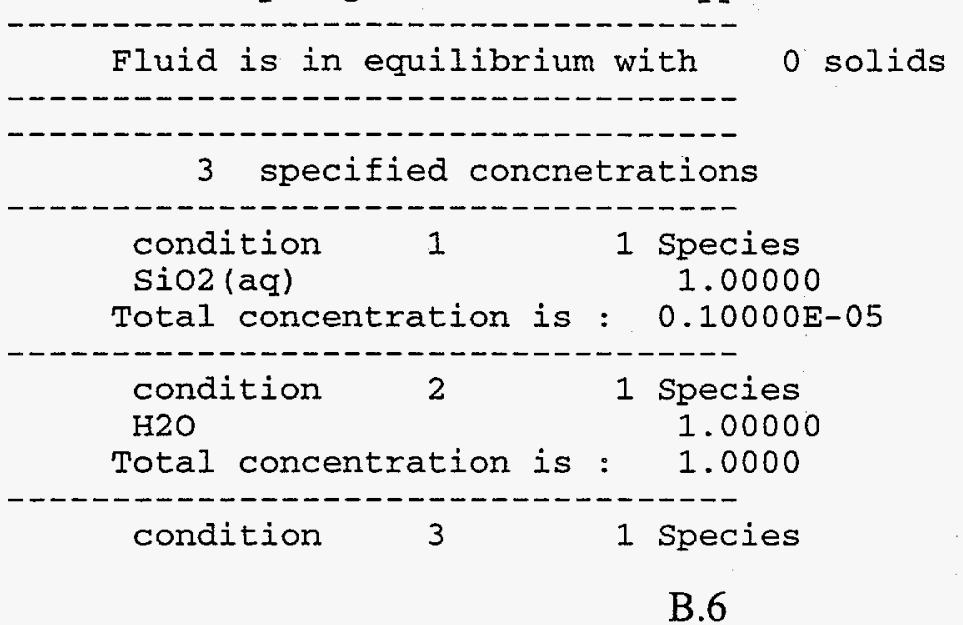


$\mathrm{H}+$

1.00000

Total concentration is : $0.10000 \mathrm{E}-06$

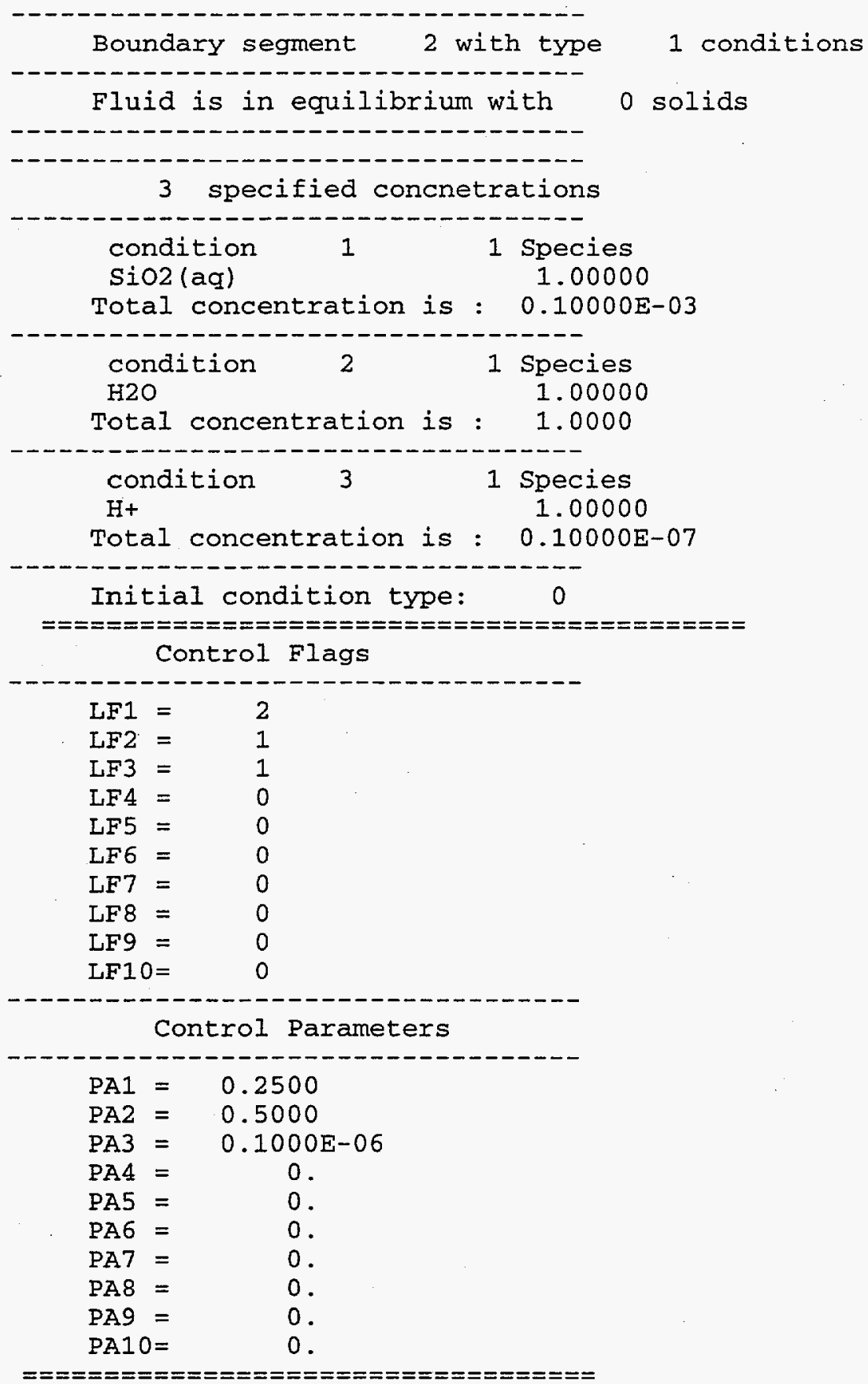

B.7 
APPENDIX C

Verification of QRDCMP Module 


\section{APPENDIX C}

\section{Verification of QRDCMP Module}

This appendix contains the input data and results of the test case runs to verify the implementation of the Q-R decomposition module.

Table C.1. Input Data File for Testing the Q-R Decomposition Module

C
C
$C$
$C$
$C$
$C$
$C$
$C$
$C$
$C$
$C$
$C$
$C$
$C$
$C$

Test input file for AREST reaction-transport module

format: 20 lines of comments

linel: nxp, nyp, ntstep

line2: vx, vy [m/sec]

line3: water saturation ( $\mathrm{Sw})$

line4: dispersion coefficient $[\mathrm{m} * * 2 / \mathrm{sec}]$

line5: density of aqueous solution $\left[\mathrm{kg} / \mathrm{m}^{* *} 3\right.$ ]

line6: xlength, ylength [m]

line7: temperature [C]

Creating Date: $12 / 14 / 94$ by: Yueting Chen

Purpose: testing AREST-CT module

-......- Data start _........-

$51 \quad 2 \quad 100$

$0.02 \quad 0.0$

1.00

3.0

1. $0 \mathrm{E}+3$

20.01 .0

C

25.0

control flags

2 ! LF1, 1D or 2D $(=2)$ simulation

1 ! LF2, boundary condition types; 1 : type 1 ; 2 : type 2

1 ! LF3, Aitken extrapolation scheme; 1: on; 0 : off

0 ! LF4, column scan switch, 0 : off, 1 : on while LF1=2

0 ! LF5, 0: uniform lithology even more than 1 units in file.

0 ! not used

0 ! not used

$0 \quad$ ! not used

$0 \quad$ ! not used

$\mathrm{C}$

$0 \quad$ ! not used

0.25 ! PAI, Max CFI

0.50 ! PA2, Crank-Nicklson parameter

1.0E-7 ! PA3, acceptable relative err for concentration

0.0 ! PA4, not used

0.0 ! PA5, not used

0.0 ! not used

$0.0 \quad$ ! not used

0.0 ! not used

0.0 ! not used

$0.0 \quad !$ not used

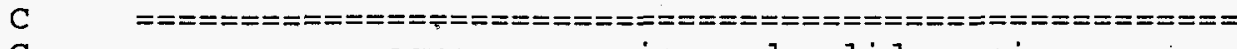

aqueous species and solid species

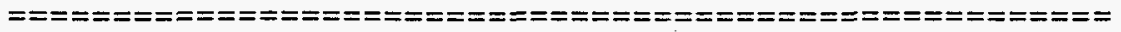

C.1 


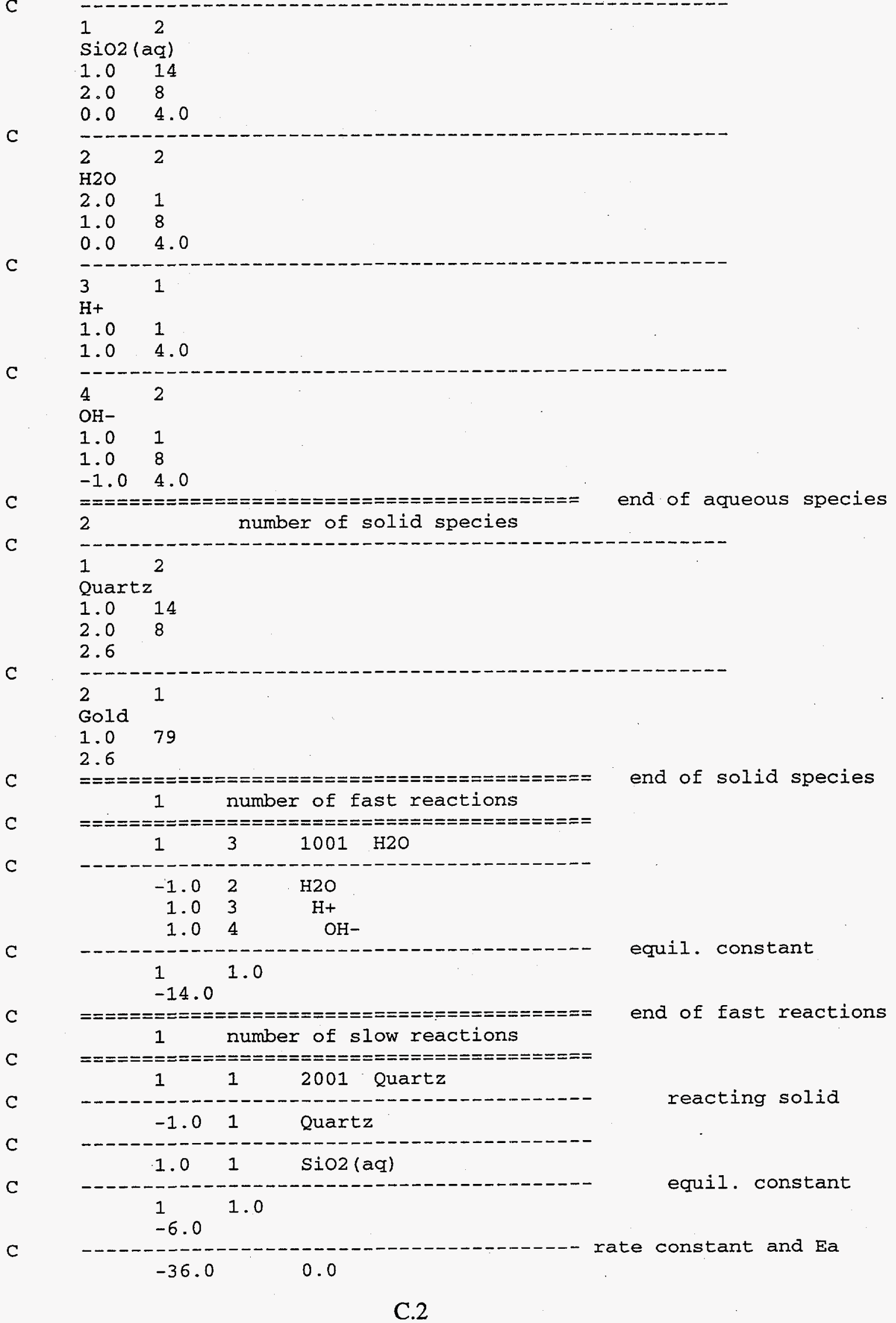




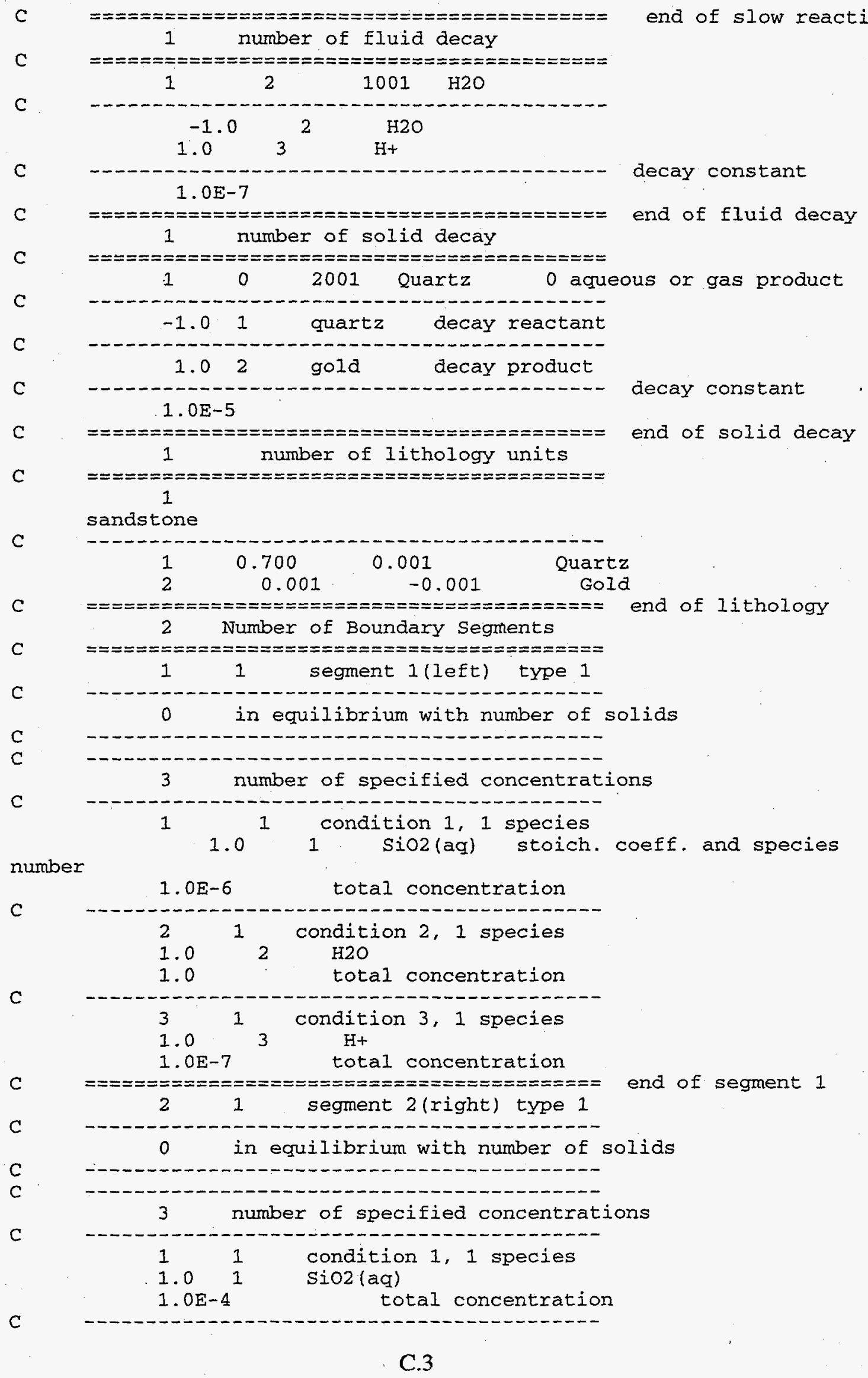




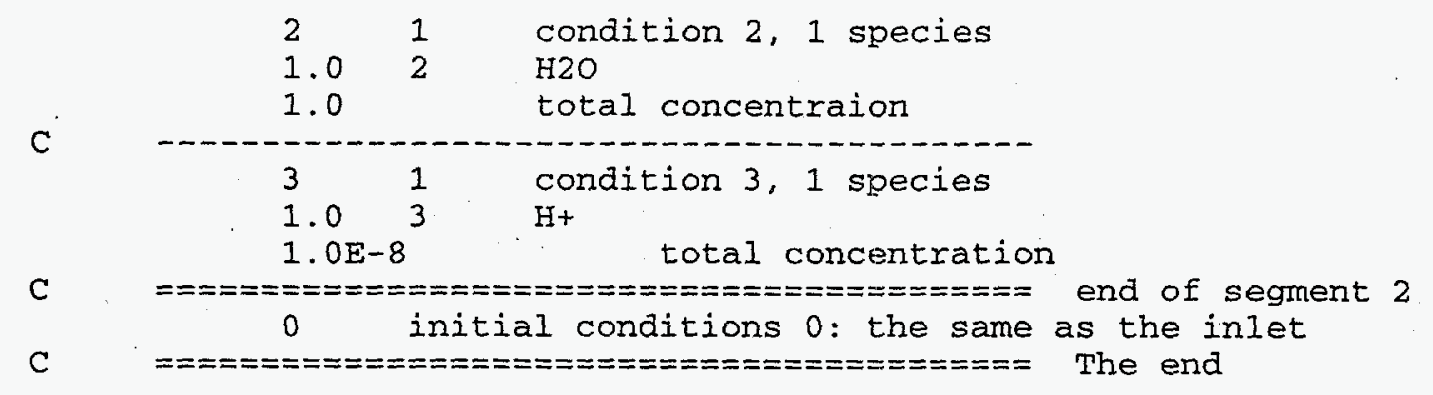

Table C.2. AREST-CT Output Data File for Testing the Q-R Decomposition Module qrentot

$\begin{array}{rrrrr}0.00000 \mathrm{E}+00 & 0.00000 \mathrm{E}+00 & 0.00000 \mathrm{E}+00 & 0.10000 \mathrm{E}+01 & 0.50000 \mathrm{E}+00 \\ -0.10000 \mathrm{E}+01 & -0.10000 \mathrm{E}+01 & -0.10000 \mathrm{E}+01 & 0.00000 \mathrm{E}+00 & 0.00000 \mathrm{E}+00 \\ 0.10000 \mathrm{E}+01 & 0.10000 \mathrm{E}+01 & 0.10000 \mathrm{E}+01 & 0.00000 \mathrm{E}+00 & 0.10000 \mathrm{E}+01 \\ 0.10000 \mathrm{E}+01 & 0.00000 \mathrm{E}+00 & 0.00000 \mathrm{E}+00 & 0.00000 \mathrm{E}+00 & 0.00000 \mathrm{E}+00 \\ 0.00000 \mathrm{E}+00 & -0.10000 \mathrm{E}+01 & 0.00000 \mathrm{E}+00 & 0.00000 \mathrm{E}+00 & 0.00000 \mathrm{E}+00 \\ 0.00000 \mathrm{E}+00 & 0.10000 \mathrm{E}+01 & 0.00000 \mathrm{E}+00 & 0.00000 \mathrm{E}+00 & 0.00000 \mathrm{E}+00\end{array}$

avector

$\begin{array}{cccccc}-0.10000 E+01 & 0.00000 E+00 & 0.00000 E+00 & 0.00000 E+00 & 0.00000 E+00 & 0.00000 E+00 \\ 0.00000 E+00 & -0.47434 E+00 & -0.79057 E+00 & 0.31623 E+00 & -0.15811 E+00 & 0.15811 E+00 \\ 0.00000 E+00 & 0.63246 E+00 & 0.00000 E+00 & 0.63246 E+00 & -0.31623 E+00 & 0.31623 E+00 \\ 0.00000 E+00 & 0.00000 E+00 & 0.00000 E+00 & 0.00000 E+00 & 0.70711 E+00 & 0.70711 E+00\end{array}$

avector * qrantot

$\begin{array}{rrrrr}0.00000 \mathrm{E}+00 & 0.00000 \mathrm{E}+00 & 0.00000 \mathrm{E}+00 & -0.10000 \mathrm{E}+01 & -0.50000 \mathrm{E}+00 \\ 0.00000 \mathrm{E}+00 & -0.11102 \mathrm{E}-15 & -0.31623 \mathrm{E}+00 & 0.00000 \mathrm{E}+00 & -0.79057 \mathrm{E}+00 \\ -0.11102 \mathrm{E}-15 & -0.22204 \mathrm{E}-15 & -0.63246 \mathrm{E}+00 & 0.00000 \mathrm{E}+00 & 0.00000 \mathrm{E}+00 \\ 0.00000 \mathrm{E}+00 & 0.11102 \mathrm{E}-15 & 0.00000 \mathrm{E}+00 & 0.00000 \mathrm{E}+00 & 0.00000 \mathrm{E}+00\end{array}$

Table C.3. CIRF.A Output Data File for Testing the Q-R Decomposition Module grxatot
$0.00000 E+00$
$0.00000 \mathrm{E}+00$
$0.00000 \mathrm{E}+00$
$0.10000 E+01$
$0.50000 E+00$
$0.10000 E+01$
$0.10000 \mathrm{E}+01$
$0.10000 E+01$
$0.00000 E+00$
$0.00000 E+00$
$0.10000 \mathrm{E}+01$
$0.10000 \mathrm{E}+01$
$0.10000 E+01$
$0.00000 \mathrm{E}+00$
$0.10000 \mathrm{E}+01$
$0.10000 \mathrm{E}+01$
$0.00000 E+00$
$0.00000 E+00$
$0.00000 E+00$
$0.00000 E+00$ 

$0.00000 E+00$
$0.10000 E+01$
$0.00000 \mathrm{E}+00$
$0.00000 E+00$
$0.00000 E+00$
$0.00000 \mathrm{E}+00$
$0.10000 \mathrm{E}+01$
$0.00000 E+00$
$0.00000 \mathrm{E}+00$
$0.00000 E+00$

avector
$-0.10000 E+01$
$0.00000 \mathrm{E}+00$
$0.00000 E+00$
$0.00000 \mathrm{E}+00$
$0.00000 E+00$
$0.00000 \mathrm{E}+00$
$0.00000 \mathrm{E}+00$
$-0.47434 \mathrm{E}+00$
$-0.79057 E+00$
$0.31623 E+00$
$0.15811 E+00$
$-0.15811 E+00$
$0.00000 \mathrm{E}+00$
$0.63246 \mathrm{E}+00$
$0.00000 E+00$
$0.63246 \mathrm{E}+00$
$-0.31623 E+00$
$0.31623 \mathrm{E}+00$
$0.00000 \mathrm{E}+00$
$0.00000 \mathrm{E}+00$
$0.00000 E+00$
$0.00000 E+00$
$0.70711 E+00$
$0.70711 \mathrm{E}+00$

avector * qrxentot
$0.00000 E+00$
$0.00000 \mathrm{E}+00$
$0.00000 E+00$
$-0.10000 \mathrm{E}+01$
$-0.50000 E+00$
$0.00000 \mathrm{E}+00$
$-0.11102 \mathrm{E}-15$
$-0.31623 E+00$
$0.00000 E+00$
$-0.79057 E+00$
$-0.11102 \mathrm{E}-15$
$-0.22204 \mathrm{E}-15 \quad-0.63246 \mathrm{E}+00$
$0.00000 \mathrm{E}+00$
$0.00000 E+00$
$0.00000 E+00$
$0.11102 \mathrm{E}-15$
$0.00000 E+00$
$0.00000 E+00$
$0.00000 E+00$ 
APPENDIX D

Verification of EQCONST, RCONST, and DHACTV Modules 


\section{APPENDIX D}

\section{Verification of EQCONST, RCONST, and DHACTV Modules}

This appendix contains the input data and results of the test case runs to verify the implementation of the equilibrium constants, rate constants, and activity coefficient modules.

Table D.1. Input Data File for Testing the Equilibrium Constants, Rate Constants, and Activity Coefficient Modules

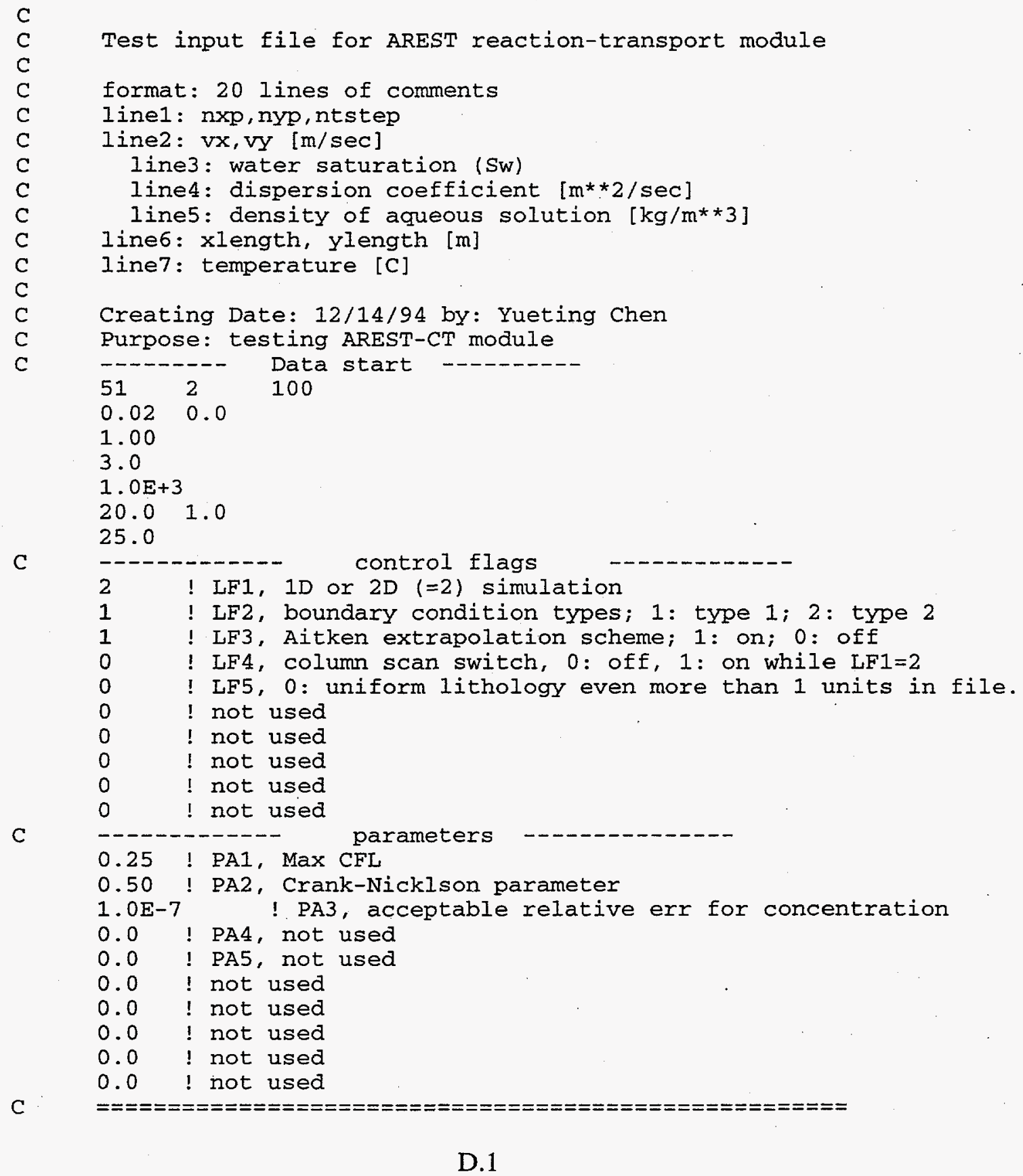

C

D. 1 


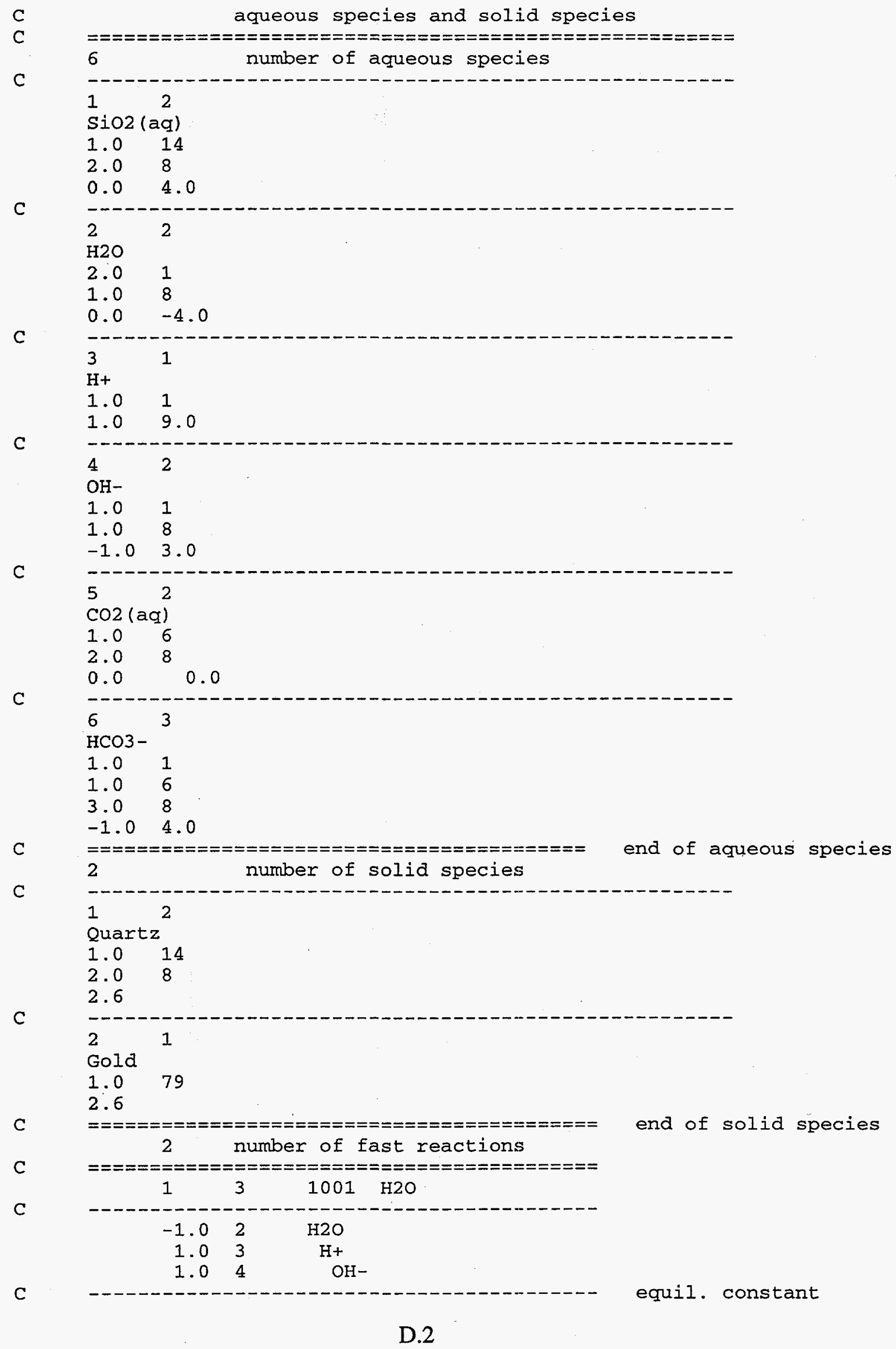




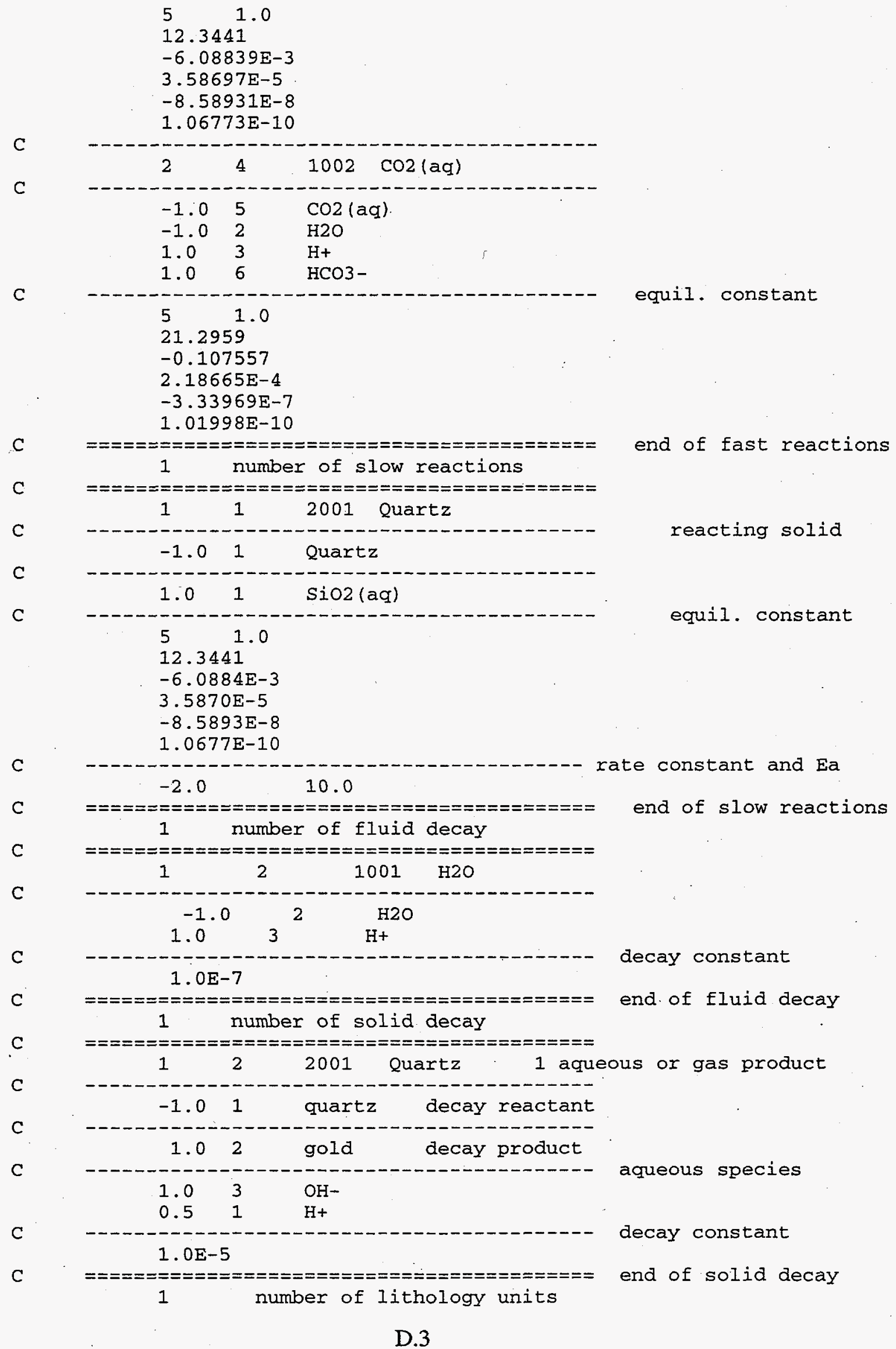




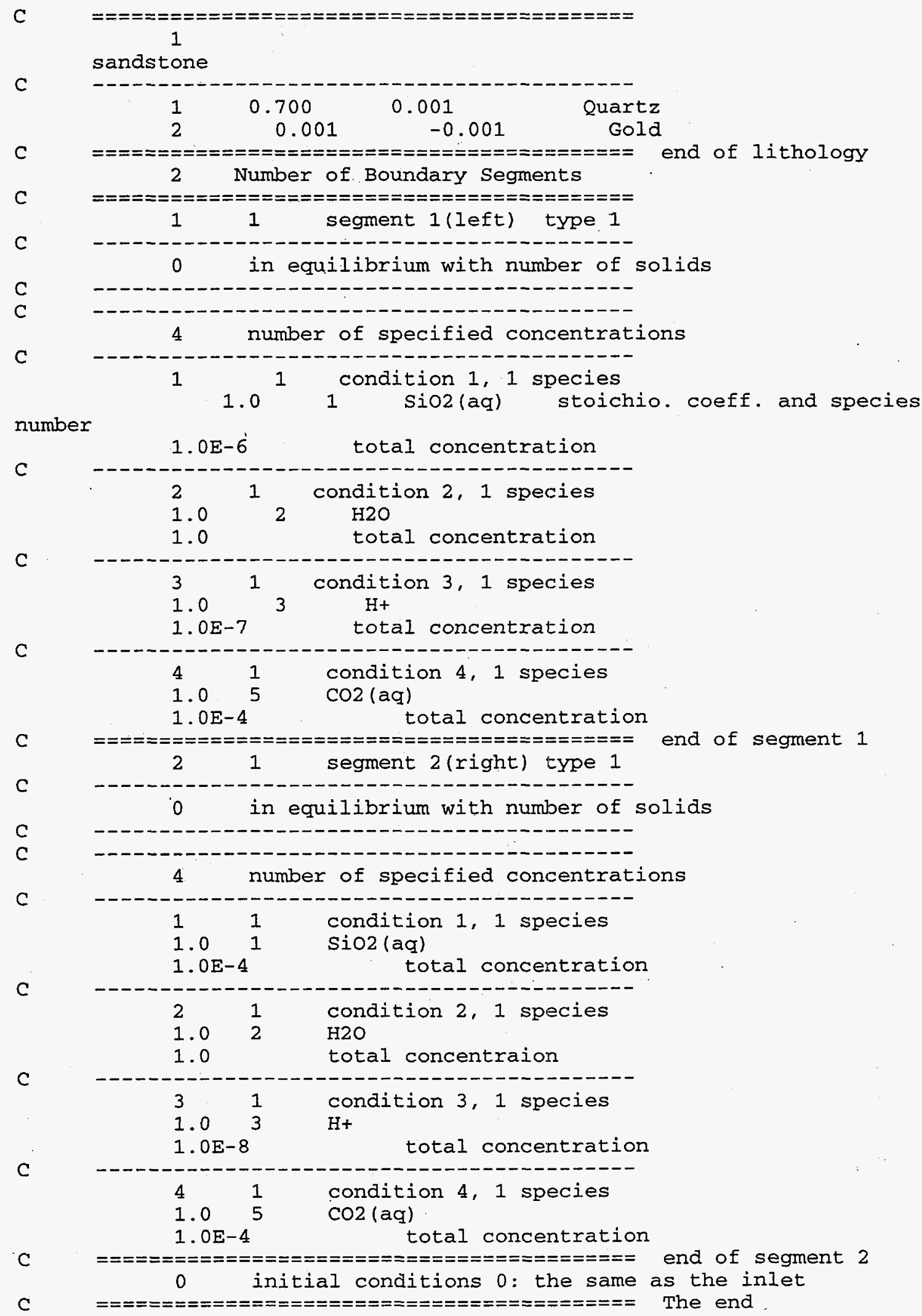

\section{4}


Table D.2. Output Data File for Testing the Equilibrium Constants, Rate Constants, and Activity Coefficient Modules

Temperature

Equlibrium and Rate Constants

$\log k_{1}$ (calc) $\quad \log k_{1}(E Q 3) \quad \log k_{2}$ (calc) $\quad \log k_{2}$ (EQ3) rate const

$\begin{array}{rlllll}0.01 & 12.3440 & 12.3460 & 21.2948 & 21.2950 & 1.22376 \mathrm{E}-04 \\ 25.00 & 12.2130 & 12.2091 & 18.7385 & 18.7390 & 1.77002 \mathrm{E}-04 \\ 60.00 & 12.0908 & 12.0918 & 15.5589 & 15.5565 & 2.70422 \mathrm{E}-04 \\ 100.00 & 12.0187 & 12.0214 & 12.4031 & 12.4046 & 3.98217 \mathrm{E}-04 \\ 150.00 & 12.0021 & 12.0011 & 9.00680 & 9.00960 & 5.82816 \mathrm{E}-04 \\ 200.00 & 12.0449 & 12.0426 & 6.02254 & 6.01750 & 7.87016 \mathrm{E}-04 \\ 250.00 & 12.1389 & 12.1412 & 3.25338 & 3.25660 & 1.00346 \mathrm{E}-03 \\ 300.00 & 12.2916 & 12.2910 & 0.51767 & 0.51700 & 1.22633 \mathrm{E}-03\end{array}$

\section{Input Values From EQ3/6}

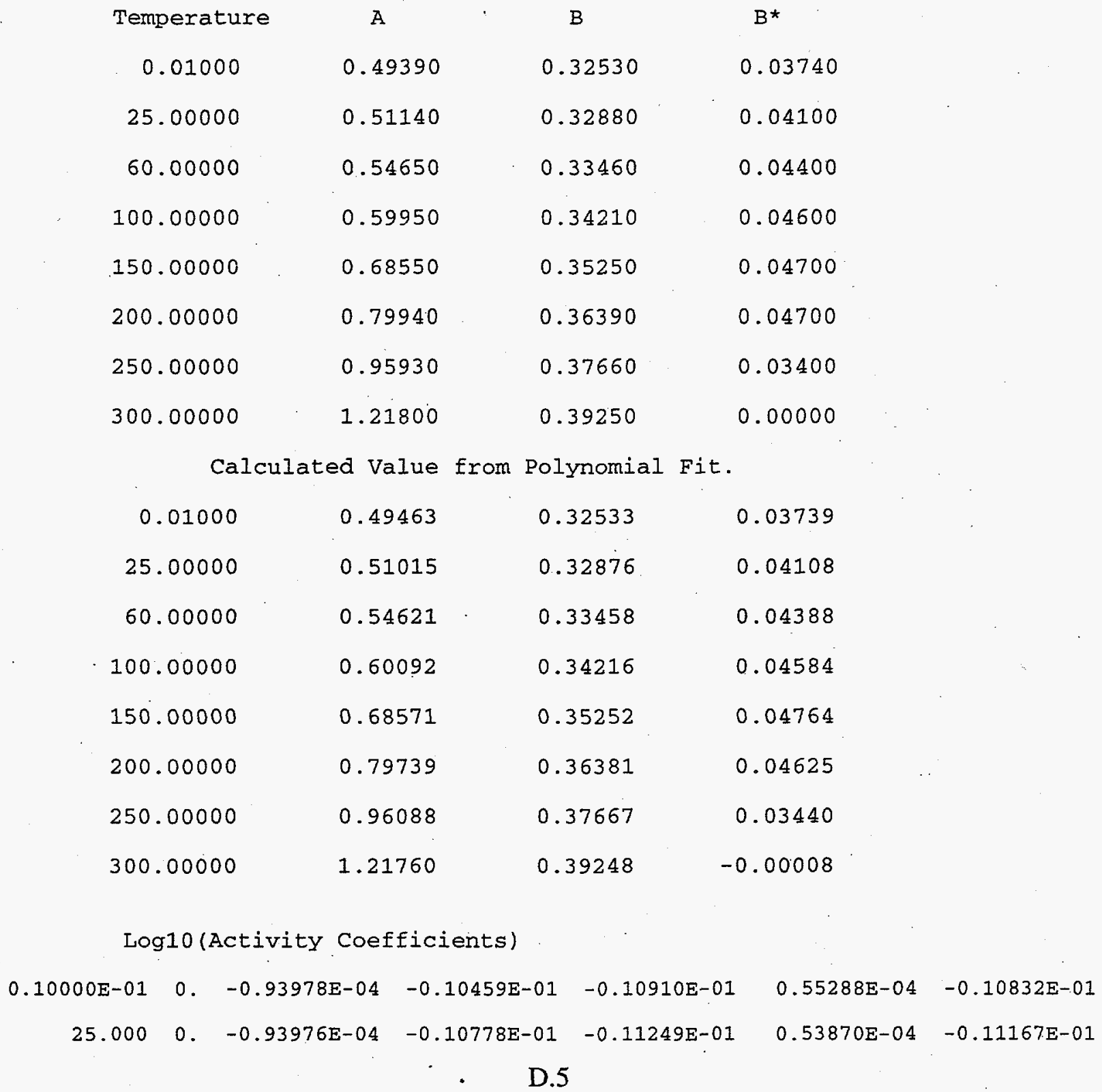




$\begin{array}{llllllll}60.000 & 0 . & -0.93972 \mathrm{E}-04 & -0.11527 \mathrm{E}-01 & -0.12039 \mathrm{E}-01 & 0.56269 \mathrm{E}-04 & -0.11951 \mathrm{E}-01 \\ 100.00 & 0 . & -0.93965 \mathrm{E}-04 & -0.12665 \mathrm{E}-01 & -0.13240 \mathrm{E}-01 & 0.63598 \mathrm{E}-04 & -0.13140 \mathrm{E}-01 \\ 150.00 & 0 . & -0.93953 \mathrm{E}-04 & -0.14426 \mathrm{E}-01 & -0.15100 \mathrm{E}-01 & 0.77609 \mathrm{E}-04 & -0.14983 \mathrm{E}-01 \\ 200.00 & 0 . & -0.93939 \mathrm{E}-04 & -0.16744 \mathrm{E}-01 & -0.17551 \mathrm{E}-01 & 0.95413 \mathrm{E}-04 & -0.17411 \mathrm{E}-01 \\ 250.00 & 0 . & -0.93917 \mathrm{E}-04 & -0.20139 \mathrm{E}-01 & -0.21142 \mathrm{E}-01 & 0.11592 \mathrm{E}-03 & -0.20968 \mathrm{E}-01 \\ 300.00 & 0 . & -0.93884 \mathrm{E}-04 & -0.25466 \mathrm{E}-01 & -0.26785 \mathrm{E}-01 & 0.13843 \mathrm{E}-03 & -0.26556 \mathrm{E}-01\end{array}$

Table D.3. Original Data From EQ3/6

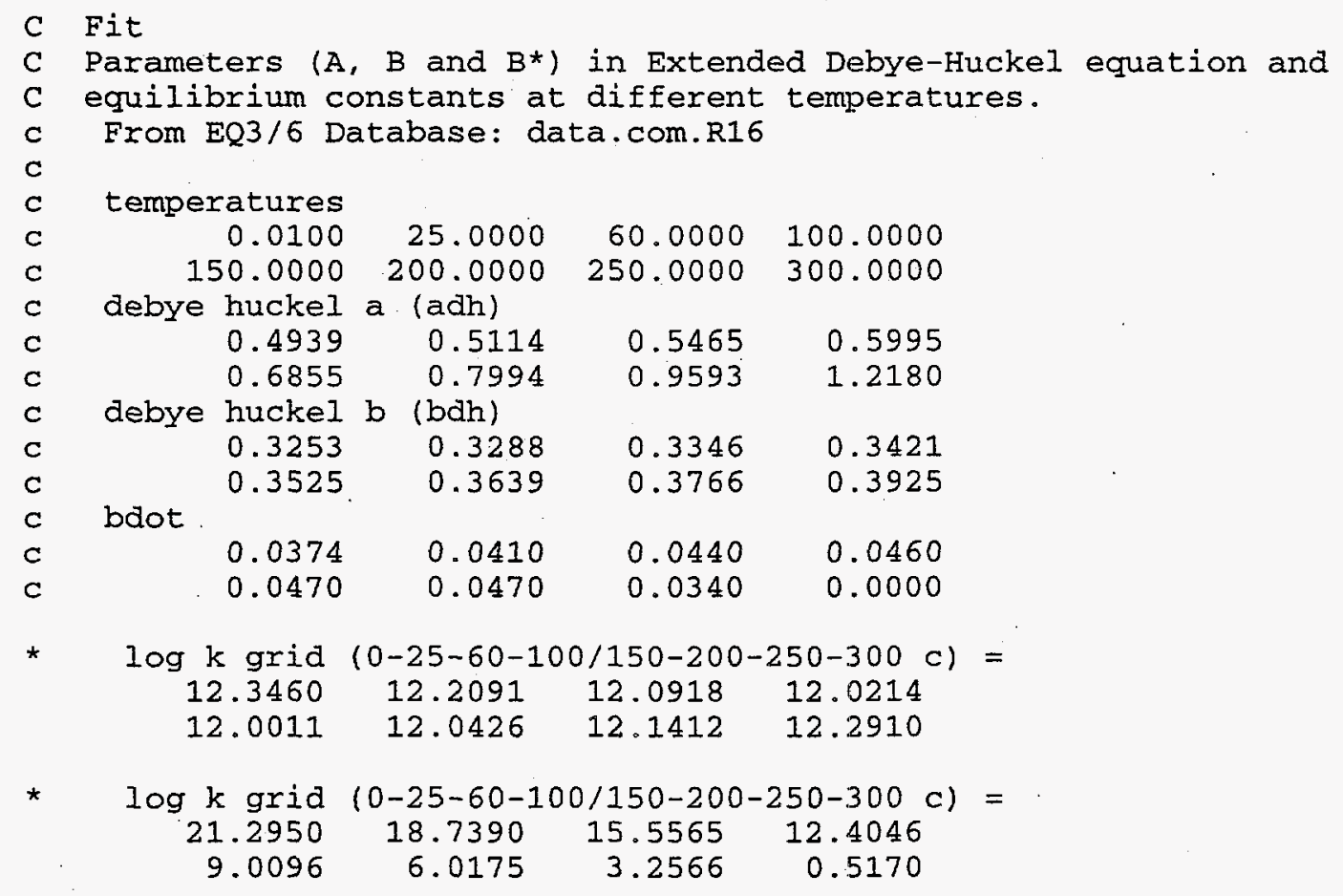


APPENDIX E

Verification of EQPT Module 


\section{APPENDIX E}

\section{Verification of EQPT Module}

This appendix contains the input data and results of the test case run to verify the implementation of the EQPT, point solver type I module.

Table E.1. Input Data File for Testing the Point Solver I Module

$C$
$C$
$C$
$C$
$C$
$C$
$C$
$C$
$C$
$C$
$C$
$C$
$C$
$C$
$C$

Test input file for AREST reaction-transport module

format: 20 lines of comments

line1: nxp, nyp, ntstep

line2: vx, vy [m/sec]

line 3: water saturation (Sw)

line4: dispersion coefficient [m**2/sec]

line5: density of aqueous solution $[\mathrm{kg} / \mathrm{m} * * 3]$

line6: xlength, $y$ length [m]

line 7: temperature [C]

Creating Date: $12 / 14 / 94$ by: Yueting Chen

Purpose: testing AREST-CT module

$\begin{array}{lll}51 & 2 & \text { Data start } \\ 0.02 & 0.0 & \end{array}$

1.00

3.0

1. $0 \mathrm{E}+3$

20.01 .0

25.0

C

2 ! IF1, ID or $2 \mathrm{D}(=2)$ simulation

1 ! LF2, boundary condition types; 1: type 1; 2: type 2

1 ! LF3, Aitken extrapolation scheme; 1: on; 0: off

o ! LF4, column scan switch, 0 : off, 1: on while LF1=2

0 ! LF5, 0: uniform lithology even more than 1 units in file.

2 ! LF6, skip factor for eq. point solver in N-R iteration

2 ! LF7, skip factor for transp. point solver in $\mathrm{N}-\mathrm{R}$ iteration

o ! not used

0 ! not used

C

! not used

parameters ---

0.25 ! PA1, Max CFL

0.50 ! PA2, Crank-Nicklson parameter

1.0E-7 ! PA3, acceptable relative err for concentration

1.0E-7 ! PA4, error tolerance in eq. point solver

1.OE-3 ! PA5; error tolerance in transp. point solver

0.0 ! not used

0.0 ! not used

0.0 ! not used

0.0 ! not used

0.0 ! not used

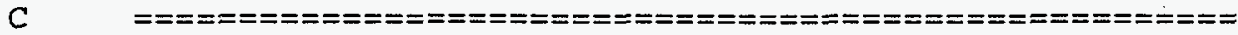
aqueous species and solid species

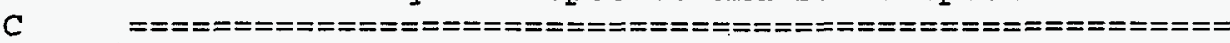

E.1 


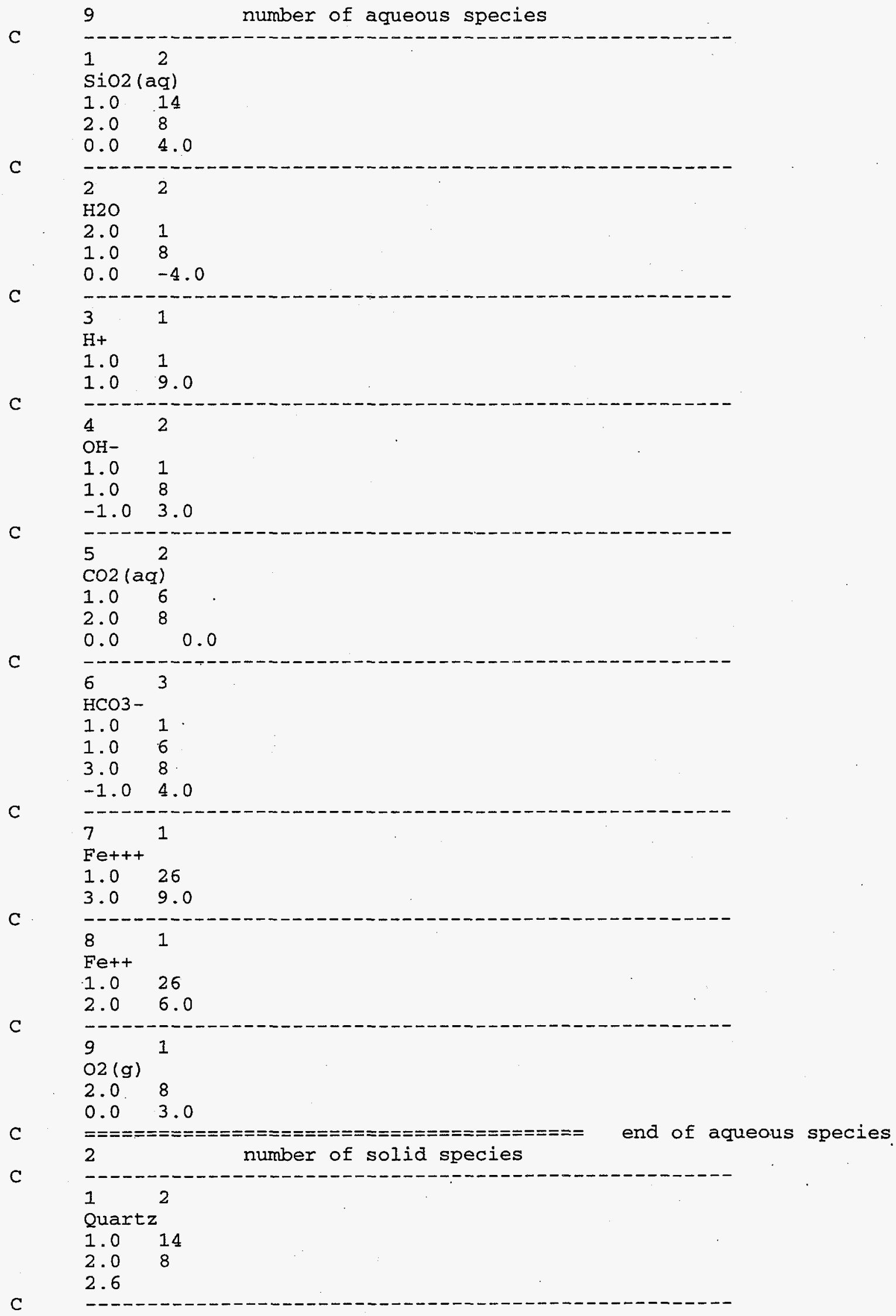

E. 2 


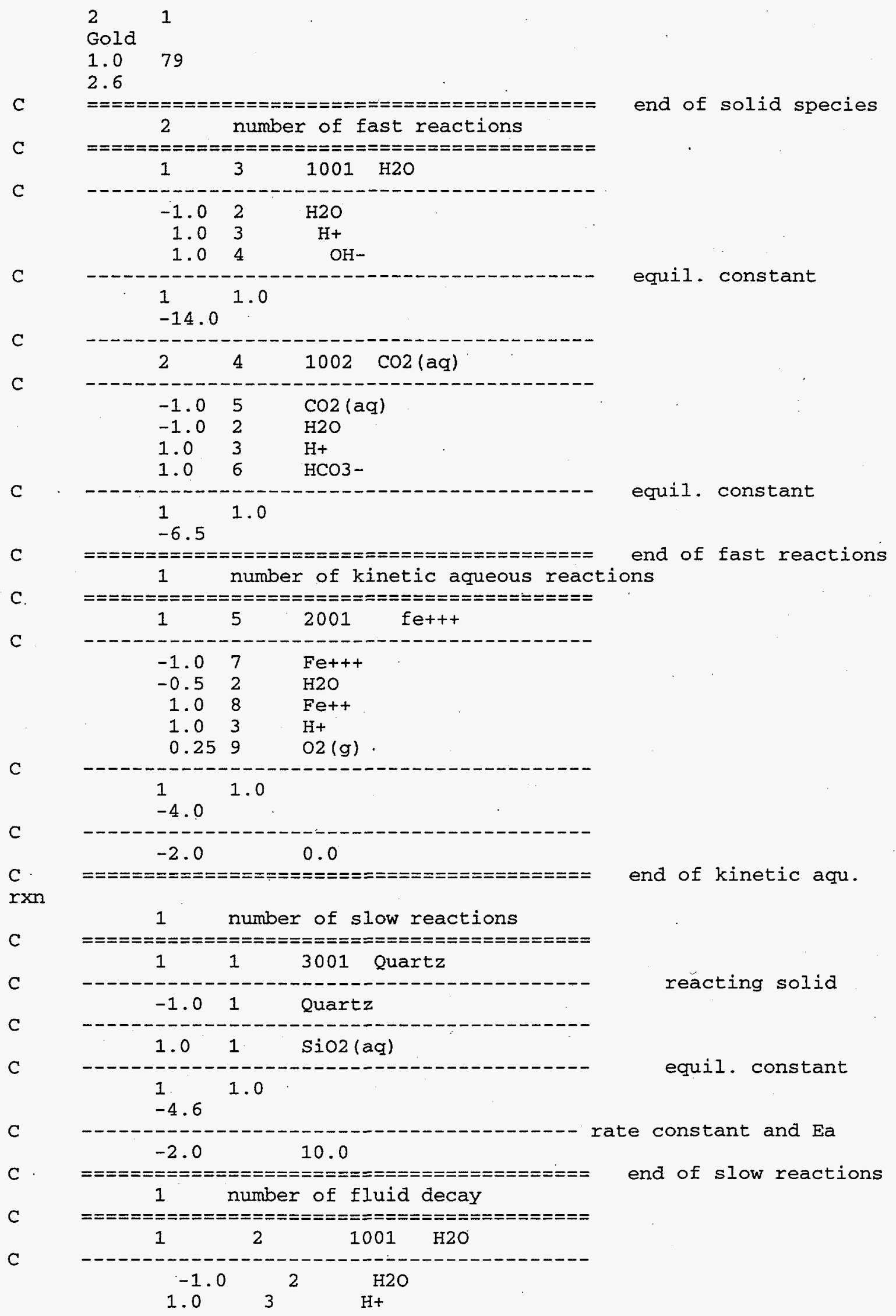

E. 3 


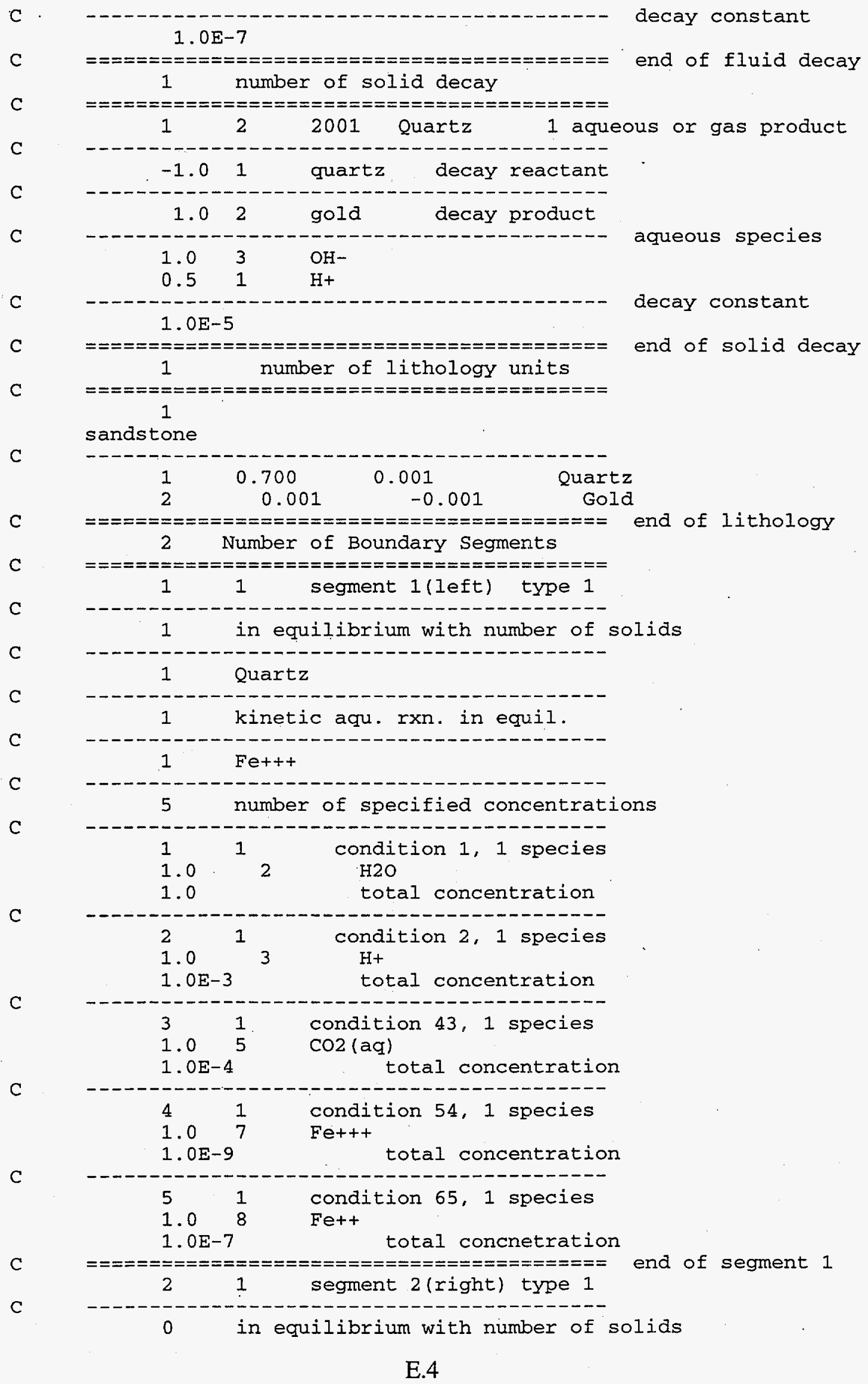




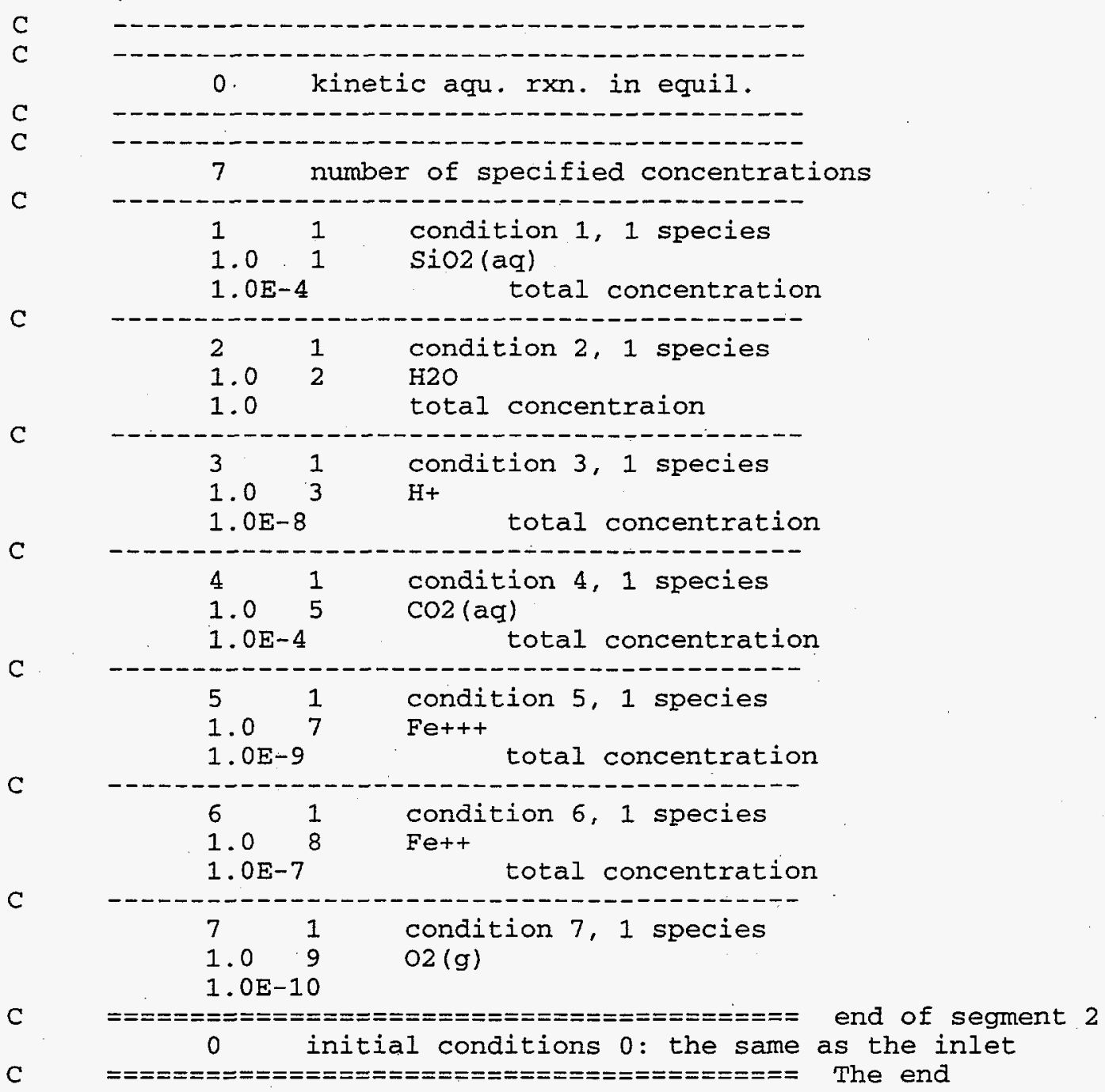


Table E.2. Output Data File for Testing the EQPT Module

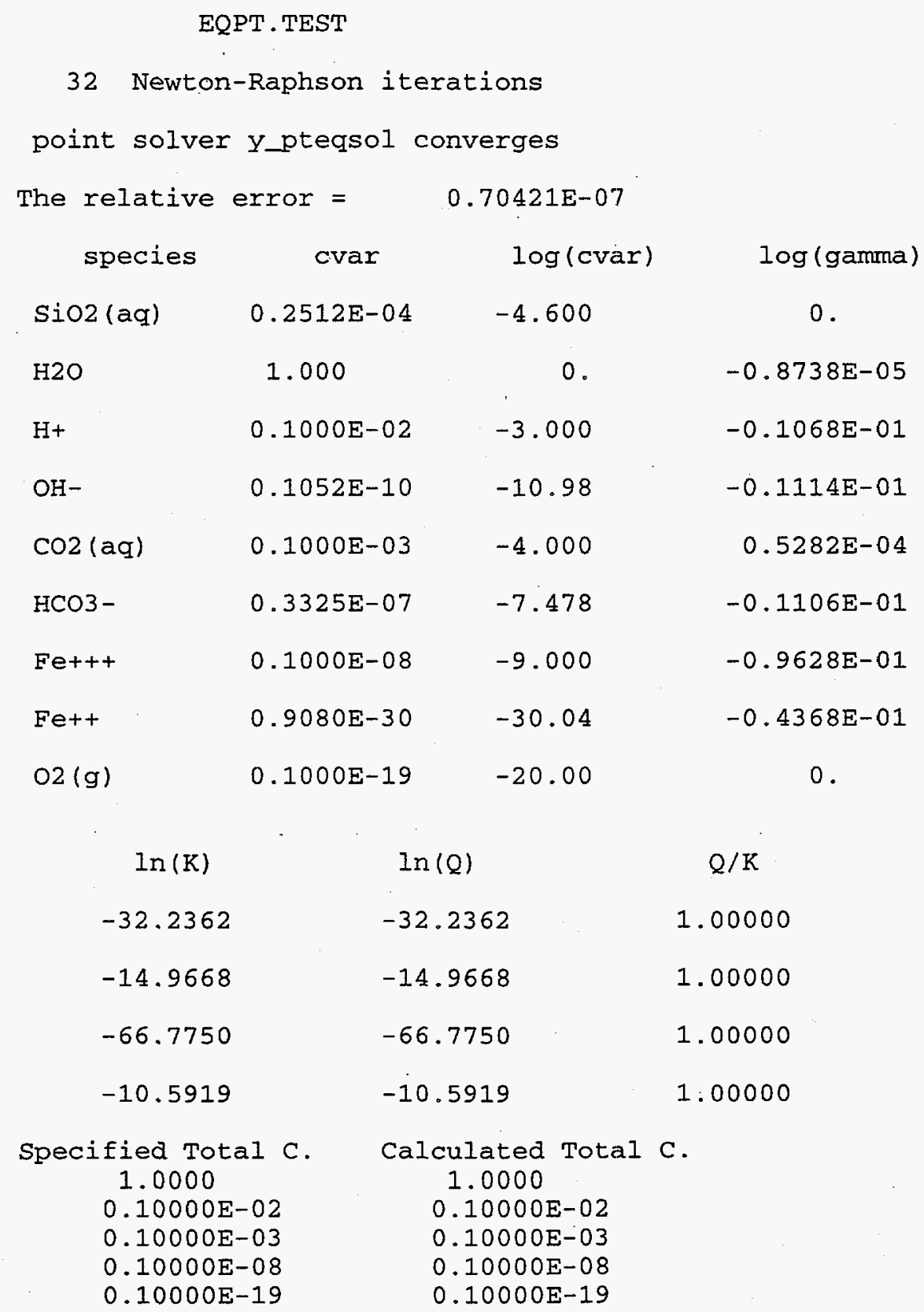


APPENDIX F

Integration Test Results 


\section{APPENDIX F}

\section{Integration Test Results}

This appendix contains the input data and results of the integration test case for the AREST-CT code. All results are shown at 5166 years into the simulation.

Table F.1. Aqueous Species List

$\begin{array}{ll}1 & \mathrm{TcO}_{4}^{-} \\ 2 & \mathrm{H}^{+} \\ 3 & \mathrm{Fe}^{2+} \\ 4 & \mathrm{H}_{2} \mathrm{O} \\ 5 & \mathrm{Tc}^{3+} \\ 6 & \mathrm{Fe}^{3+} \\ 7 & \mathrm{OH}^{-} \\ 8 & \mathrm{Fe}(\mathrm{OH})_{2(\mathrm{aq})} \\ 9 & \mathrm{Fe}(\mathrm{OH})_{3(\mathrm{aq})} \\ 10 & \mathrm{CO}_{2} \\ 11 & \mathrm{HCO}_{3}^{-} \\ 12 & \mathrm{SiO}_{2(\mathrm{aq})}\end{array}$

Table F.2. Solid Species List

1

2 .

3

4

5

6

7

\author{
Natural Iron $\mathrm{Fe}_{(\mathrm{s})}$ \\ $\mathrm{Fe}(\mathrm{OH})_{2(\mathrm{~s})}$ \\ $\mathrm{Fe}(\mathrm{OH})_{3(\mathrm{~s})}$ \\ $\mathrm{Tc}_{3} \mathrm{O}_{4(\mathrm{~s})}$ \\ Glass $\left(\mathrm{SiO}_{2}\right)$ \\ Quartz $\left(\mathrm{SiO}_{2}\right)$ \\ Tc waste $\left(\mathrm{TcO}_{4}{ }^{\circ}\right)$
}

Table F.3. Equilibrium Aqueous Reactions

$\begin{array}{ll}1 & \mathrm{H}_{2} \mathrm{O}=\mathrm{H}^{+}+\mathrm{OH}^{-} \\ 2 & \mathrm{CO}_{2}+\mathrm{H}_{2} \mathrm{O}=\mathrm{H}^{+}+\mathrm{HCO}_{3}^{-} \\ 3 & \mathrm{Fe}^{2+}+2 \mathrm{H}_{2} \mathrm{O}=\mathrm{Fe}(\mathrm{OH})_{2(\mathrm{aq})}+2 \mathrm{H}^{+} \\ 4 & \mathrm{Fe}^{3+}+3 \mathrm{H}_{2} \mathrm{O}=\mathrm{Fe}(\mathrm{OH})_{3(\mathrm{aq})}+3 \mathrm{H}^{+}\end{array}$


Table F.4. Dissolution/Precipitation Reactions

$\begin{array}{ll}1 & 2 \mathrm{Fe}_{(\mathrm{s})}+8 \mathrm{H}^{+}+\mathrm{TcO}_{4}{ }^{-}=\mathrm{Tc}^{3+}+2 \mathrm{Fe}^{2+}+4 \mathrm{H}_{2} \mathrm{O} \\ 2 & \mathrm{Fe}(\mathrm{OH})_{2(\mathrm{~s})}+2 \mathrm{H}^{+}=\mathrm{Fe}^{2+}+2 \mathrm{H}_{2} \mathrm{O} \\ 3 & \mathrm{Fe}(\mathrm{OH})_{3(\mathrm{~s})}+3 \mathrm{H}^{+}=\mathrm{Fe}^{3+}+3 \mathrm{H}_{2} \mathrm{O} \\ 4 & \mathrm{Tc}_{3} \mathrm{O}_{4(\mathrm{~s})}+8 \mathrm{H}^{+}+\mathrm{Fe}^{3+}=3 \mathrm{Tc}^{3+}+\mathrm{Fe}^{2+}+ \\ & 4 \mathrm{H}_{2} \mathrm{O} \\ 5 & \text { Glass }\left(\mathrm{SiO}_{2(\mathrm{~s})}\right)=\mathrm{SiO}_{2(\mathrm{aq})} \\ 6 & \text { Quartz }=\mathrm{SiO}_{2 \text { (aq) }} \\ 7 & \text { Tc Waste }=\mathrm{TcO}_{4}{ }^{-}\end{array}$

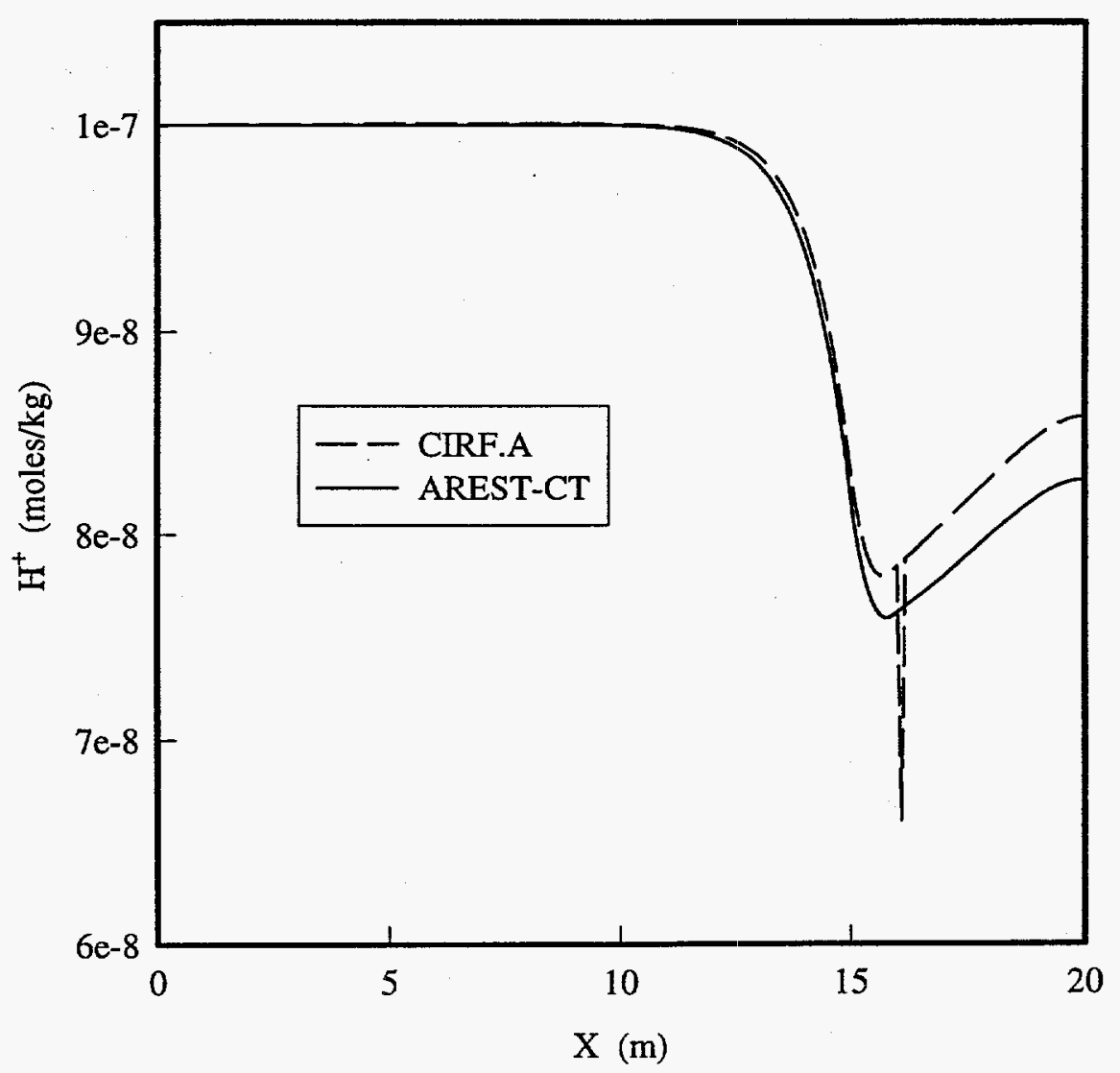




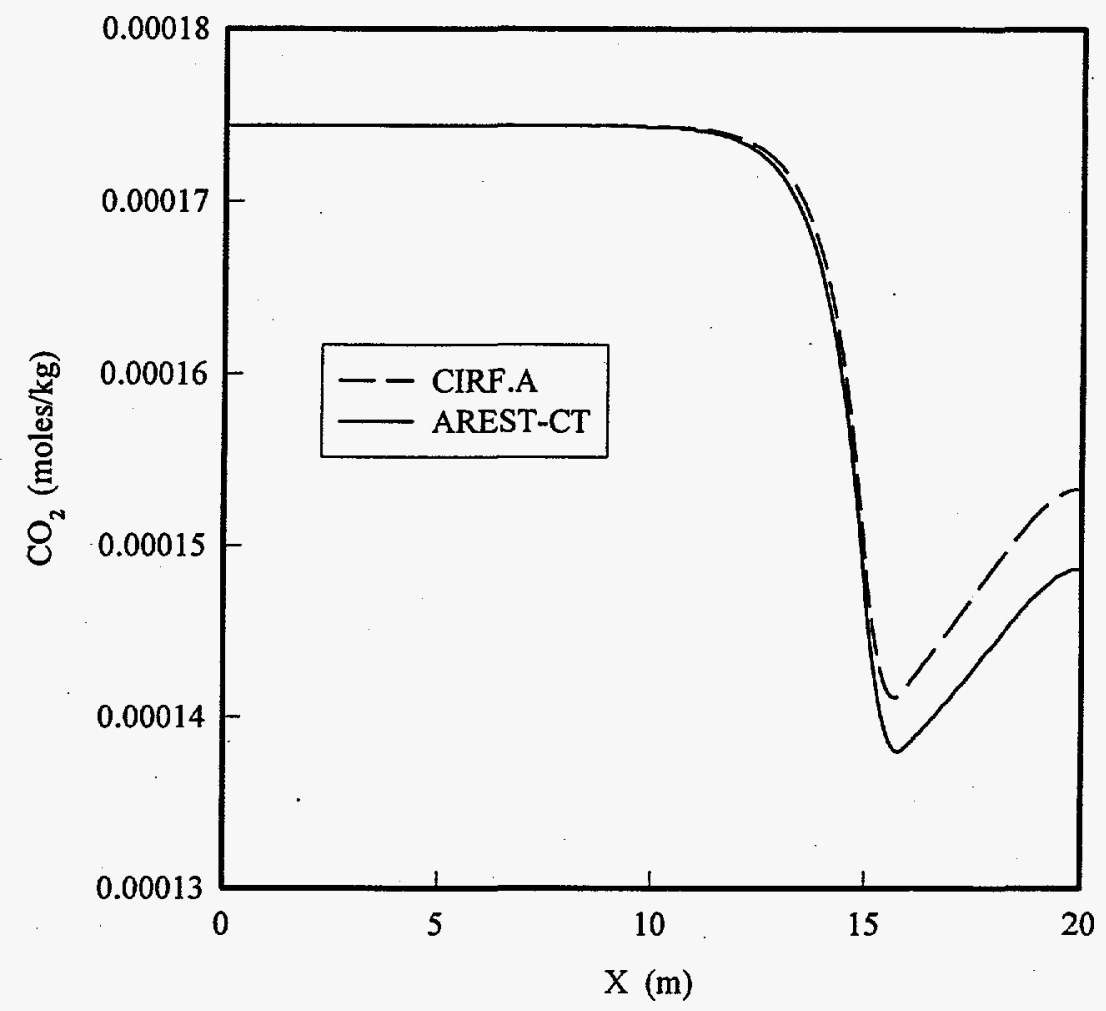

Figure F.2 Simulated Profiles of $\mathrm{CO}_{2}(\mathrm{aq})$ by AREST-CT and CIRF.A

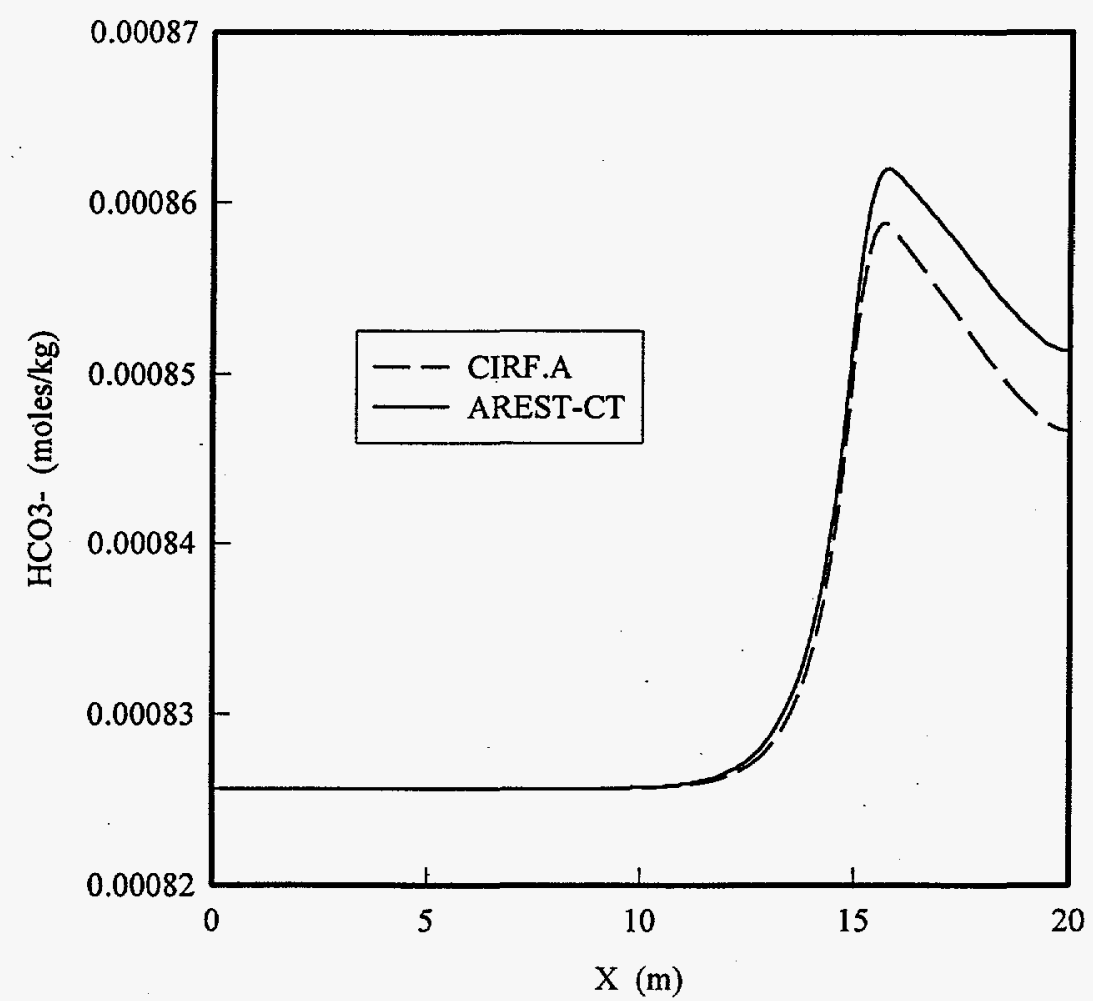

Figure F.3 Simulated $\mathrm{HCO}_{3}{ }^{-}$Concentrations From AREST-CT and CIRF.A F.3 


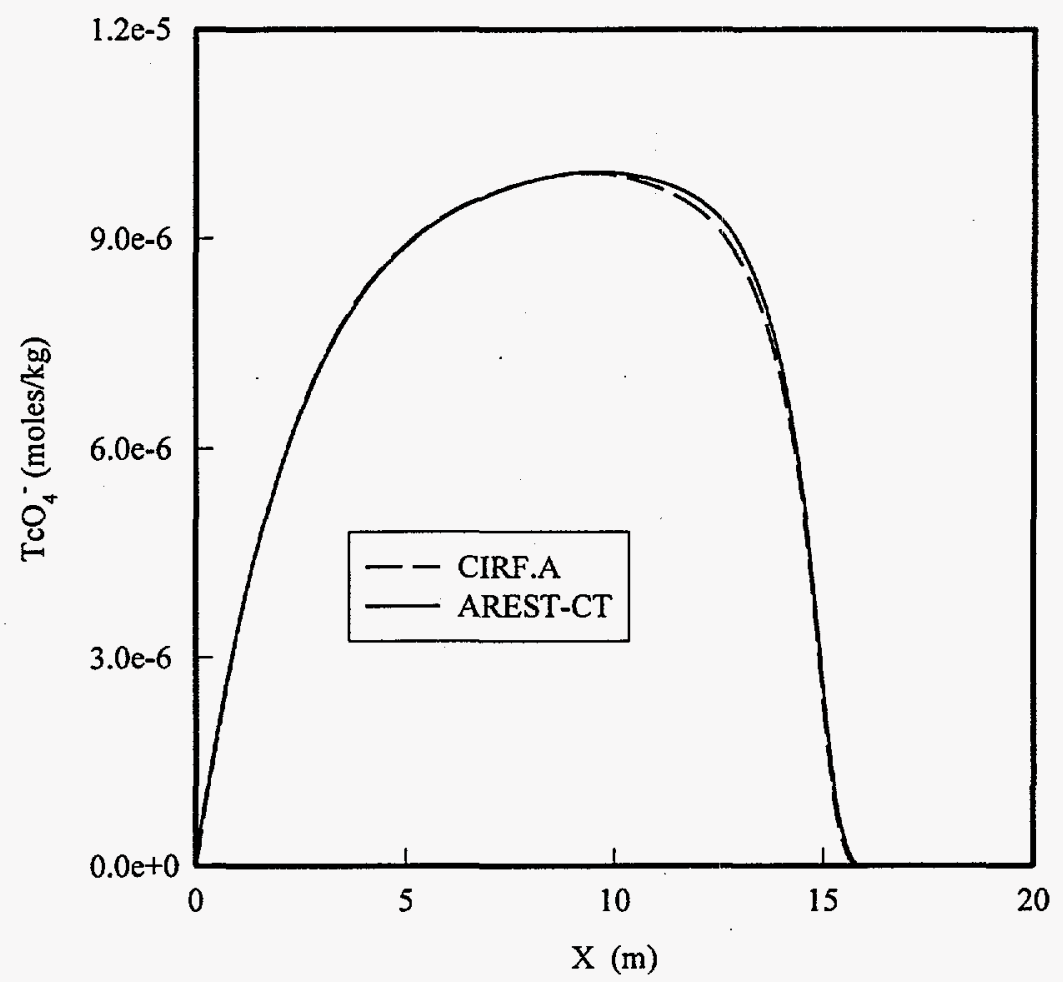

Figure F.4. $\mathrm{TcO}_{4}{ }^{-}$Profiles From AREST-CT and CIRF.A

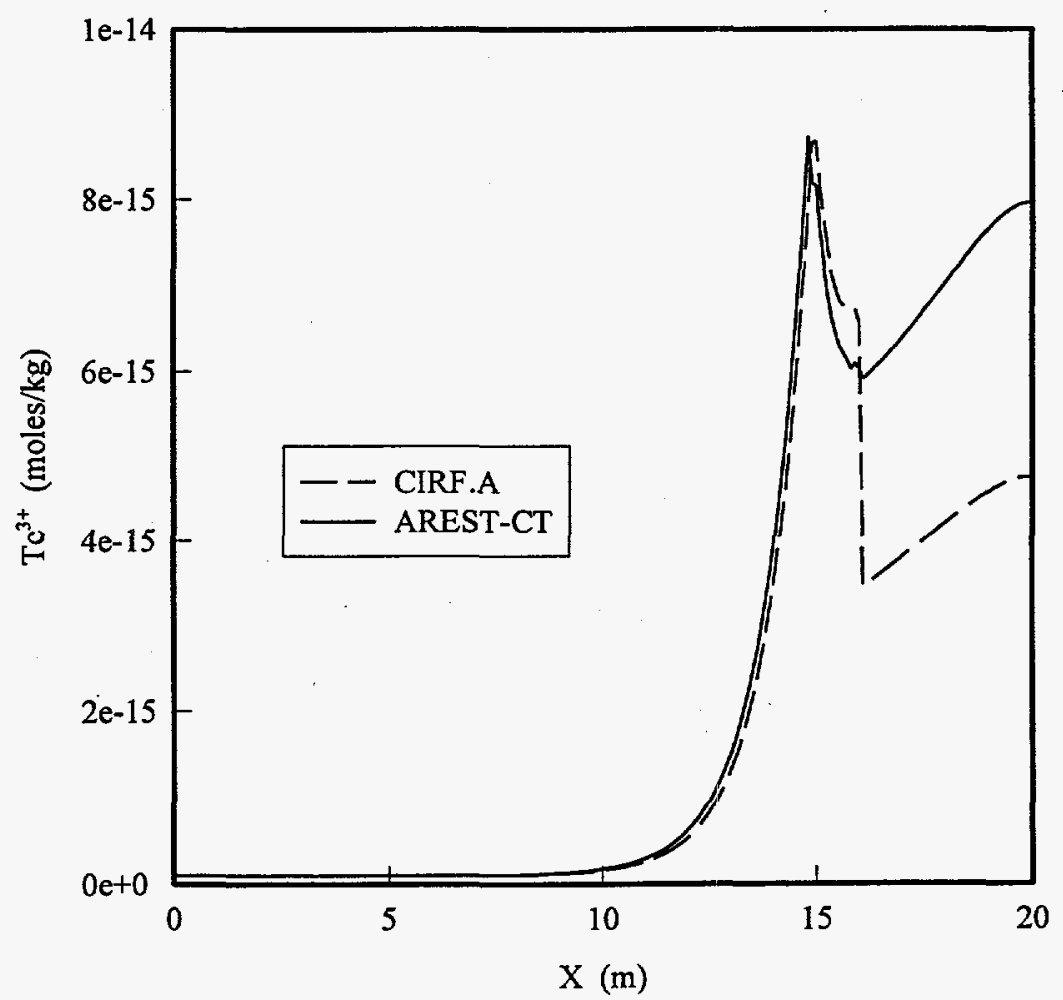

Figure F.5. $\mathrm{Tc}^{3+}$ Profiles From AREST-CT and CIRF.A 


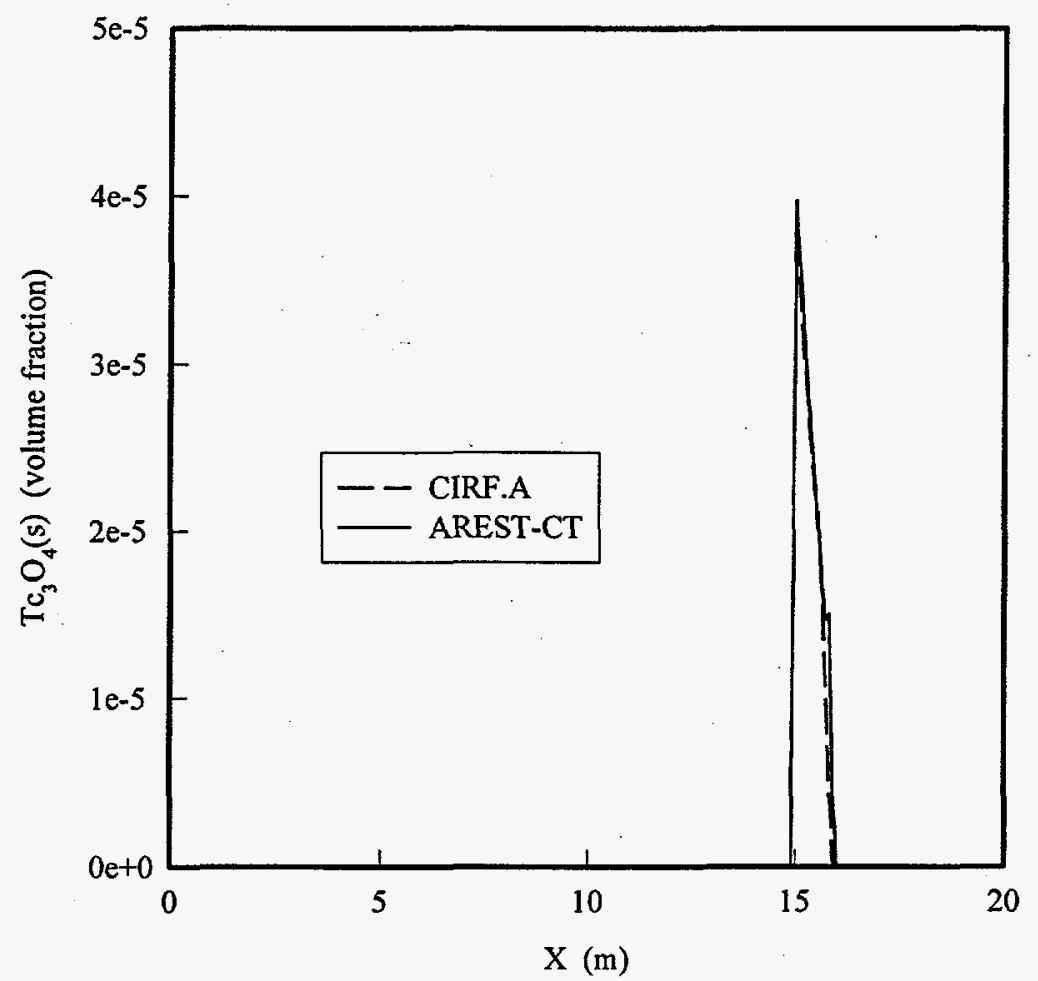

Figure F.6. Comparison of the Amount of $\mathrm{Tc}_{3} \mathrm{O}_{4}(\mathrm{~s})$ Precipitated in Volume Fraction from the AREST-CT and CIRF.A Codes

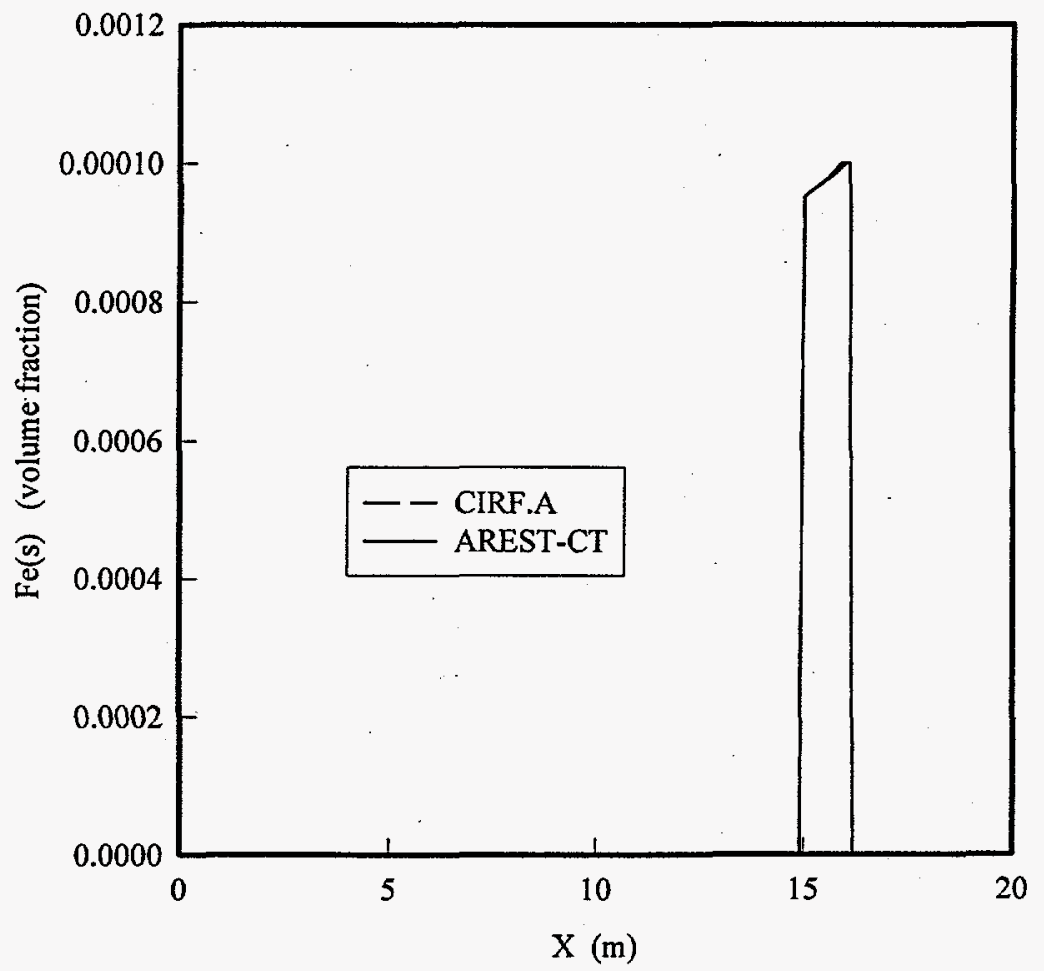

Figure F.7. Calculated Profiles of Fe(s) from AREST-CT and CIRF.A 


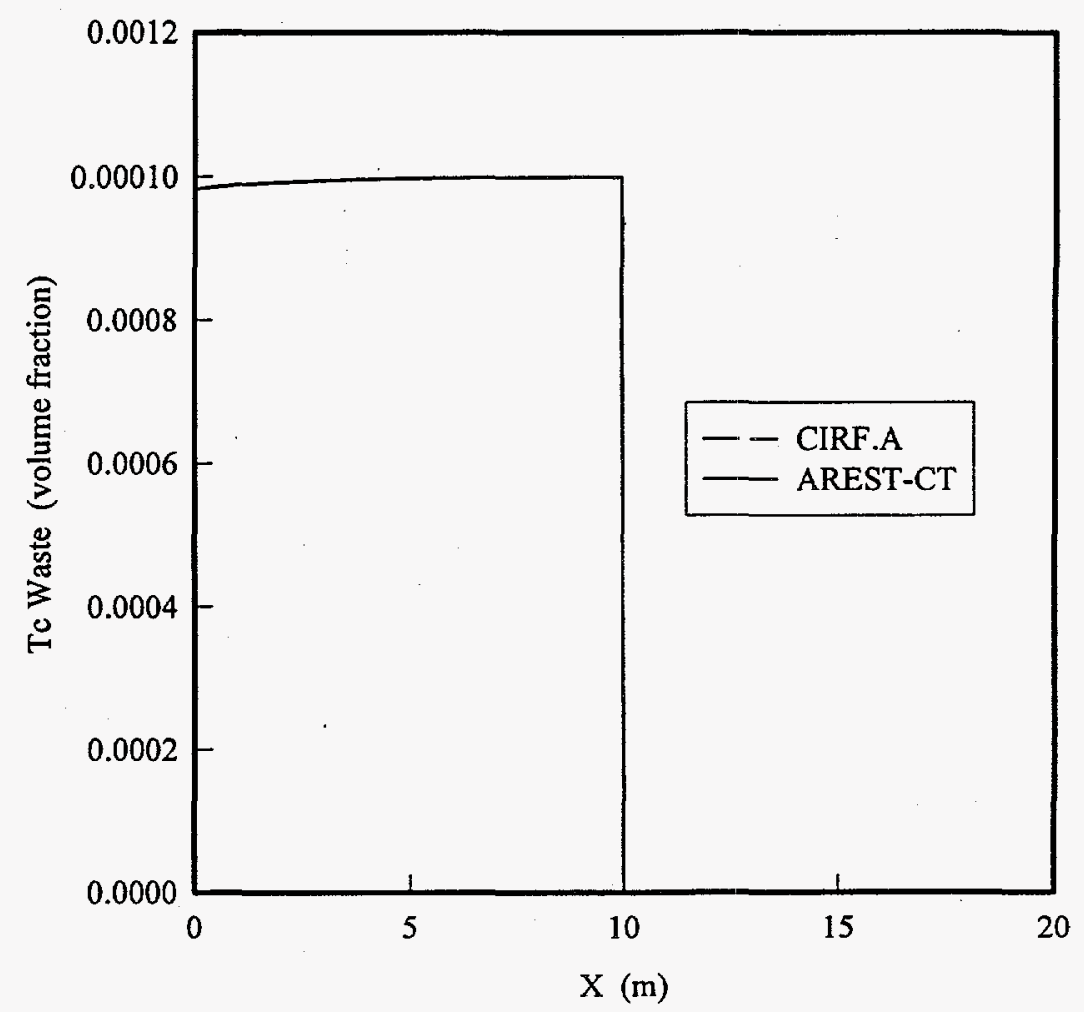

Figure F.8. Profiles of Tc Concentration in the Waste Glass

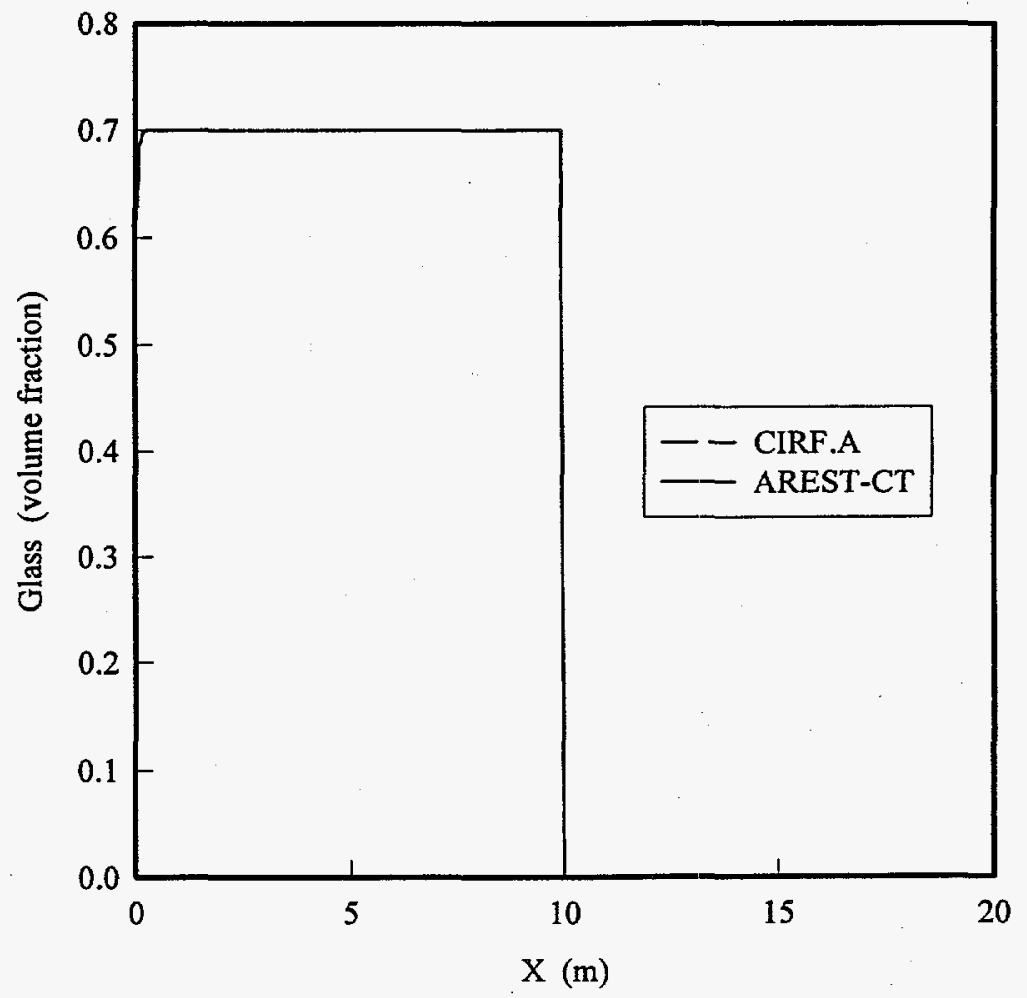

Figure F.9. Profiles of Glass Remaining After 5166 Years 


\section{DISTRIBUTION}

No. of

Copies

OFFSITE

$2 \quad$ U.S. Department of Energy

Office of Scientific and

Technical Information

4 Civilian Radioactive Waste

Management System Management \&

Operating Contractor

101 Convention Center Drive, Suite

P110 Las Vegas, NV 89109-2006

Attn: Robert Andrews

E. Bartlett Mann

Joon Lee

David Sevougian

Eric Smistad

Yucca Mountain Site

Characterization Project Office

U.S. Department of Energy

P.O. Box 98608 - MS 523

Las Vegas, NV 89193-8608

\section{ONSITE}

4 U.S. Department of Energy Richland Operations Office

N. R. Brown, S7-54

Public Reading Room, H2-53

RL Docket File, H5-36 (2)

14 Westinghouse Hanford Company

C. R. Eiholzer, H0-36

F. N. Hodges, H6-06

R. Khaleel, H0-36

N. W. Kline, H0-36
A. H. Lu, H0-36
F. M. Mann, H0-36
F. A. Schmittroth, $\mathrm{H} 0-35$
G. F. Williamson, G6-13

No. of

Copies

Central Files, L8-04

Document Processing and

Distribution, L8-15 (2)

Information Release

Administration, R1-05 (3)

21 Pacific Northwest Laboratory

M. R. Bergeron, K9-33

Y. Chen, K2-44 (5)

D. W. Engel, K5-12

J. A. Fort, K7-15

K. S. Lessor, K7-22

B. P. McGrail, K2-44 (5)

R. J. Serne, K6-81

S. B. Yabusaki, K9-36

Publishing Coordination

Technical Report Files, K1-11 (5) 